\title{
Use of direct instruction to teach reading to students with significant cognitive impairments: Student outcomes and teacher perceptions
}

Philip Michael Kanfush III

West Virginia University

Follow this and additional works at: https://researchrepository.wvu.edu/etd

\section{Recommended Citation}

Kanfush, Philip Michael III, "Use of direct instruction to teach reading to students with significant cognitive impairments: Student outcomes and teacher perceptions" (2010). Graduate Theses, Dissertations, and Problem Reports. 4612.

https://researchrepository.wvu.edu/etd/4612

This Dissertation is protected by copyright and/or related rights. It has been brought to you by the The Research Repository @ WVU with permission from the rights-holder(s). You are free to use this Dissertation in any way that is permitted by the copyright and related rights legislation that applies to your use. For other uses you must obtain permission from the rights-holder(s) directly, unless additional rights are indicated by a Creative Commons license in the record and/ or on the work itself. This Dissertation has been accepted for inclusion in WVU Graduate Theses, Dissertations, and Problem Reports collection by an authorized administrator of The Research Repository @ WVU.

For more information, please contact researchrepository@mail.wvu.edu. 
Use of Direct Instruction to Teach Reading to Students with Significant Cognitive Impairments:

Student Outcomes and Teacher Perceptions

Philip Michael Kanfush, III

A dissertation submitted to the College of Human Resources and Education at West Virginia University in partial fulfillment of the requirements of the degree of

Doctor of Education

\author{
Dr. Barbara Ludlow, Chair \\ Dr. Daniel Hursh \\ Dr. Ann Richards \\ Dr. Cathy Galyon-Keramidas \\ Dr. Kristin Harty \\ Department of Special Education \\ Morgantown, West Virginia \\ 2010
}

Key Words: Special Education, Direct Instruction, Teacher Perceptions, Significant Cognitive Impairment

Copyright 2010, Philip Michael Kanfush, III 


\begin{abstract}
Use of Direct Instruction to Teach Reading to Students with Significant Cognitive Impairments: Student Outcomes and Teacher Perceptions
\end{abstract}

\title{
Philip Michael Kanfush, III
}

The purpose of this study was to determine whether students with significant cognitive impairments make measurable gains in reading skills as measured by the Woodcock Reading Mastery Tests - Revised when taught using Direct Instruction reading programs. Additionally, the study explored teacher perceptions of the effectiveness of Direct Instruction for teaching students with significant cognitive impairments, and examined whether a relationship exists between teacher perceptions and student gains on the Woodcock Reading Mastery Test- Revised. Four special education teachers employed at a private licensed school for exceptional children in the Commonwealth of Pennsylvania participated in the study. Repeated measures analyses of variance conducted on students' scores from the Woodcock Reading Mastery Test - Revised/NU at five separate points in time across a 4-year period demonstrated statistically significant gains. Teacher interviews, observations, and surveys revealed positive attitudes toward the efficacy of Direct Instruction for teaching reading to students with significant cognitive impairments. Linear regression analysis showed a significant positive relationship between teacher perceptions and student gains for the first, but not subsequent years of the study. 


\section{Acknowledgements}

The author very gratefully acknowledges the members of his dissertation committee, most especially Dr. Barbara Ludlow, for their assistance and guidance throughout this project.

Additionally, the administration and teacher participants at the Clelian Heights School for Exceptional Children are acknowledged with gratitude for their willingness to participate in this study and their assistance with data collection.

The author offers his heartfelt gratitude to Dr. Dean Nelson for his guidance and support with the statistical analyses, and to Mrs. Kim Metzgar and Mrs. Elizabeth Cousins Kujawa for their technical support in the production of this document. 


\section{Table of Contents}

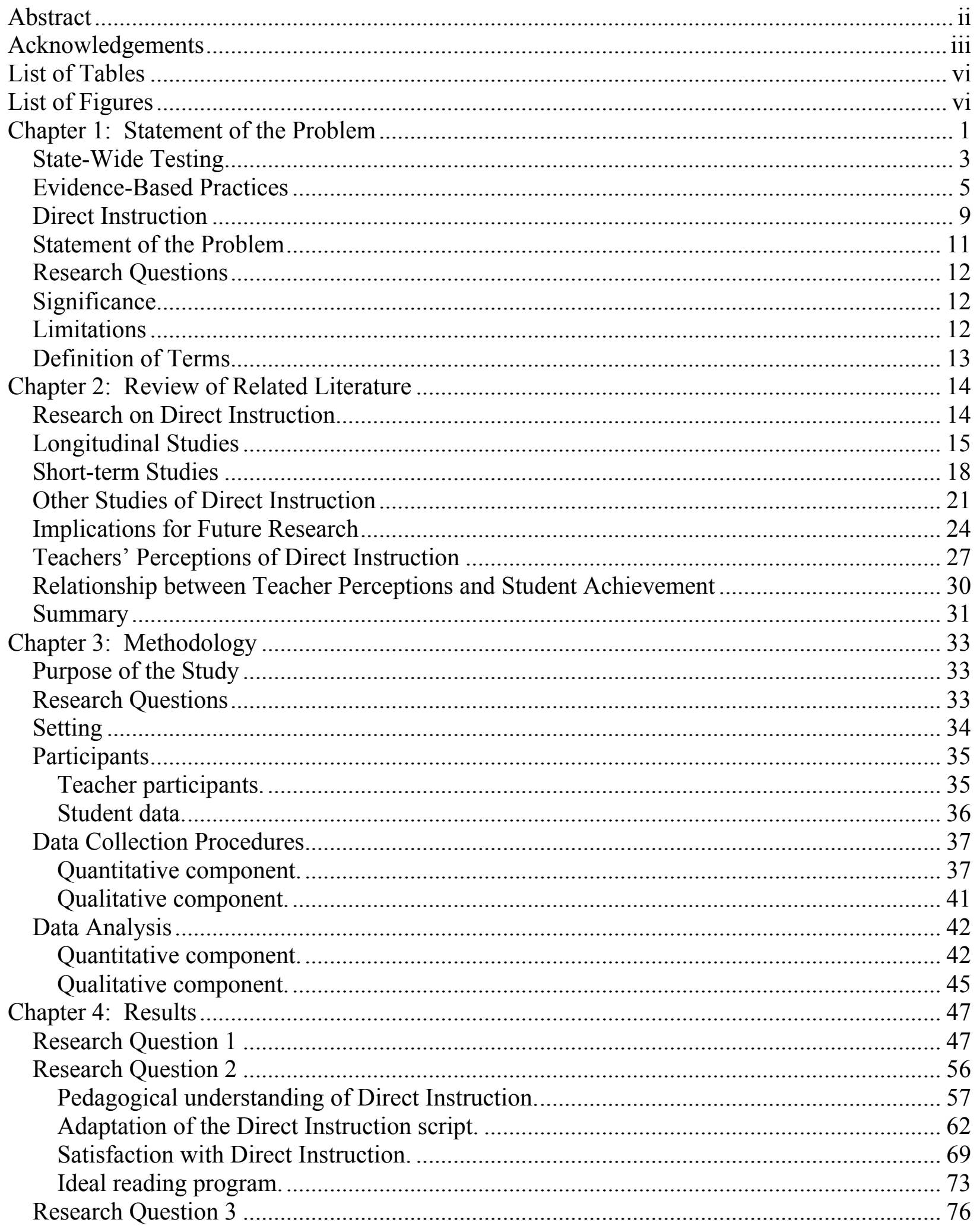




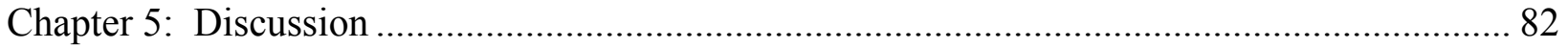

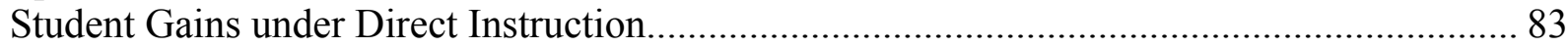

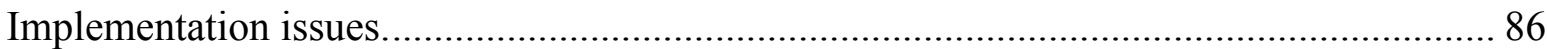

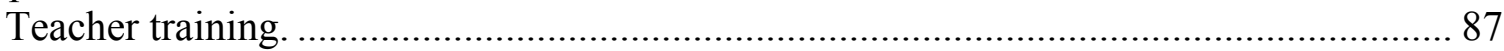

Incomplete understanding of Direct Instruction. ..................................................... 88

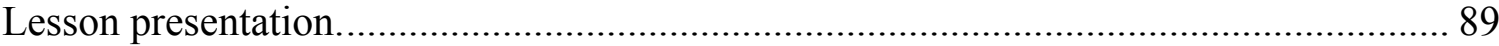

Teacher Perceptions of the Effectiveness of Direct Instruction..................................... 92

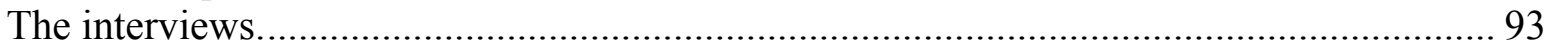

General satisfaction with Direct Instruction. .......................................................... 93

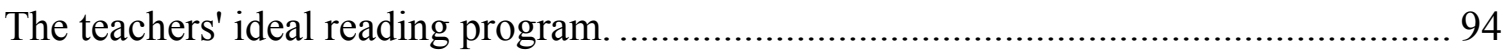

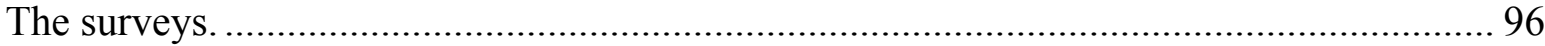

Relationship between Student Gains and Teachers' Perceptions ....................................... 97

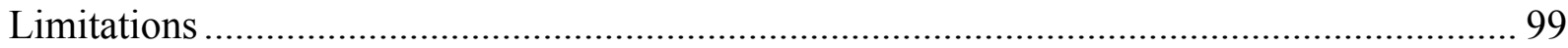

Recommendations for Instructional Programming ...................................................... 100

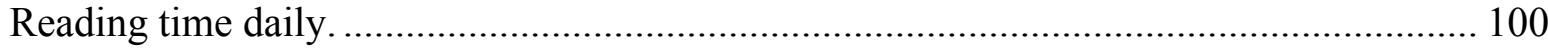

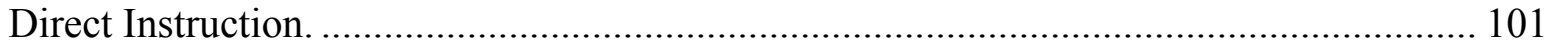

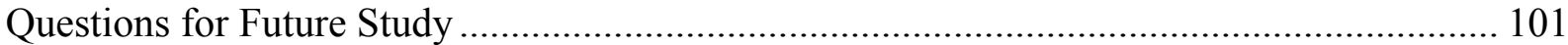

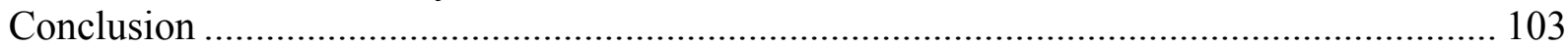

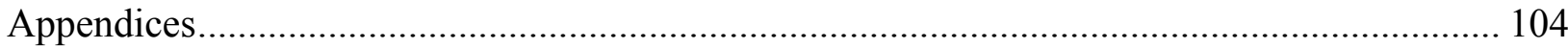

Appendix A: Sample Letter \& Consent Form for Teacher Participants ............................. 105

Appendix B: Teacher Interview Script .......................................................................... 109

Appendix C: Teachers' Perception of Direct Instruction Survey ....................................... 110

Appendix D: Direct Instruction Teacher Presentation Rubric ........................................... 111

Appendix E: Repeated Measures Analysis of Variance Results - W Scores ....................... 112

Appendix F: Repeated Measures Analysis of Variance Results - Standard Scores............. 114

Appendix G: Teacher Perception Survey Questions by Subcategory ............................... 116

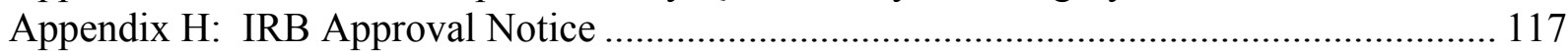

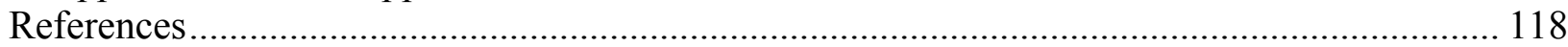




\section{List of Tables}

Table 1: Demographic Description of Teacher Participants at time of Direct Instruction

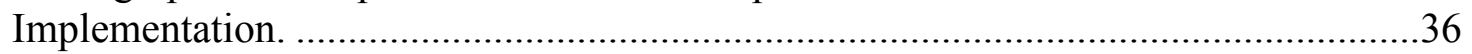

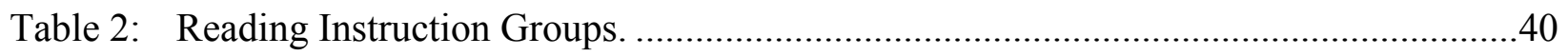

Table 3: Summary of Repeated Measures Analysis of Variance.............................................43

Table 4: Description of WRMT subtests and score clusters. ..............................................48

Table 5: $\quad$ Relative dates of WRMT administrations.............................................................49

Table 6: Student W score gains across time ( $\mathrm{p}$-values in parentheses)....................................50

Table 7: Student SS score gains across time (p-values in parentheses).................................52

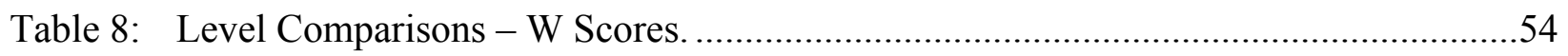

Table 9: Level Comparisons - Standard Scores..................................................................55

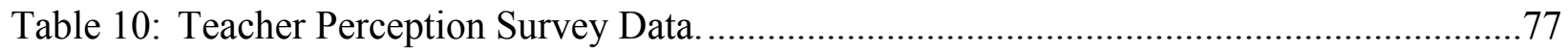

Table 11: Teacher perception and student gains, Total Reading-FS Cluster, Year 1.................78

Table 12: Teacher perception and student gains, Total Reading - FS Cluster, Years $2-4$........80

\section{List of Figures}

Figure 1: Regression relationship between teacher perception and WRMT scores $t_{2}-t_{1} \ldots \ldots \ldots \ldots . . . .79$

Figure 2: Regression relationship between teacher perception and WRMT scores $\mathrm{t}_{6}-\mathrm{t}_{3} \ldots \ldots \ldots \ldots . . . .81$ 


\section{Chapter 1}

\section{Use of Direct Instruction to Teach Reading to Students with Significant Cognitive Impairments: Student Outcomes and Teacher Perceptions}

In 2001, the United States Congress enacted Public Law 107-110, a reauthorization of the Elementary and Secondary Education Act of 1965. This reauthorization, popularly known as No Child Left Behind (NCLB), made several additions to the previous act. Among these additions were the requirements that statewide testing programs be developed for all students in the areas of reading and mathematics, and that evidence-based practices be used to provide instruction. These requirements were reiterated in the Individuals with Disabilities Education Improvement Act (IDEIA) of 2004, which brought the previous Individuals with Disabilities Education Act in line with No Child Left Behind. The ramifications of these two acts will impact all students with disabilities, but of particular concern is the impact that these laws will have on students having moderate and/or severe cognitive and other developmental disabilities.

During the 2005-2006 academic year an estimated 6,109,569 American students between the ages of 6 and 21 were identified as having disabilities (U.S. Department of Education, 2006). This number includes all disability categories. However, special educators typically distinguish between high and low incidence disabilities. The Individuals with Disabilities Education Improvement Act of 2004 defines low incidence disabilities as

a visual or hearing impairment, or simultaneous visual and hearing impairments; a significant cognitive impairment; or any impairment for which a small number of personnel with highly specialized skills and knowledge are needed in order for children with that impairment to receive early intervention services or a free appropriate public education (20 U.S.C. $1462 \S 662(c)(3))$. 
Using this definition, an estimated 2,093,066 children between the ages of 6 and 21 having low incidence disabilities were served in schools during the fall 2005 (U.S. Department of Education, 2006).

Of those who meet this definition of low incidence disabilities, an estimated $6.4 \%$ and $26.1 \%$ were served under the categories of multiple disabilities and mental retardation, respectively. This figure does not include students having specific learning disabilities or speech or language impairments, nor those having developmental delays. Children having significant cognitive impairment account for less than $1 \%$ of the estimated school-aged population in the United States (U.S. Census Bureau, 2005). Despite their minimal representation in today’s schools, the combined impact of No Child Left Behind and the Individuals with Disabilities Education Improvement Act will be considerable for these students and those who teach them.

This impact is most evident in the emphasis of basic academic skills, including reading and mathematics, which has begun to place pressure on teachers to develop critical reading and mathematics skills among students having significant cognitive impairment. In the area of reading instruction, the impact of the No Child Left Behind legislation can be seen in at least two ways. First, the inclusion of students having significant cognitive impairments in statewide assessments has required a reconsideration of curriculum content in order to give these students greater access to the general educational curriculum on which they will be assessed. Second, the requirement that teachers use evidence-based practices to guide instruction creates a challenge for special education teachers to identify research-based strategies that are proven to be effective with this student population. 


\section{State-Wide Testing}

No Child Left Behind targets the quality of instruction in the nation's schools, especially in the area of reading. To address concerns about children's reading proficiency, the law established several initiatives, including Reading First. This program, targeted toward students in kindergarten through grade three, identifies five essential elements of effective reading programs: phonemic awareness, phonics, fluency, vocabulary, and comprehension. These elements, based on the report of the National Reading Panel (2000), must be the focus of reading instruction in schools. The purpose of the Reading First initiative as it relates to No Child Left Behind is "to ensure that every student can read at grade level or above not later than the end of grade 3" (Title I, Part B, Subpart 1, Section 120).

Toward this end, schools must demonstrate that their students are making adequate yearly progress in specified areas, most notably reading and math. No Child Left Behind stipulates that:

Adequate yearly progress shall be defined by the State in a manner that - (i) applies the same high standards of academic achievement to all public elementary school and secondary students in the state . . . (iii) results in continuous and substantial academic improvement for all students; . . . (v) includes separate measurable annual objectives for continuous and substantial improvement for each of the following: (I) The achievement of all public elementary school and secondary school students; (II) The achievement of - (aa) economically disadvantaged students; (bb) students from major racial and ethnic groups; (cc) students with disabilities; (dd) students with limited English proficiency. (Title I, Subpart I, Section 1111[B]) 
In order to comply with the adequate yearly progress component of No Child Left Behind, schools must administer annual state assessments. The focus of these assessments in reading is to demonstrate that students are in fact making adequate yearly progress as they move toward reading at or above grade level. The law ambitiously stipulates that this goal be achieved by the 2013-14 school year for all students, including those having disabilities.

The requirement that students with disabilities participate in district and statewide assessments is not a new concept. The Individuals with Disabilities Education Act (IDEA) of 1997 required that individualized educational plans (IEPs) include provision for participation of students having disabilities in district-wide and statewide testing programs, and required that the accommodations that would make such participation possible be identified in the students' IEPs. However, when No Child Left Behind mandated documentation of adequate yearly progress for all students, such assessments became much more significant. Kohl, McLaughlin, and Nagle (2006) note that:

Consistent with IDEA 1997, the U.S. Department of Education recognized that it was not appropriate to hold all students with disabilities to grade level achievement standards or to require them to participate in the general statewide assessments. Therefore, another method of evaluating the progress and achievement of some students with disabilities was necessary. (p. 108)

This recognition became codified in the final regulations of No Child Left Behind enacted in 2003 in the form of an allowance for alternative assessment for students whose disabilities prohibited them from participating in the general statewide assessments to measure adequate yearly progress. Alternative assessment is targeted toward including in the mandatory testing those students who have significant cognitive impairment due to multiple or severe 
disabilities. The alternative assessment process provides for the evaluation of such students against a separate set of standards, which should approximate the state standards for typically developing students but allow for realistic achievement in light of the students' disabilities. States were authorized to develop alternative assessments to evaluate progress according to these alternate standards, and were mandated to include scores from the alternative assessments in their calculation of adequate yearly progress for each school.

One of the key impacts of this provision of No Child Left Behind is the effect that it will have on curricula for students receiving special education services throughout the country. In the past, the emphasis in special education programming, particularly for students having significant cognitive impairments, has been on teaching functional life skills. The curriculum was designed to maximize independence for these students by teaching them independent living skills, vocational skills, choice-making, and social skills. In light of the requirements of No Child Left Behind and the Individuals with Disabilities Education Improvement Act, a shift in curriculum emphasis has occurred. In order to meet the demands of the adequate yearly progress requirement, schools now need to divert resources, in terms of instructional time and materials, to what might be described as functional academics. Such functional academics, in terms of reading instruction, have begun to shift from simple sight word recognition skills to the Reading First initiative skills: phonemic awareness, phonics, vocabulary, fluency, and comprehension. This has resulted in major differences in instructional programs for those students having the most significant cognitive impairments.

\section{Evidence-Based Practices}

Another provision of No Child Left Behind is the requirement that teachers use evidencebased teaching strategies to provide reading instruction to all students. While special education 
has a longstanding tradition emphasizing the use of instructional techniques supported by clinical evidence, for the purposes of No Child Left Behind, evidence-based, or scientifically-based, practices are those which have been validated through rigorous scientific research. In general, in order to meet the criteria for scientifically-based research under No Child Left Behind, a research study must involve:

Rigorous, systematic and objective methods, which includes research that employs systematic, empirical methods; involves rigorous data analyses that justifies the conclusions; relies on methods that provide reliable and valid data; is evaluated using experimental or quasi-experimental designs with appropriate controls, with a preference for random-assignment; allows for replication; and is accepted by a peer reviewed journal or is approved by a panel of independent experts. (U.S. Dept of Education, 2002, in Collins and Salzberg, 2005, p. 60)

At least two problems arise from the application of this definition to instruction for students having significant cognitive impairments. First, difficulties arise from the past emphasis on functional curricula, which have focused on skills that are not germane to measuring adequate yearly progress. Consequently, while there is a considerable body of research on effective practices to teach life skills, only limited research has been conducted on teaching functional academics. Nietupski, Hamre-Nietupski, Curtin, and Shrikanth (1997) conducted a review of the research that was done between 1976 and 1995 in the area of curriculum for students with severe disabilities. The research group identified 785 studies, of which less than $10 \%$ involved study of cognitive or academic skills, and further noted "students with multiple disabilities are underrepresented in the curricular research literature" (p. 50). Browder and Xin (1998) identified 48 studies that dealt with the teaching of sight word recognition skills to students 
having severe mental impairment or autistic spectrum disorders, but sight word recognition is not listed among the five essential elements of reading instruction identified by the National Reading Panel. These two reviews of the relevant literature suggest that there is a disconnect between the law's requirement of evidence-based practices and the current research base available on effective instructional practices for students with significant cognitive impairments. Browder and Cooper-Duffy (2003) identify three critical limitations relating to this research base:

1. Sparse literature with students with complex, multiple disabilities;

2. Limited range of functional academics and lack of reading comprehension measures; and

3. A lack of research on teaching a broader range of academics to students having multiple and cognitive disabilities. (p. 159)

A second area of difficulty relating to the evidence-based practices requirement of No Child Left Behind and students having significant cognitive impairments is the nature of the research that is available relating to this group of students, which tends to rely on single-subject research designs. This is because group comparison designs are not possible in many cases with this population because limited numbers and heterogeneity of individual characteristics prevents the formulation of two or more comparison groups (Gay and Airasian, 1996). While single subject research designs recognize the individual differences of these students, they may not exemplify what No Child Left Behind identifies as rigorous scientific research.

In order to assist educators in making determinations about the degree to which any particular instructional practice can be considered evidence-based, the United States Department of Education refers teachers and administrators to the What Works Clearinghouse. This agency evaluates educational research on teaching practices to determine whether it meets the evidencebased standards of No Child Left Behind. After reviewing the body of literature on a particular 
instructional strategy, the Clearinghouse assigns the practice one of three ratings and disseminates the rating to the general public. These three ratings are as follows:

1. "Meets Evidence Standards"-randomized controlled trials (RCTs) that do not have problems with randomization, attrition, or disruption, and regression discontinuity designs that do not have problems with attrition or disruption;

2. "Meets Evidence Standards with Reservations"- -strong quasi-experimental studies that have comparison groups and meet other WWC Evidence Standards, as well as randomized trials with randomization, attrition, or disruption problems and regression discontinuity designs with attrition or disruption problems;

3. "Does Not Meet Evidence Standards"- studies that provide insufficient evidence of causal validity or are not relevant to the topic being reviewed. (U.S. Dept. of Education, n.d., Standards Section, ๆ 2, in Collins and Salzberg, 2005, p. 61)

With regard to the degree of evidence that must be provided in order for a practice to be identified as evidence-based, Collins and Salzberg (2005) note that a practice meets the definition of evidence-based if two or more high quality studies or four or more acceptable quality studies using an experimental or quasi-experimental group design demonstrate a weighted effect size significantly greater than zero with respect to that instructional practice. Alternatively, studies using single-subject designs may be used to demonstrate an evidence base provided that five or more studies using this design meet the acceptable criteria. These criteria include the provision of an operational definition of the practice under consideration, clear description of the context and outcomes of the study, and documented fidelity in the implementation of the practice under study. Additionally, the practice must be functionally related to the outcomes and the studies must have been published in peer-reviewed journals. 
Finally, the studies employing the single-subject design must have been conducted by at least three different researchers in three different geographical locations, and the body of studies must have included twenty or more participants. A review of these criteria demonstrates that preference is clearly given to experimental group research designs.

Given these requirements and the fact that the practice of research on students having significant cognitive impairments has historically centered on single-subject designs, teachers may experience considerable difficulty in identifying a sufficient number of high quality research studies to validate any given instructional strategy for use in assisting their students to make adequate yearly progress.

\section{Direct Instruction}

One instructional practice that may show promise for meeting the evidence-based standard of No Child Left Behind is Direct Instruction (DI). Direct Instruction is one specific model of teacher-directed explicit instruction. It is distinguished from other approaches to explicit instruction by the teaching techniques used and the curriculum design (Tarver, 1999, p. 1). One of the features that sets DI apart from other teacher-directed instructional models is its mode of presentation. Direct Instruction is highly scripted and makes use of very specific physical signals or prompts. Its goal is to promote a maximum rate of learning in a minimal amount of time. Watkins and Slocum (2003) note that:

The purpose of Direct Instruction is to teach subject matter efficiently so that all the students learn all the material in the minimum amount of time. Every strategy, tactic and specific technique employed in Direct Instruction is designed to serve this purpose. (p. 
Direct Instruction accomplishes this by careful attention to presentation style, student grouping, and curriculum design that carefully scaffolds concepts and skills to promote opportunities for practice. Watkins and Slocum (2003) identify three main components of Direct Instruction.

First, programs are designed to identify concepts, rules, strategies, and "big ideas" that should be taught and clearly conveys these through detailed teaching scripts. Second, instruction is thoroughly organized with attention to the details of scheduling, grouping, and progress monitoring to ensure that appropriate and sufficient instruction is provided to each individual student. Third, students are actively engaged in the instructional process through specific student-teacher interaction techniques.

Direct Instruction has received wide support. The American Federation of Teachers lists Direct Instruction among a group of instructional practices that it identifies as "Five Promising Programs for Remedial Reading Intervention" (1999). The Council on Exceptional Children gave Direct Instruction the "Go For It!" rating among instructional practices in its "Current Practice Alerts" (Tarver, 1999). Both of these groups identify the scripted lessons, fast pace, maximized engaged time, and frequent progress monitoring as key features of this instructional model that make it worthy of recommendation. They cite its vast research base as evidence to support their ratings.

While there is a significant research base to support the use of Direct Instruction in Special Education, the majority of research done centers on students having high incidence disabilities. Marchand-Martella, Kinder, and Kubina (n.d.) identified 45 studies that assessed the efficacy of the Direct Instruction programs marketed by the Scientific Research Association (SRA). Of the 45 studies examined in their report, only eight evaluated the use of the programs with students having significant cognitive impairments. Marchand-Martella, Martella, and 
Przychodzin-Havis (n.d.) reviewed 28 studies that assessed the efficacy of SRA's Corrective

Reading Program. Of the 28 studies examined, only two of the studies involved students having significant cognitive impairments as participants. Swanson (2001) evaluated 180 studies in a research synthesis that compared Direct Instruction to strategies instruction with students having learning disabilities, but all of the 180 studies considered examined a high-incidence disabilities population. Gersten (1985) reviewed six studies as samples of evaluative research measuring the effectiveness of Direct Instruction in teaching special education students. Of the six studies reviewed, only two studies examined the effectiveness of Direct Instruction with students having significant cognitive impairments. Browder, Wakeman, Spooner, Ahlgrim-Delzell, and Algozzine (2006) examined 128 studies that investigated reading instruction for children with significant cognitive impairments. While all 128 studies involved participants having significant cognitive impairments, only 13 of the studies examined phonics instruction for this population. These research syntheses demonstrate the dearth of research on Direct Instruction with populations having significant cognitive impairments and suggest the need for research in Direct Instruction in reading with this population.

\section{Statement of the Problem}

Given the requirements of No Child Left Behind regarding the inclusion of students having significant cognitive impairments in statewide testing and the need to use evidence-based practices to achieve adequate yearly progress in reading, there is a need for more research in the area of reading instruction for these students. The purpose of the current study is to examine whether students having significant cognitive impairments demonstrate measurable gains in decoding skills and comprehension skills when placed in a Direct Instruction reading program, 
and to explore the attitudes and perceptions of teachers regarding the effectiveness of their use of Direct Instruction reading programs.

\section{Research Questions}

This study proposes to explore the following research questions:

1. Do students with significant cognitive impairments make measurable gains on the Woodcock Reading Mastery Test when taught using a Direct Instruction reading program?

2. How do teachers using a Direct Instruction reading program to teach students with significant cognitive impairments perceive the effectiveness of the methodology?

3. Is there a relationship between teacher perceptions and the gains on the Woodcock Reading Mastery Test that students having significant cognitive impairments achieve in a Direct Instruction reading program?

\section{Significance}

The significance of this study is three-fold. First, limited research has been conducted on the implementation of Direct Instruction reading methodologies with students having significant cognitive impairments, so this study adds to that research base. Second, because the study used existing data on the effects of Direct Instruction as teachers have implemented it in their classrooms, it adds to the knowledge base by illustrating the methodology's effectiveness with this population when teachers use it under real life conditions. Third, this study sheds light on how teachers feel about using the Direct Instruction methodology.

\section{Limitations}

The findings from this study are limited in several ways. First, the small student sample size and its specific characteristics limit the extent to which assertions about cause and effect can 
be made, and the degree to which the findings may generalize to other students and settings. The same can be said of the small number of teachers sampled. A second limitation is that because extant data were used that were collected by teachers in the typical conduct of their instructional duties, rigorous experimental control was not possible, which introduces threats to validity. However, using real world data provides a unique opportunity to observe the impact of the Direct Instructional methodology as it is actually implemented with all the contingencies of classroom life.

\section{Definition of Terms}

The following are operational terms defined for use in this study.

Direct Instruction

Significant cognitive impairment

Decoding Skills

Phonemic Awareness

Reading Comprehension
Any of the instructional programs, most notably those developed by Englemann and his associates, which involve the following five curriculum design principles: 1) organizes content around "big ideas;" 2) teaches explicit, generalizable strategies; 3) scaffolds instruction; 4) integrates skills and concepts; 5) provides copious review (Stein, Carnine, and Dixon, 1998).

Significant cognitive impairment is defined in this study to mean mental retardation measured as an IQ below 70 or an IQ above 70 coupled with other disabilities, the combination of which causes severe educational needs.

Decoding skills refer to the ability to convert letters into sounds and blend them to form recognizable words (National Reading Panel, 2000).

Phonemic awareness refers to the ability to focus on and manipulate phonemes in spoken words (National Reading Panel, 2000).

Reading comprehension is the construction of the meaning of a written text through a reciprocal interchange of ideas between the reader and the message in a particular text (National Reading Panel, 2000). 


\section{Chapter 2}

\section{Review of Related Literature}

The current study examines the impact of reading instruction utilizing Direct Instruction methodology with students with significant cognitive impairments as well as teacher perceptions on Direct Instruction based upon their experiences implementing Direct Instruction with those students. In order to situate the study within the stream of other work in this field, a review of the literature was conducted. This review is organized around the research questions being investigated, and thus, is presented in three separate sections: a review of literature on Direct Instruction reading methodology; a review of literature concerning teachers' perceptions of the Direct Instruction methodology, and a review of literature that reports on the relationship between student gains and teachers' perceptions in the implementation of Direct Instruction reading programs.

\section{Research on Direct Instruction}

A considerable volume of research investigating the implementation and impact of Direct Instruction reading methodologies has been conducted over the past 30 years. This research has demonstrated the efficacy of the methodology repeatedly with diverse populations. As early as 1982, Lockery and Maggs analyzed research on Direct Instruction in Australia. They reviewed a total of 21 studies. Their review indicated that Direct Instruction had been found to be effective for use with students with ability levels ranging from severely retarded to gifted and across a wide range of geographic regions. Maggs (1983) further illustrated the findings of their 10-year analysis in the International Journal of Rehabilitation Research. There he described Direct Instruction, observing,

it is certainly unique in the history of educational programming to have a model that consistently extends both basic and advanced skills across the range of "severely 
retarded," "behaviorally disturbed," "dyslectic," "spastic," etc. to "normal" children and those of "superior intelligence" (p. 478).

In1996, Adams and Englemann accumulated 37 studies for a meta-analysis of the research that spanned the preceding 25 years. In their analysis, Adams and Englemann evaluated a total of 37 studies, three of which dealt with longitudinal effects of Direct Instruction. The remaining 34 articles, which dealt with implementation of Direct Instruction, generated a total of 173 points of comparison. They then subjected these points of comparison to three analyses: the pooling of means and statistically significant differences and the meta-analysis. In their pooling of the means of these 34 studies, they found that $87.3 \%$ of the studies favored Direct Instruction. When Adams and Englemann examined the studies for statistically significant differences between the relevant variables, they found that $64.1 \%$ of the studies found statistically significant differences that favored Direct Instruction. Finally, in their meta-analysis of the 34 studies, these investigators noted a mean effect size per study of more than .75 , which suggests significant gains through the implementation of Direct Instruction across all the studies examined.

\section{Longitudinal Studies}

Longitudinal studies have also demonstrated that impact of Direct Instruction over extended periods in students with significant cognitive impairments. Booth, Hewitt, Jenkins, and Maggs (1979) conducted one of the first longitudinal studies of Direct Instruction. Across a 5year period, they studied the progress of 33 children with significant cognitive impairment at the Kurrambee Public School, Australia. The children were enrolled in the Distar language and reading programs beginning in 1974 . The investigators noted, after approximately thirty-two months of daily instruction on the Distar language and reading programs, most of the children in this study performed better than 'normal' 
children. The Kurrambee children had an average gain of thirty-four language age months in the actual thirty-two months of instruction (p. 259).

In another study involving 28 institutionalized moderately and severely retarded children in Australia, Maggs and Morath (1976) found that after instruction using the Distar language program, the students in the experimental group had higher mean gain scores on each of six measures, including the Standford-Binet Intelligence Test and the Reynell Dvelopmental Language Scale.

Becker and Gersten (1982) analyzed the impact of Project Follow Through, a program that evaluated a series of methods used to teach children from low socioeconomic backgrounds. The authors theorized that gains achieved through Head Start programming could be enhanced if students were taught using systematic instruction for the first three to four years of school. Becker and Gersten looked at Follow Through students at the fifth- and sixth-grade level. Using a quasi-experimental design, Becker and Gersten evaluated students at the fifth and sixth grade levels in five Follow Through schools that had utilized Direct Instruction. The students had been in a three-year Follow Through program. The investigators administered the Intermediate Form of the Metropolitan Achievement Test (MAT) and the Reading Subtest of the Wide Range Achievement Test (WRAT). Their scores were then compared to those of other students in the local community who had not been Follow Through participants. This was investigated in two studies a year apart for replication purposes. The 1975 study included 624 Follow Through students and 567 others, while the 1976 replication study involved 475 Follow Through students and 403 students who had not been a part of Project Follow Through. Becker and Gersten found that students in the Direct Instruction program performed better on the standardized measures (WRAT and MAT) than did the comparison group of non-DI students. Because the finding was 
replicated in the 1976 groups, more confidence can be placed in their results. Their findings suggested that, unless Direct Instruction was continued during Follow Through, the students in their samples appeared likely to fall behind their middle-income peers in the intermediate grades.

Gersten and Keating (1987) again examined Project Follow Through alumni in 1981 and 1982 when the first two groups of Follow Through students graduated high school to determine whether the effects of Project Follow Through impacted students' high school performance. Students at four high schools in varied settings participated in the study. The students studied had entered Project Follow Through in either kindergarten or first grade. When they evaluated these students in twelfth grade, Gersten and Keating noted consistent positive long-term effects across the four schools. They found that fewer students who had participated in the Direct Instruction Follow Through experience dropped out of high school, 47\% versus 58\% for the comparison group, and more applied to college than their non-Follow Through peers. In three out of four schools, the students' ninth-grade reading achievement was within 10 percentile points of the national median and considerably higher than the levels typical of students from low socioeconomic status at the time of the study. Gersten and Keating also noted that those students who had entered Project Follow Through in kindergarten performed better than those who started Project Follow Through in first grade.

Kraemer, Kramer, Koch, Madigan and Steely (2001) studied the impact of DI on deaf and hard of hearing students across a 6-year period. In this study, 160 students received Direct Instruction in reading comprehension, spelling, and writing in grades six through twelve. Although some modifications were made to the prompts in the presentation of the Direct Instruction lessons to accommodate the needs of the deaf and hard of hearing students, the core features of Direct Instruction remained intact. The investigators compared student achievement 
for the sample population against data from the Gallaudet Center for Assessment and Demographics (CADS). Kraemer and colleagues noted that twelfth-grade students who had been in the Direct Instruction program for four years averaged grade-level scores of 5.7 in reading comprehension, 7.0 in spelling, and 7.2 in total language as measured on the Comprehensive Test of Basic Skills (CTB). The investigators note that:

These grade-level averages are above the national averages for deaf students in selfcontained classrooms by 2.8 years, 2.2 years and 4.4 years respectively (as reported by Holt, Traxler, and Allen [1992] of the Gallaudet Center for Assessment and Demographics [CADS]). The Direct Instruction averages are also above the CADS averages for all deaf and hard-of-hearing students (including mainstreamed) by 1.2 years, .9 years, and 2.7 years respectively. (p. 27)

The investigators also observed gains for the DI group that were higher than those of the comparison population. When they compared gains from students tested at the close of eighth grade and tested again in twelfth grade, the investigators found that their sample:

Averaged gains of 2.5 years in reading comprehension, 3.8 years in spelling, and 3.0 years in total language. Gains over the same period for CADS self-contained students were .0 years, 1.3 years and .0 years respectively. Gains for all CADS students (including mainstreamed) were .4 years, .9 years and .3 years respectively. (p. 27)

\section{Short-term Studies}

Bracey, Maggs, and Morath (1975) studied the impact of Direct Instruction in reading with 6 moderately mentally retarded students in an institutional setting in New South Wales, Australia. The students were instructed using the Distar Reading Level 1 program. Bracey and 
her colleagues found that the students demonstrated statistically significant gains in blending, spelling and sound identification.

Malmgren and Leone (2000) studied the impact of Direct Instruction implemented with incarcerated youth in July 1998. Using the Gray Oral Reading Tests, $3^{\text {rd }}$ edition (GORT-3), the investigators pre-tested 100 juveniles in two categories: detained and committed. They defined detained as those juveniles who were held at the facility awaiting court hearings, and used committed to designate those found guilty of criminal activity. Forty-five male inmates with a mean age of 17.07 years whose scores on the pre-test were at least $2 / 3$ of a standard deviation below the mean composite score were selected to participate in the study: all were AfricanAmerican with 35 committed and 10 detained. Additionally, $44.4 \%$ or 20 of the boys were receiving special education services under the diagnoses of emotional disturbance (10 students), learning disabilities ( 7 students), and mental retardation ( 3 students). The selected inmates received 6 weeks of multifaceted intensive reading instruction in a summer program.

Malmgren and Leone crafted a daily reading intervention comprised of direct instruction in decoding and comprehension from the SRA Corrective Reading Direct Instruction program, whole language reading instruction through reciprocal peer tutoring, and teacher read-alouds. Students received 45 minutes each of Corrective Reading decoding and comprehension instruction, 60 minutes of peer tutoring whole language activities, and 20 minutes of teacher read-aloud. Treatment fidelity was assessed and calculated to be $100 \%$. Using an equivalent form of the GORT-3, the researchers administered a post-test at the end of the 6-week intervention period. The 45 students participating in the study demonstrated statistically significant gains in three of four subtest areas on the GORT-3. Malmgren and Leone report that: 
Analyses were conducted utilizing t-tests for paired observations of the participants' preand post-test scores. Using an alpha level of .05, pre- and post-test differences on the Rate sub-test were found to be highly statistically significant, $\mathrm{t}(44)=2.81, \mathrm{p}=.007$. Preand post-test differences on the Accuracy sub-test were also highly significant, $t(44)=$ $3.13, p=.003$. Gains on the Passage sub-test were significant as well $t(44)=2.42, p=$ .020 , though pre- post-test differences on the Comprehension sub-test did not reach statistical significance, $\mathrm{t}(44)=1.53, \mathrm{p}=.133 .(\mathrm{p} .244)$

Even though gains on the Comprehension subtest were not statistically significant, the findings from this very brief study suggested that Direct Instruction may be of benefit to this population. In another study with youth court-ordered to residential treatment facilities, Scarlato and Asahara (2004) also demonstrated student gains when utilizing the SRA Corrective Reading Direct Instruction curriculum. In their study, nine 16 to 17 year old males having diagnoses of either emotional disturbance or specific learning disabilities that were court ordered to a residential treatment facility were selected to receive intervention. These boys were each found to perform significantly below grade-level when assessed using the Woodcock Reading Mastery Test-Revised (WRMT-R) at pre-test. The participants were divided into two groups, but their scores on the pre-test were comparable. Five students received 180 minutes per week of instruction from the SRA Corrective Reading Program in decoding. The other four students received 345 minutes of instruction weekly designed by a reading specialist. Instruction was provided for 19 weeks, after which the WRMT-R was administered again. In analyzing the posttest scores, Scarlato and Asahara found that $60 \%$ of the students in the Corrective Reading group showed moderate to large gains on the WRMT-R subtest scores, and 73\% showed moderate to large gains on cluster scores. None of those who received the reading specialist-designed 
intervention showed moderate or large gains on either the subtest or cluster scores on the WRMT-R at post-test. While this study was small in scale and lacked rigorous controls, it further demonstrates the potential of Direct Instruction for remediating reading difficulties.

\section{Other Studies of Direct Instruction}

Waldron-Soler, Martella, Marchand-Martella, Tso, Warner, and Miller (2002) conducted a study of Direct Instruction implementation with preschool children. In their study, 36 students between the ages of 3 and 5 years old in three preschool programs received instruction using the Language for Learning Direct Instruction curriculum. Of the 36 students, eight had demonstrated evidence of developmental delays, while 28 were typically developing. The study evaluated the students' growth in language and social interaction skills across a 15-week implementation of Language for Learning. Waldron-Soler and colleagues measured the students' growth in receptive and expressive language skills using the Peabody Picture Vocabulary Test-Third Edition (PPVT-III) and the Expressive Vocabulary Test (EVT). The investigators measured students' growth in social interaction skills using the Social Skills Rating System: Preschool Teacher Questionnaire (SSRS). Evaluation of pre-test and post-test data revealed that students with developmental delays made language gains as measured by the PPVT-III and the EVT. The authors note that:

On the PPVT-III, there was an increase from the pre-test and post-test means for the Language for Learning Group (on average, 11.25 standard score point gain), while the mean from pre-test to post-test for the control group decreased by 3.25 standard score points. In contrast to the pre-test scores, the mean post-test EVT standard score for the Language for Learning group increased slightly (2.0 standard score point gain), while the 
mean for the control group actually decreased slightly (1.5 standard score point loss). (p. 81)

For the typically developing students, the results revealed a strong statistical relationship between the Language for Learning instruction and PPVT-III post-test scores. No significant relationship was found for the students without developmental delays on the EVT post-test scores.

In another study conducted by O'Connor, Jenkins, Cole, and Mills (1992), the researchers investigated whether the gains seen with economically disadvantaged children using Direct Instruction might also be observed with students having disabilities. In their 4-year study, O’Connor and colleagues worked with 816 -year old children who received one of two interventions at a transitional kindergarten. One of the treatments consisted of instruction from the SRA Reading Mastery I and II Direct Instruction curricula $(\mathrm{n}=43)$. The other intervention consisted of instruction in the Superkids program $(n=38)$. While children in both reading programs demonstrated improved skills, there was no appreciable difference between the two interventions at the end of the intervention year and at a one-year follow-up. However, among those students who stayed in the two reading programs beyond the one-year follow-up, those students who stayed in Reading Mastery showed greater gains. These findings suggested that for children having disabilities, gains may take longer than one year to become evident.

Kuder (1990) examined the reading skills of students having learning disabilities placed in the DISTAR program, a precursor to the SRA Reading Mastery and Corrective Reading Direct Instruction programs. In his study, Kuder compared the impact of the DISTAR Direct Instruction curriculum with a basal reading program for 48 students having learning disabilities. The two groups of 24 students were found to be evenly matched on the PPVT-R at pre-test; the 
average age of the students participating was 8 years, 10 months. Kuder assessed student reading achievement at the end of the first year and again at the end of the second year of implementation using the Woodcock Reading Mastery Test (WRMT). Kuder found that while the basal group did better on the letter identification subtest and the DISTAR group did better on word attack and word comprehension, there was no significant difference between the two groups. He attributed these results to the differences in the population he was studying when compared to populations studied in most of the literature that had been reported prior to 2001 . In a study of inner-city children with low socioeconomic status, Ogletree (2001) compared the DISTAR Direct Instruction curriculum to the Eclectic reading program. His study found that the group receiving the Eclectic instruction performed better than the DISTAR group, although the group was significantly larger $(n=191)$ than the DISTAR group $(n=64)$. In a similar study, Sexton (2001) evaluated the DISTAR reading program in relation to a basal reading program. A total of 18 students were split evenly between the DISTAR and basal groups. Conducting an analysis of covariance on the students' scores on the Slosson Intelligence Test (SIT), Sexton noted significantly improved scores for the group in the DISTAR program, suggesting that the DISTAR reading program was significantly more effective in influencing the SIT scores than the basal reading program, regardless of students' initial language ability.

In another 2001 study, Frankhauser, Tso, and Martella investigated the impact of adding daily timed reading exercises to students' Reading Mastery Direct Instruction lessons. Using an alternating treatments design with four students, the investigators found that the addition of daily timed readings did not improve the students' reading rates, which continued to increase steadily throughout the alternating treatment phases. They concluded that "the systematic practice and curriculum-specified reading checkouts within the Reading Mastery program provide the 
structure needed for students in need of reading remediation to make consistent progress in reading" (p. 94). These findings demonstrate that implementation of these programs without supplementation is sufficient to improve student reading skills.

Benner, Trout, Nordness, Nelson, Epstein, Knobel, Epstein, Maguire, and Birdsell (2002) evaluated the impact of the DISTAR Language for Learning program on the receptive language abilities of 45 kindergarten students. In contrast to other studies that focused on inner-city schools, the setting was two small rural Midwest elementary schools. Using a pre-post quasiexperimental design, Benner and colleagues measured student performance on the Test of Auditory Comprehension of Language (TACL-3). The investigators noted, "the post-test mean scores obtained by children receiving the Language for Learning program were larger than those from the comparison school in all cases" (p. 72).

Frederick, Keel, and Neel (2002) investigated the implementation of Reading Mastery to a group of first- and second-graders $(\mathrm{n}=107)$ at a large urban elementary school. Using a repeated-measures design in which students received seven months of instruction in small groups, the researchers found statistically significant differences at post-test on the Word Attack and Short Scale Total Reading scores on the Woodcock Reading Mastery Test for the firstgraders and on the Word Identification and Short Scale Total Reading scores for the secondgraders. They concluded that students at risk for reading failure can be taught efficiently using Direct Instruction.

\section{Implications for Future Research}

Each of the studies described above involved either students who were economically disadvantaged but who did not have disabilities, or students who had mild disabilities. None of the studies identified involved students with significant cognitive impairments. The lack of 
studies in this area suggests one way the current study adds to the literature base. Gersten and Maggs (1982) studied the implementation of DISTAR Direct Instruction over a five-year period with 12 pre-adolescent students with significant cognitive impairments in a self-contained classroom in Sydney, Australia. Using a pre-test-post-test design, Gersten and Maggs found significant IQ gains (seven IQ points) on the Stanford-Binet Test of Intelligence. The investigators concluded that it was the elements of Direct Instruction, most notably the teaching of the general case, which led to the students' growth. Gersten and Maggs described the general case strategy as, "one that uses the minimum number of rules to enable the child to solve a wide range of problems" (p. 330). Their findings suggested that the application of the general case strategy through Direct Instruction may prove beneficial to students having significant cognitive impairments.

Glang, Singer, Cooley, and Tish (1992) used Direct Instruction to teach reading, math, language, and keyboarding to students having traumatic brain injury (TBI). Working with three children, two boys aged 8 and 10 and a 6-year-old girl, Glang and colleages documented substantial gains after about 12 hours of one-on-one Direct Instruction. While one of the boys received instruction in mathematics and reasoning skills and the other received instruction in positive behavior skills, the girl received basic reading instruction using Reading Mastery and DISTAR Language curricula. The girl demonstrated an impressive improvement, from 0 to $31 \%$ of the 20 letter sounds presented during 12 instructional sessions. The boys also showed impressive gains in their respective skill areas.

Flores, Shippen, Alberto, and Crowe (2004) examined the use of Direct Instruction to teach letter-sound identification, blending, sounding out, and decoding, which they defined as sounding out then telescoping the sounds (p. 173). The participants in their study included 3 
males and 3 females, ages 8 to 13, in a self-contained classroom for students having moderate intellectual disability, with IQs in the range of 40 to 55 plus obvious deficits in adaptive behavior. The students, who attended a school in a large Southeastern city, were given instruction using the SRA Corrective Reading Direct Instruction curriculum. A multiple probe across behaviors with embedded changing conditions design was used to evaluate the students' growth in reading skills. Flores and colleagues noted that five of the 6 students mastered lettersound correspondences and were able to blend and telescope the sounds into words. The investigators cautiously concluded that "Direct Instruction techniques are effective for teaching the critical components of decoding to some students with moderate intellectual disabilities" (p. 186). They also interpreted their results in light of the kinds of students for whom Direct Instruction might not be appropriate, observing that:

These results also have implications for which students should or should not receive this type of instruction. Behavioral concerns such as refusing to participate in academic tasks and selective mutism did not prevent Gail and Rae from participating in Direct Instruction and learning systematic decoding skills. However, as discussed earlier, severe language articulation disorders may be an exclusionary characteristic for this type of reading instruction, or the instruction may have to be modified in substantial ways. Students such as Sam [whose articulation deficit interfered with the performance of the letter s sound] may be better served through a functional sight-word approach to reading instruction. (p. 186)

In a review of 128 studies on teaching reading to students having significant cognitive impairments, Browder, Wakeman, Spooner, Ahlgrim-Delzell, and Algozzine (2006) found many articles describing studies that stressed the importance of teaching sight words using systematic 
prompting hierarchies and fading techniques, but only one article that discussed phonetic approaches to reading instruction with this population. These authors further stressed the need for more research about phonetic approaches to reading instruction with students having significant cognitive impairments.

A large body of research supports the implementation of Direct Instruction with struggling readers, students with specific learning disabilities, students with speech and hearing impairments and those from disadvantaged economic environments. This review of literature has demonstrated much less research that examined Direct Instruction with students with significant cognitive impairments. The current study provides a step toward filling the gap in the research with this population.

\section{Teachers' Perceptions of Direct Instruction}

Very limited literature is available that describes teachers' perceptions of Direct Instruction gathered in scientific studies. One such study, conducted in Australia, investigated elementary teachers' attitudes during the general implementation of direct instruction. In this study, Demant and Yates (2003) surveyed 58 teachers using a Likert-scale presenting five positive and six negative statements about direct instruction. The teachers reported mixed opinions about direct instruction, but $81 \%$ of those surveyed expressed positive attitudes toward this instructional approach. The researchers noted a positive correlation between the teachers' attitudes and years of experience. They further noted that female teachers tended to report more positive attitudes toward direct instruction than males.

Sterbinski, Ross, and Redfield (2006) studied comprehensive school reforms across multiple sites. A total of 12 schools were studied, with variation in setting (e.g., rural or urban) and reform programs that were implemented (Success for All, Direct Instruction, Core 
Knowledge, and Balanced Early Literacy). Two rural elementary schools implemented Direct Instruction, measuring teacher perceptions of comprehensive school reform in general using two instruments, the School Climate Inventory and the Comprehensive School Reform Teacher Questionnaire. A total of 678 teachers from comprehensive school reform schools and 471 teachers from the control, non-reform schools replied to the instruments. Two rural elementary schools, one in Virginia and one in West Virginia, implemented Direct Instruction. Perceptions from the teachers in the Direct Instruction schools were mixed; teachers at one school were more positive in the first year of the three-year study and less so in the subsequent years.

Grossen (2004) conducted attitude surveys of teachers and students involved in a Direct Instruction program in a middle school with a record of low achievement that served low-income students in Sacramento, California. Both teachers and students were asked to respond to a series of questions using a 4-point Likert scale designed to elicit their attitudes toward and perceptions of Direct Instruction when compared to the year preceding implementation of Direct Instruction. Using a chi square test, Grossen found that responses were significantly more positive for Direct Instruction implementation in contrast to the reading program that had been in place at the school before the study was begun. Students also gave positive responses.

Greenberg, Fredrick, Hughes, and Bunting (2002) reported on the implementation of the Corrective Reading Direct Instruction program with adults in two classes. They found:

Both instructors noted that the following characteristics made the program a huge success with the learners and created a supportive environment for learning to read: (a) learners loved getting much positive feedback and were pleased that they could answer so many questions correctly, (b) learners were required to participate equally and therefore all enjoyed the same level of daily success. (p. 629) 
The adult students in both classes reported strong positive impressions of the program, but students in one of the classes did not like the finger snapping and hand clapping signals that were part of the program. These were subsequently modified to less offensive signals.

Lingo, Slaton, and Jolivette (2006) conducted a study of the effects of the Corrective Reading program on the reading skills and behaviors of students in two special education classrooms at a southeastern public middle school. The students' IQs ranged from 73 to 99 . On the social validity questionnaires, the 6 student participants and two teacher participants gave the program positive ratings. Students indicated that the Corrective Reading Program helped improve their reading skills and that they enjoyed the reading passages, but four of the students were uncertain as to whether they would like to continue the program. Both of the teachers reported that the Corrective Reading program had been successful in improving their students' reading abilities, and that they would continue to use the program for instruction. Additionally, Lingo and colleagues included a question about the teachers' perceived readiness to implement the Corrective Reading program. Both teachers reported feeling prepared to implement the curriculum.

Dakin (1999), reporting on a study of the effectiveness of a skill-based explicit phonics reading program, noted the importance of teacher philosophies toward teaching reading. Though her study did not explicitly investigate the SRA Direct Instruction curricula, Dakin found that "teachers interviewed showed similar philosophy and methodology in emphasizing explicit phonics instruction within their respective reading programs" (p. 40). Reporting on the work of Chall (1963, 1986), Dakin pointed out that teacher motivation and attitude play an important role in reading instruction and its outcomes. 
This notion of motivation and teacher attitude or perceptions of Direct Instruction would seem to go hand in hand. One of the frequently postulated criticisms of Direct Instruction is that it is boring and strips the teacher of his or her creativity. Denise Gelberg (2008), discussing her views on the question of whether scripted curricula impedes teacher creativity and autonomy, argued:

When I hear commentators and policy analysts bemoan the mandated use of scripted curriculums - particularly by beginning teachers - I think what I would have missed had I not been obliged to learn the Distar techniques. Ultimately, I determined which students needed those techniques and for how long. But I relied on the research done by others who developed the programs to know the optimal sequence in which I should introduce the sounds and the ideal number of times I should repeat activities to engender the highest possible learning and retention. (p. 82)

She continued, "Any stance that characterizes scripted curriculums and teacher professionalism as mutually exclusive strikes me as doctrinaire” (p. 82).

\section{Relationship between Teacher Perceptions and Student Achievement}

There were no notable studies located in the search conducted for this literature review that specifically addressed the measurement of possible relationships between teachers' perceptions of Direct Instruction and students' reading gains through the implementation of Direct Instruction methodology. There was some literature that explored the relationship between teacher attitudes and student achievement in general. That literature suggested the existence of relationships between teacher perceptions and student outcomes. Doyle, Hancock, and Kifer (1971) conducted an exploratory study of teacher perceptions of student ability as it related to reading achievement in first grade. After collecting teacher estimates of IQ for each 
first grader in the 11 participating teachers' classes, Doyle and colleagues had counselors administer the Otis-Lennon Mental Ability Test. Finding a discrepancy between teachers' estimates of students' IQs and the students' measured IQs based on gender, the researchers then looked at student achievement. Their findings suggested that "mean reading achievement level of classes whose teachers have high aspirations should exceed that of classes whose teachers underestimate pupil potential" (p.7).

In another study, Knight (1992) evaluated the role of students' perceptions of teacher behaviors and possible relationships between those perceptions and students' selection and utilization of reading comprehension strategies. Knight reported findings that "suggest that teacher behaviors create certain conditions that are influential in the determination of student strategy use" (p. 335). Teacher behaviors influenced students' choice of reading strategies. The implication is that to the extent that teachers perceive Direct Instruction to be effective, they will be more likely to convey that sentiment through their teaching and their students will be more likely to utilize the skills learned through Direct Instruction.

\section{Summary}

This review of the literature relating to the implementation of Direct Instruction has demonstrated a need for the current study in at least three ways. First, while there is a great deal of literature exploring the implementation of Direct Instruction with students who live in low socioeconomic backgrounds and who have mild disabilities, there is a dearth of research demonstrating the effects of implementing Direct Instruction with students with significant cognitive impairments. Second, even among the plethora of studies completed that have investigated the impact of Direct Instruction among the various populations studied, very limited research has extended the question beyond the efficacy of the programming to investigate 
teachers' perceptions of Direct Instruction. Finally, no studies have examined the relationship between teachers' perceptions of Direct Instruction and student achievement under Direct Instruction. The current study is designed to address all three of these areas. 


\section{Chapter 3}

\section{Methodology}

A great body of literature about the efficacy of Direct Instruction programs implemented with populations having mild disabilities or specific demographic attributes supports Direct Instruction's general effectiveness. However, there is much less research available describing the effectiveness of Direct Instruction reading programs as they are implemented with students with significant cognitive impairments or chronicling the experiences and perceptions of teachers implementing Direct Instruction programs with this population.

\section{Purpose of the Study}

This study examines three research questions. The first question asks whether students with multiple and cognitive disabilities make measurable gains when they are placed in a Direct Instruction reading program. The second question assesses teacher perceptions of teaching using the Direct Instruction methodology with this population. The third question investigates whether a relationship exists between teacher perceptions and student gains. The researcher designed a mixed methods study to answer the research questions. To identify the impact of Direct Instruction on the reading skills of these students, existing data collected by classroom teachers in the typical discharge of their instructional duties was analyzed. For this purpose, a repeated measures design was used (quantitative component). To identify teacher perceptions of Direct Instruction, teachers' responses during interviews were analyzed (qualitative component).

\section{Research Questions}

This study proposes to explore the following research questions:

1. Do students with significant cognitive impairments make measurable gains on the Woodcock Reading Mastery Test when taught using a Direct Instruction reading program? 
2. How do teachers using a Direct Instruction reading program to teach students with significant cognitive impairments perceive the effectiveness of the methodology?

3. Is there a relationship between teacher perceptions and the gains on the Woodcock Reading Mastery Test that students having significant cognitive impairments achieve in a Direct Instruction reading program?

\section{Setting}

The setting for this study was an approved, private-licensed school for exceptional children in Greensburg, Pennsylvania. The school serves approximately 85 students ranging in age from 4 to 21 , while 11 teachers (10 female, 1 male) and approximately 25 classroom and personal care aides staff the school. Operated under the auspices of a community of religious sisters, the school is included in the school system of the Catholic Diocese of Greensburg. As is common among Catholic schools, this school operates under budgetary constraints. These limited resources impact teacher salaries, which are well below the average earned by public school teachers in the general region, as well as the availability of resources, such as instructional materials and professional development opportunities for the teachers.

The students enrolled in the school typically have multiple cognitive, communication, and behavioral disabilities. The public school districts they would have attended sponsor most of the students who attend the school. However, there are a few students whose families choose to pay the tuition for their enrollment. In order to be admitted to the school, a student must demonstrate, at a minimum, a cognitive impairment. Review of the school's license shows that this school is approved to offer special education from preschool through secondary levels to students with varying disabilities. However, typically the students admitted demonstrate mental retardation in the moderate to severe range. At the time of this study, no students with profound 
mental retardation were enrolled at the school. Most of the students admitted to the school have multiple disabilities. According to IDEA 2004, multiple disabilities is defined as "concomitant impairments such as mental retardation-blindness or mental retardation-orthopedic impairment that result in complex educational needs that require special services." (34 C.F.R., Sec. $300[\mathrm{~b}][6])$ All of the students would be considered to have significant cognitive impairments and participate in state-wide testing through the alternative assessment process.

\section{Participants}

The participants in this study included 4 classroom teachers and 23 students with significant cognitive impairments in three classrooms at the school. These ungraded life skills support classrooms serve students between the ages of 14 and 21. Life skills classrooms are those that focus on the provision of Life Skills Instruction. According to Cronin, Patton, and Wood (2005), Life Skills Instruction includes 147 major life demands that are associated with a variety of specific life skills and organized around six domains of adult functioning. Students were assigned to the three classrooms on the basis of ability.

\section{Teacher participants.}

The teachers, all female, were $25,35,39$, and 58 years of age respectively at the beginning of the study, and had teaching experience ranging from 1 to 35 years at the time Direct Instruction was implemented. Anita left the school after the initial year of Direct Instruction program implementation and was replaced by Catherine. Teacher participants were recruited through a consent and information form sent to them at the school (see Appendix A). Anita and Catherine taught the highest functioning group of students. Jennifer taught what would constitute, for this age group in this school, the mid-level functioning group of students. Betty 
taught the lowest functioning group of students participating in this study. Characteristics of the teacher participants at the time Direct Instruction was implemented are summarized in Table 1.

Table 1

Demographic Description of Teacher Participants at time of Direct Instruction Implementation.

\begin{tabular}{l|l|l|l|l}
\hline Participant & Age & \multicolumn{1}{|c|}{ Education } & \multicolumn{1}{|c}{$\begin{array}{l}\text { PA Teaching } \\
\text { Certification(s) }\end{array}$} & \multicolumn{1}{|c}{ Experience } \\
\hline Anita & 39 & $\begin{array}{l}\text { B.A. Early Childhood } \\
\text { Education; M.S. Special } \\
\text { Education }\end{array}$ & $\begin{array}{l}\text { Early Childhood Education; } \\
\text { Elementary Education; } \\
\text { Special Education }\end{array}$ & 11 years \\
\hline Jennifer & 35 & $\begin{array}{l}\text { B.S. Art Therapy; M.S. } \\
\text { Special Education }\end{array}$ & Special Education & 6 years \\
\hline Betty & 58 & $\begin{array}{l}\text { B.A. Secondary } \\
\text { Education; M.Ed. Early } \\
\text { Childhood Education }\end{array}$ & $\begin{array}{l}\text { Secondary Education; Early } \\
\text { Childhood Education; } \\
\text { Private School }\end{array}$ & 35 years \\
\hline Catherine & 25 & B.A. Psychology & $\begin{array}{l}\text { Elementary Education; } \\
\text { Special Education }\end{array}$ & 1 year \\
\hline
\end{tabular}

The researcher is a priest and special educator who taught at the school between 2002 and 2006. While he did not teach at the school during the period when this study was conducted, he enjoyed a collegial relationship with the teacher participants. He at no time, either before or during the study, exercised pastoral ministry with the participants.

\section{Student data.}

This study makes use of student data, de-identified and provided to the researcher by the school. Data were reported for 23 Caucasian students, ages 15 to 20, with a mean age of 17.5 years at the beginning of the study. At the time of this study, no minority students were attending the school. Among the 23 students whose data were identified for inclusion in the study, 11 were female and 12 were male. Students have a variety of diagnoses, the most common being mental retardation, with a mean IQ estimated at 56 (range 20 to 94). No full- 
scale IQ scores were available for the students whose data were reported for the study. However, a team of three board-certified speech language pathologists estimated the students' verbal IQs using the students' standard scores on the Peabody Picture Vocabulary Test. Studies have shown (Bell, Lassiter, Matthews, and Hutchinson (2001); Carvajal, Nowak, Fraas, and McConnell (2000); Snitz, Bieliauskas, Crossland, Basso, and Roper (2000); Weisner and Beer (1991); and Craig and Olson (1991)) significant correlations between standard scores on the Peabody Picture Vocabulary Test and various instruments measuring intelligence.

In order for their data to be included in the study, the students had to meet two criteria. First, each student had to present with a significant cognitive impairment. As this is a criterion for admission to the school, all students met this criterion. Second, each student must never have been enrolled in a Direct Instruction reading program. Review of students' academic histories disclosed that none of the students whose data were reported for inclusion in the study had been exposed to Direct Instruction methodology in the past. School personnel identified students who met the inclusion criteria, de-identified their data, and presented it to the researcher in deidentified form.

\section{Data Collection Procedures}

\section{Quantitative component.}

This study makes use of existing data. These data were collected by the teachers while they were teaching in the first four years of the Direct Instruction program implementation in these classrooms. At the school where this study took place, formal and informal measures are typically administered at the beginning and end of each year. These assessments are primarily for determining present levels of achievement for the composition of the students' individualized 
educational plans, for summarizing IEP goals at the end of the year, and for determining eligibility for Extended School Year services.

Consequently, the data naturally available lent themselves to a repeated measures design. Using the Woodcock Reading Mastery Test-R, each student was tested at the beginning of the first year of Direct Instruction program implementation, and multiple times at various intervals over the remaining years of the study. The school made these scores available to the investigator for those students who met the inclusion criteria for the study. Comprised of several subtests, the Woodcock Reading Mastery Test-R measures reading achievement. The Word Identification subtest requires students to orally read a series of words. On the Word Attack subtest, students are shown nonsense words and asked to read them aloud. The Word Comprehension subtests present students with synonyms, antonyms, and analogies to solve. The Passage Comprehension subtest presents cloze tasks in which the students are required to read a sentence or sentences and provide the missing word using context clues. Review of the normative update information about the Woodcock Reading Mastery Tests-R disclosed that individuals with mental retardation were included in the normative sample. The 4 teacher participants conducted the testing. According to Pearson, persons are qualified to purchase and administer the Woodcock Reading Mastery Tests-R/NU provided that they:

1. Hold “a master's degree in psychology, education, occupational therapy, speech-language pathology, social work, or in a field closely related to the intended use of the assessment, and formal training in the ethical administration, scoring, and interpretation of clinical assessments;" (accessed at http://www.pearsonassessments.com/forms/levels.htm) or

2. Had "formal supervised mental health, speech/language, and/or educational training specific to working with parents and assessing children, or formal supervised training in 
infant and child development, and formal training in the ethical use, administration, and interpretation of standardized assessment tools and psychometrics." (accessed at http://www.pearsonassessments.com/forms/levels.htm)

Each of the 4 teacher participants met one or both of these qualifying criteria.

Additionally, each student was tested to determine his or her placement in the SRA Reading Mastery Direct Instruction curriculum. The SRA Direct Instruction programs provide commercially designed placement testing materials. These tests vary slightly between program levels but all include measurements of timed oral reading, word attack, or decoding skills, and comprehension. This placement testing rendered a total of seven instructional groups in six SRA DI programs, summarized in Table 2.

The first method of data collection served to assess the impact of the Direct Instruction reading protocol on the students' reading skills. The investigator compared the students' scores on the Woodcock Reading Mastery Test at multiple points in time. This evaluation considered the students' overall scores and scores on the subtests both as a complete sample and within and between the levels of the reading program outlined in Table 2. 
Table 2

Reading Instruction Groups.

\begin{tabular}{lcl}
\hline Group & Number of Students & Program/Level \\
1 & 4 & Corrective Reading: Word Attack, Decoding A \\
2 & 3 & Corrective Reading: Word Attack, Decoding A \\
3 & 3 & Corrective Reading: Word Attack, Decoding B-1 \\
4 & 2 & Corrective Reading: Word Attack, Decoding B-2 \\
5 & 3 & Reading Mastery III, A series \\
6 & 4 & Reading Mastery IV, A series \\
7 & 4 & Reading Mastery Plus \\
\hline
\end{tabular}

The second method of data collection was the administration of a survey that was designed to measure teachers' perceptions of Direct Instruction. This survey, found in Appendix C, consisted of 20 statements concerning Direct Instruction to which the respondent was asked to respond on a Likert scale by indicating her degree of agreement or disagreement with each statement. The survey items were designed by the researcher based upon the work of Bessellieu (2001), who used a Likert scale questionnaire to collect teachers' self-assessment of their Direct Instruction presentation skills. Content validity was assessed through review by members of the Association for Direct Instruction. The survey data were utilized in two ways. First, the scores from the survey were averaged for each teacher and used in a regression analysis to address the third research question concerning any relationship between teachers' perceptions and students' gains under Direct Instruction. Second, the survey responses were used to triangulate qualitative data gathered through teacher interviews. 


\section{Qualitative component.}

The descriptive portion of the study utilized qualitative methods to identify common themes that might shed light on the following research question:

How do teachers using a Direct Instruction reading program to teach students with significant cognitive impairments perceive the effectiveness of the methodology?

Interviews, observation, and teacher perception surveys served as the primary tools for data collection. An interview protocol was developed for use with the teacher participants and piloted with other teachers. Additionally, the interview protocol was submitted to peer review by members of the Association for Direct Instruction for content validation purposes. Each interview was videotaped and transcribed verbatim by the investigator. Interview tapes, field notes, and transcripts were encoded to ensure confidentiality. An interview script appears in Appendix B. Participants were offered the opportunity to select a woman's name as a pseudonym. Each participant reviewed her completed transcript to ensure accuracy in the transcription process and to verify that the transcript contents accurately portrayed her point of view. This process, known as member-checking, has long been supported as a method for insuring that the data and findings of a qualitative study accurately reflect the points of view and experiences of study respondents (Curtin and Fossey, 2007; McBrien, 2008).

The second form of qualitative data collection employed in this study was observation. The school-provided teacher videotapes were reviewed by the investigator to identify any evidence that could triangulate the interview data along with member checking. These taped segments were used to provide visual evidence confirming teacher statements about their experiences using Direct Instruction to teach reading. De-identified student IEP progress reports were reviewed by the investigator to triangulate findings from the interviews and to provide 
information about informal assessment of student progress. IEP progress reports provided a means of triangulating teachers' impressions of student progress as reported in the interviews.

A third form of data collection employed in this study was a teacher perception survey. Data collected from the survey, while primarily used in the quantitative analysis to investigate a relationship between student achievement and teacher perceptions of Direct Instruction, were also utilized to triangulate data gathered through teacher interviews.

The third research question, considering whether any relationship exists between teacher perceptions and student gains, was addressed through a questionnaire. The questionnaire was designed using a Likert scale to assess teachers' perceptions regarding Direct Instruction and its implementation in their classrooms (see Appendix C). The questionnaire data were then compared to student gains measured on the Woodcock Reading Mastery Test-R to determine whether any relationships exist.

\section{Data Analysis}

\section{Quantitative component.}

In this study, multiple reading groups based on skill level were each receiving Direct Instruction. Reading skills were measured by their teachers at four points in time using the Woodcock Reading Mastery Test-R. Because of this, statistical analysis included the use of a repeated measures analysis of variance. This statistical test is appropriate when the number of participants is small, when studying learning over time, and for reducing effects caused by individual differences like IQ (Gravetter and Wallnau, 2007). The repeated measures ANOVA enabled the researcher to determine whether differences in the means occurred between the four points in time when the Woodcock Reading Mastery Test - R was administered. Where such mean differences were discovered, post hoc comparisons between pairs of means, for example, 
between test 1 and test 2 , test 1 and test 3 , etc., enabled the researcher to identify where those differences occurred. These analyses were conducted for each of the subtests as well as the composite scores rendered by the Woodcock Reading Mastery Test-R. Additionally, simple individual gains were evaluated using raw scores from the tests. Outcomes from these analyses enabled the researcher to determine whether students made gains as measured by the Woodcock Reading Mastery Test-R. These analyses are summarized in Table 3.

Table 3

Summary of Repeated Measures Analysis of Variance.

\begin{tabular}{|c|c|c|}
\hline Dependent Variable & Independent Variable & Hypothesis tested \\
\hline WRMT Composite Scores & Time administered & $\begin{array}{l}\mu_{1}=\mu_{2}=\mu_{3}=\mu_{4} ; \\
\mu_{1}=\mu_{i}, i=2,3,4 ;\end{array}$ \\
\hline WRMT Subtest Scores & Time administered & $\begin{array}{l}\mu_{1}=\mu_{2}=\mu_{3}=\mu_{4} \\
\mu_{1}=\mu_{i, i}, i=2,3,4\end{array}$ \\
\hline WRMT Raw Scores & Time administered & $\begin{array}{l}\mu_{1}=\mu_{2}=\mu_{3}=\mu_{4} \\
\mu_{1}=\mu_{i}, i=2,3,4\end{array}$ \\
\hline
\end{tabular}

Treatment fidelity was measured using school-provided videotapes of each teacher

presenting lessons. The videotapes were evaluated by the investigator using a Direct Instruction rubric to determine whether the teachers have maintained fidelity to the Direct Instruction protocol. The Direct Instruction Teacher Presentation Rubric was adapted for this purpose by the researcher based upon a rubric provided by Watkins (personal correspondence, June 11, 2008) and appears in Appendix D. The rubric's reliability and validity, established through its use by Watkins and her associates, were reviewed for content validity by members of the Association for Direct Instruction. A second observer trained in the Direct Instruction protocol and certified as both a Special Education teacher and a Reading Specialist in the Commonwealth of Pennsylvania independently evaluated each teaching videotape so that interrater reliability 
could be measured and treatment fidelity validated. Treatment fidelity was calculated based on the number of teacher behaviors observed. Interrater reliability was calculated by comparing the ratings of the two independent reviewers using the formula (Wolery, Bailey, \& Sugai, 1988, p. 92):

$$
\text { Interrater Reliability }=\frac{\text { Agreements }}{\text { Agreements }+ \text { Disagreements }} \times 100 \%
$$

Interrater reliability of at least $90 \%$ was considered acceptable for this analysis (Wolery et al., p. 94).

The second research question asked how the teachers perceive the effectiveness of Direct Instruction. The question was investigated, in part, through the administration of a teacher perception survey that was designed to measure teachers' perceptions of Direct Instruction. The survey data were used as a means of triangulating other sources of data regarding the teachers' perceptions of Direct Instruction. While calculation of descriptive statistics could be performed using the survey data, given the small number of teachers (i.e., 4) participating and the brevity of the survey, it was deemed logical to report the survey responses in their entirety for the readers of the study report.

The third research question investigated whether a relationship existed between student gains on the Woodcock Reading Mastery Test-R and the teacher participants' perceptions of Direct Instruction in reading. To determine whether a relationship existed, simple linear regression was calculated comparing classroom-wide gains and the corresponding teachers' scores on the teacher perception survey. Assuming an ordinal scale for teacher perception scores collected on the survey, the teachers' individual mean scores could serve as the predictor variable in the regression analysis, while the students' individual scores served as responses. This analysis rendered a slope value that describes the relationship between the two variables and 
is equivalent to calculating a correlation statistic (Gravetter \& Wallnau, p. 556), but preferable in this case because a correlation would require a 1:1 pairing of teacher score with each individual student score and there are only 4 teachers in this study.

\section{Qualitative component.}

The second research question investigated teacher perceptions about the effectiveness of Direct Instruction in reading with students with significant cognitive impairment. Interviews, observations, and surveys were used as the means of data collection. To analyze interview data, the researcher conducted case-comparative inductive analysis of interview data across participants to identify any themes arising from the interviews that might shed light upon this second research question. In case-comparative analysis, data across individual cases are compared to identify common themes and patterns (Patton, 2002, p. 57). An inductive approach qualitative analysis “involves discovering patterns, themes, and categories in one's data. Findings emerge out of the data, through the analyst's interactions with the data, in contrast to deductive analysis where the data are analyzed according to an existing framework" (Patton, 2002, p. 453). Emerging themes and patterns were then used to identify the teachers' perceptions concerning the effectiveness of Direct Instruction methodology.

The findings from the qualitative component of the study were validated through several methods of triangulation. First, member checking enabled the teachers interviewed to review their individual transcripts for accuracy. Second, an additional analyst independently analyzed the data. Findings were then compared to ensure accuracy. A third means of triangulation was document analysis. Periodic IEP reports issued by the teachers were analyzed to determine whether the progress reported to parents agreed with the teachers' perceptions of Direct Instruction as collected through interview and survey data. Finally, the data collected from the 
individual teachers' perception surveys was used to further verify the data collected in the interviews. 


\section{Chapter 4}

\section{Results}

This study examined three research questions as they relate to the implementation of a Direct Instruction reading program with students having significant cognitive impairments. Those questions considered whether students with significant cognitive impairments made measurable gains when taught using a Direct Instruction reading program, how the teachers involved perceive the effectiveness of Direct Instruction and whether a relationship exists between teacher perceptions of Direct Instruction and student gains when taught reading using this methodology. This chapter will present the results of the study organized by research question.

The subjects of the study were 4 teachers who implemented the SRA Direct Instruction programs in three life skills support classrooms over a period of 4 years with students having significant cognitive impairments. The teachers taught a total of seven reading groups in three SRA Direct Instruction Reading programs: Corrective Reading, Reading Mastery, and Reading Mastery Plus.

\section{Research Question 1}

The first research question examined in this study was whether students with significant cognitive impairments make measurable gains on the Woodcock Reading Mastery Test when taught using a Direct Instruction reading program. In order to evaluate student gains in the Direct Instruction reading program, the Woodcock Reading Mastery Test-Revised was administered to the students at the beginning of the 2006-2007 school year before instruction using the Direct Instruction programs was implemented and then at multiple points in time over four academic years. W scores and Standard scores for a total of 25 students for the pretest and each available posttest were entered into Statistical Analysis Software (SAS) for computation of 
a repeated measures analysis of variance. The Woodcock Reading Mastery Test renders a total

of ten scores: six subtest scores and four cluster scores. A description of the individual subtests and clusters provided by the Woodcock Reading Mastery Test are summarized in Table 4.

\section{Table 4}

Description of WRMT subtests and score clusters.

\begin{tabular}{|c|c|}
\hline Test/Cluster & Description \\
\hline Visual-Auditory Learning Subtest & $\begin{array}{l}\text { Student is presented with a vocabulary of unfamiliar visual symbols that represent } \\
\text { common words and then translates stories made of the rebuses. }\end{array}$ \\
\hline Letter Identification Subtest & $\begin{array}{l}\text { Requires the student to identify lower- and upper-case letters, presented in a variety } \\
\text { of orthographic styles. }\end{array}$ \\
\hline Word Identification Subtest & $\begin{array}{l}\text { Presents isolated words arranged in order of difficulty that the student is required to } \\
\text { read aloud. }\end{array}$ \\
\hline Word Attack Subtest & Measures the student's ability to decode nonsense words or uncommon words. \\
\hline Word Comprehension Subtest & $\begin{array}{l}\text { Comprised of three separate subtests, Synonyms, Antonyms, and Analogies, this } \\
\text { subtest requires the student to deliver an appropriate synonym or antonym for the test } \\
\text { item, or to complete an analogy. }\end{array}$ \\
\hline Passage Comprehension Subtest & $\begin{array}{l}\text { Using a modified cloze procedure, the student must read a passage from which a key } \\
\text { word has been omitted and supply the missing word. }\end{array}$ \\
\hline Total Reading - Full Scale (F.S.) Cluster & $\begin{array}{l}\text { This cluster combines Word Identification, Word Attack, Word Comprehension, and } \\
\text { Passage Comprehension to provide a broad measure of the student's global reading } \\
\text { ability. }\end{array}$ \\
\hline Readiness Cluster & $\begin{array}{l}\text { The readiness cluster consists of the Visual-Auditory Learning and the Letter } \\
\text { Identification subtests. It provides information about skills necessary for beginning } \\
\text { reading. }\end{array}$ \\
\hline Basic Skills Cluster & $\begin{array}{l}\text { Composed of the Word Identification and Word Attack subtests, this cluster renders } \\
\text { a broad measure of basic reading skills. }\end{array}$ \\
\hline Reading Comprehension Cluster & $\begin{array}{l}\text { This cluster is comprised of the Word Comprehension and Passage Comprehension } \\
\text { subtests, and provides a broad measure of reading comprehension skills. }\end{array}$ \\
\hline
\end{tabular}

Note: Descriptions based upon Woodcock, 1998, p. 4-9.

In this study, W scores were used as an indicator of the students' raw scores because the word comprehension subtest and the four clusters are calculated scores for which no raw score 
exists. Woodcock created W scores as an intermediate step in the process of converting raw scores into standard scores. The W score transforms the student's raw score into a score that can be situated on an equal interval scale that ranges from 340 to 606 , and is centered at approximately 500, which approximates achievement at the beginning of fifth grade. (Woodcock, 1998, p. 38).

Using de-identified, coded WRMT score reports provided by the school, the researcher conducted repeated measures analyses of variance for each subtest and for each of the four test clusters. The school provided as many score reports for each student as were available for the time period covered by this study. The maximum number of score reports provided for a student was six as summarized in Table 5.

\section{Table 5}

Relative dates of WRMT administrations.

\begin{tabular}{c|c|c}
\hline Time & Description & Date Administered \\
\hline $\mathrm{t}_{1}$ & Pretest & August/September 2006 \\
\hline $\mathrm{t}_{2}$ & Post-test & May/June 2007 \\
\hline $\mathrm{t}_{3}$ & Post-test & August/September 2007 \\
\hline $\mathrm{t}_{4}$ & Post-test & May/June 2008 \\
\hline $\mathrm{t}_{5}$ & Post-test & Varied widely throughout the 2008-2009 school year \\
\hline $\mathrm{t}_{6}$ & Post-test & April/May 2010 \\
\hline
\end{tabular}

Scores were included in the analyses for a total of five points in time. The scores for $\mathrm{t}_{5} \mathrm{were}$ excluded from the analyses because the wide variability of testing dates posed concerns about their comparability for inclusion in the analyses. Additionally, SAS systematically excluded any student for whom scores from any of the relevant time points were missing. 
The results of the repeated measures ANOVA of the student gains in W scores across time are summarized in Table 6.

Table 6

Student W score gains across time ( $\mathrm{p}$-values in parentheses).

\begin{tabular}{|c|c|c|c|c|c|c|c|}
\hline \multirow[b]{2}{*}{ Test } & \multirow[b]{2}{*}{$\mathrm{t}_{1}$ mean } & \multicolumn{2}{|r|}{$\mathrm{H}_{0}$} & \multicolumn{4}{|c|}{ Mean Differences } \\
\hline & & $\mathrm{N}$ & p-value & $\mathrm{t}_{2}-\mathrm{t}_{1}$ & $\mathrm{t}_{3-} \mathrm{t}_{1}$ & $t_{4-} t_{1}$ & $\mathrm{t}_{6-}-\mathrm{t}_{1}$ \\
\hline $\begin{array}{l}\text { Visual - } \\
\text { Auditory } \\
\text { Learning }\end{array}$ & 466.75 & 4 & 0.2358 & $\begin{array}{c}-2.75 \\
(0.8559)\end{array}$ & $\begin{array}{c}-3.25 \\
(0.7974)\end{array}$ & $\begin{array}{c}9.25 \\
(0.2641)\end{array}$ & $\begin{array}{c}14.25 \\
(0.1159)\end{array}$ \\
\hline $\begin{array}{l}\text { Letter } \\
\text { Identification }\end{array}$ & 448.71 & 7 & 0.0907 & $\begin{array}{c}2.43 \\
(0.3893) \\
\end{array}$ & $\begin{array}{c}5.14 \\
(0.0893)\end{array}$ & $\begin{array}{c}7.14 \\
(0.0793)\end{array}$ & $\begin{array}{c}7.86 \\
(0.0295) \\
\end{array}$ \\
\hline $\begin{array}{l}\text { Word } \\
\text { Identification }\end{array}$ & 462.60 & 15 & $<0.0001$ & $\begin{array}{c}5.53 \\
(0.0804) \\
\end{array}$ & $\begin{array}{c}9.67 \\
(0.0041) \\
\end{array}$ & $\begin{array}{c}10.73 \\
(0.0035) \\
\end{array}$ & $\begin{array}{c}14.67 \\
(0.0029)\end{array}$ \\
\hline Word Attack & 469.57 & 7 & 0.0026 & $\begin{array}{c}18.14 \\
(0.0150)\end{array}$ & $\begin{array}{c}13.86 \\
(0.0703)\end{array}$ & $\begin{array}{c}19.00 \\
(0.0370)\end{array}$ & $\begin{array}{c}20.71 \\
(0.0103)\end{array}$ \\
\hline $\begin{array}{l}\text { Word } \\
\text { Comprehension }\end{array}$ & 475.20 & 15 & 0.0285 & $\begin{array}{c}6.93 \\
(0.0220)\end{array}$ & $\begin{array}{c}8.40 \\
(0.0173)\end{array}$ & $\begin{array}{c}5.07 \\
(0.0599)\end{array}$ & $\begin{array}{c}11.2 \\
(0.0305)\end{array}$ \\
\hline $\begin{array}{l}\text { Passage } \\
\text { Comprehension }\end{array}$ & 463.27 & 15 & 0.0034 & $\begin{array}{c}12.13 \\
(0.0229) \\
\end{array}$ & $\begin{array}{c}9.80 \\
(0.0857) \\
\end{array}$ & $\begin{array}{c}11.40 \\
(0.0556) \\
\end{array}$ & $\begin{array}{c}15.13 \\
(0.0288) \\
\end{array}$ \\
\hline $\begin{array}{l}\text { Readiness } \\
\text { Cluster }\end{array}$ & 453.00 & 4 & 0.1263 & $\begin{array}{c}0.25 \\
(0.9796)\end{array}$ & $\begin{array}{c}6.50 \\
(0.1417)\end{array}$ & $\begin{array}{c}11.50 \\
(0.0424)\end{array}$ & $\begin{array}{c}12.25 \\
(0.0662)\end{array}$ \\
\hline $\begin{array}{l}\text { Basic Skills } \\
\text { Cluster } \\
\end{array}$ & 447.14 & 7 & 0.0002 & $\begin{array}{c}14.86 \\
(0.0158) \\
\end{array}$ & $\begin{array}{c}13.43 \\
(0.0345) \\
\end{array}$ & $\begin{array}{c}17.14 \\
(0.0252)\end{array}$ & $\begin{array}{c}22.00 \\
(0.0088)\end{array}$ \\
\hline $\begin{array}{l}\text { Comprehension } \\
\text { Cluster }\end{array}$ & 469.13 & 15 & 0.0019 & $\begin{array}{c}9.60 \\
(0.0146) \\
\end{array}$ & $\begin{array}{c}8.93 \\
(0.0274) \\
\end{array}$ & $\begin{array}{c}8.27 \\
(0.0418) \\
\end{array}$ & $\begin{array}{c}13.40 \\
(0.0204)\end{array}$ \\
\hline $\begin{array}{l}\text { Total Reading- } \\
\text { FS Cluster }\end{array}$ & 471.00 & 15 & $<0.0001$ & $\begin{array}{c}9.07 \\
(0.0100)\end{array}$ & $\begin{array}{c}9.73 \\
(0.0071)\end{array}$ & $\begin{array}{c}10.27 \\
(0.0077)\end{array}$ & $\begin{array}{c}14.07 \\
(0.0033)\end{array}$ \\
\hline
\end{tabular}

Note: $\mathrm{H}_{0}: \mathrm{t}_{1}=\mathrm{t}_{2}=\mathrm{t}_{3}=\mathrm{t}_{4}=\mathrm{t}_{6}$

Review of the results of the repeated measures ANOVA disclosed significant differences over time in several of the tests and subtests when evaluated using $\mathrm{W}$ scores. Where a significant difference in the means across all five administrations of the Woodcock Reading Mastery Test was found in any given subtest or cluster, further analysis was used to pinpoint which points in time showed significant differences from the pretest $\left(t_{1}\right)$. This analysis, the results of which are included in Table 6, involved post hoc comparisons between pairs of means, for example, $t_{2}=t_{1}, t_{3}=t_{1}$, etc., to identify individual points in time when significant differences 
occurred. It is noteworthy that the repeated measures analysis of variance disclosed significant differences in students' W scores across time except in the Readiness Cluster and the Visual Auditory Learning and Letter Identification subtests. The Readiness Cluster is comprised of the scores from the Visual Auditory Learning and Letter Identification subtests. A more global measure of the students' gain in reading ability might be to consider the gains made in the Basic Skills $(F(4,24)=8.75, p=0.0002)$, Total Reading $(F(4,56)=8.21, p<0.0001)$ Clusters, and the Word Attack Skills subtest $(F(4,24)=5.57, p=0.0026)$. A table showing the results of the repeated measures ANOVAs using W scores for all subtests and clusters is found in Appendix E. Additional analysis was conducted using the students' standard scores. These analyses are summarized in Table 7. Standard scores take the student's performance on the WRMT-R and scales it for presentation on a distribution where the mean is 100 and the standard deviation is 15 . This makes it possible to compare the student's scores on the Woodcock Reading Mastery Test to performance on other standardized measures that gauge student achievement using the same mean and standard deviation. Only the Word Attack subtest $(F(4,24)=3.50, p=0.0218)$ and the Letter Identification subtest $(F(4,24)=5.19, p=0.0037)$ showed significant differences from pretest when evaluated using standard scores, While the Word Attack subtest showed a statistically significant gain, the majority of the subtests and clusters did not demonstrate significant increases. In fact, according to the analyses, some areas, including the Readiness Cluster and the Letter Identification and Word Identification subtests, showed declines. A table showing the results of the repeated measures ANOVAs using standard scores for all subtests and clusters is found in Appendix F. 
Table 7

Student SS score gains across time (p-values in parentheses).

\begin{tabular}{|c|c|c|c|c|c|c|c|}
\hline & & & $\mathrm{H}_{0}$ & & Mean D & erences & \\
\hline Test & $t_{1}$ mean & $\mathrm{N}$ & $\mathrm{p}$-value & $t_{2-}-t_{1}$ & $t_{3-}-t_{1}$ & $\mathrm{t}_{4-\mathrm{t}_{1}}$ & $t_{6}-t_{1}$ \\
\hline $\begin{array}{l}\text { Visual - } \\
\text { Auditory } \\
\text { Learning }\end{array}$ & 45.50 & 4 & 0.3463 & $\begin{array}{c}0.50 \\
(0.9771)\end{array}$ & $\begin{array}{c}7.75 \\
(0.3680)\end{array}$ & $\begin{array}{c}13.25 \\
(0.2673)\end{array}$ & $\begin{array}{c}17.75 \\
(0.1828)\end{array}$ \\
\hline $\begin{array}{l}\text { Letter } \\
\text { Identification }\end{array}$ & 35.43 & 7 & 0.0037 & $\begin{array}{c}-14.57 \\
(0.0554)\end{array}$ & $\begin{array}{c}-13.14 \\
(0.0651)\end{array}$ & $\begin{array}{c}-18.29 \\
(0.0053)\end{array}$ & $\begin{array}{c}-20.71 \\
(0.0205)\end{array}$ \\
\hline $\begin{array}{l}\text { Word } \\
\text { Identification }\end{array}$ & 67.40 & 15 & 0.4137 & $\begin{array}{c}-3.00 \\
(0.0093)\end{array}$ & $\begin{array}{c}-2.20 \\
(0.3541)\end{array}$ & $\begin{array}{c}-3.53 \\
(0.0264)\end{array}$ & $\begin{array}{c}-3.33 \\
(0.0504)\end{array}$ \\
\hline Word Attack & 63.86 & 7 & 0.0218 & $\begin{array}{c}13.14 \\
(0.0259)\end{array}$ & $\begin{array}{c}9.00 \\
(0.2085)\end{array}$ & $\begin{array}{c}13.57 \\
(0.0548)\end{array}$ & $\begin{array}{c}14.57 \\
(0.0054)\end{array}$ \\
\hline $\begin{array}{l}\text { Word } \\
\text { Comprehension }\end{array}$ & 57.40 & 15 & 0.2473 & $\begin{array}{c}4.73 \\
(0.0768)\end{array}$ & $\begin{array}{c}3.07 \\
(0.3883)\end{array}$ & $\begin{array}{c}-1.20 \\
(0.7059)\end{array}$ & $\begin{array}{c}4.80 \\
(0.2877)\end{array}$ \\
\hline $\begin{array}{l}\text { Passage } \\
\text { Comprehension }\end{array}$ & 58.00 & 15 & 0.1136 & $\begin{array}{c}3.40 \\
(0.1520)\end{array}$ & $\begin{array}{c}-1.53 \\
(0.6190)\end{array}$ & $\begin{array}{c}-3.53 \\
(0.3576)\end{array}$ & $\begin{array}{c}-1.00 \\
(0.7266)\end{array}$ \\
\hline $\begin{array}{l}\text { Readiness } \\
\text { Cluster }\end{array}$ & 38.25 & 4 & 0.5946 & $\begin{array}{c}-7.25 \\
(0.5392)\end{array}$ & $\begin{array}{c}-2.75 \\
(0.6142)\end{array}$ & $\begin{array}{c}-3.25 \\
(0.6062)\end{array}$ & $\begin{array}{c}-10.75 \\
(0.1853)\end{array}$ \\
\hline $\begin{array}{l}\text { Basic Skills } \\
\text { Cluster }\end{array}$ & 51.14 & 7 & 0.1559 & $\begin{array}{c}5.43 \\
(0.1673)\end{array}$ & $\begin{array}{c}5.00 \\
(0.1840)\end{array}$ & $\begin{array}{c}7.00 \\
(0.0993)\end{array}$ & $\begin{array}{c}6.14 \\
(0.0469)\end{array}$ \\
\hline $\begin{array}{l}\text { Comprehension } \\
\text { Cluster }\end{array}$ & 54.40 & 15 & 0.1526 & $\begin{array}{c}5.60 \\
(0.0582)\end{array}$ & $\begin{array}{c}2.47 \\
(0.4500)\end{array}$ & $\begin{array}{c}-0.33 \\
(0.9227)\end{array}$ & $\begin{array}{c}4.07 \\
(0.3056)\end{array}$ \\
\hline $\begin{array}{l}\text { Total Reading- } \\
\text { FS Cluster }\end{array}$ & 60.73 & 15 & 0.2947 & $\begin{array}{c}3.93 \\
(0.0772)\end{array}$ & $\begin{array}{c}3.13 \\
(0.3352)\end{array}$ & $\begin{array}{c}0.80 \\
(0.8176)\end{array}$ & $\begin{array}{c}5.33 \\
(0.0125)\end{array}$ \\
\hline
\end{tabular}

Note: $\mathrm{H}_{0}: \mathrm{t}_{1}=\mathrm{t}_{2}=\mathrm{t}_{3}=\mathrm{t}_{4}=\mathrm{t}_{6}$

Based on these analyses, a main effect for time was demonstrated in this study. While they did not do so in every area, the students with significant cognitive impairments did show statistically significant gains across time using W scores in at least the Total Reading-FS and Basic Skills Clusters, as well as the Word Attack subtest, measured using both W and standard scores on the Woodcock Reading Mastery Test. Additionally, the Letter Identification subtest scores showed statistically significant changes in a negative direction. Based on the Direct Instruction reading programs' emphasis on developing decoding skills, these three score sets were deemed to provide the best overall measure of the students' growth as a result of Direct Instruction. 
Analyses were also conducted to determine a main effect existed across levels of the Direct Instruction Program. Across the three classrooms, there were a total of seven reading groups, but these groups were placed into three Direct Instruction programs. Four of the groups identified in Table 2 were placed in Corrective Reading, which constituted Level 1 for this analysis. The What Works Clearinghouse describes Corrective Reading as being designed to promote reading accuracy (decoding), fluency, and comprehension skills of students in third grade or higher who are reading below their grade level. ... Corrective Reading can be implemented in small groups of four to five students or in a whole-class format. Corrective Reading is intended to be taught in 45-minute lessons four to five times a week (accessed at http://ies.ed.gov/ncee/wwc/reports/beginning_reading/cr/). Two of the groups were in Reading Mastery, which constituted Level 2 for this analysis. According to Jerry Silbert, National Institute for Direct Instruction, Reading Mastery is a developmental reading program. It was made for students who are in the process of learning to read. It has been used to help students who are behind, because it is so highly systematic and explicit ... Reading Mastery levels III an IV are for when students transition from learning to read to reading to learn. These levels are designed to teach students to learn from a variety of text structures - narrative and non-narrative (personal communication, June 7, 2010).

One group was placed in Reading Mastery Plus, and constituted Level 3. The Reading Mastery Plus students were treated as a separate group because the program is different from Reading Mastery. Distinguishing between Reading Mastery and Reading Mastery Plus, Jerry Silbert noted, "Reading Mastery Plus has the same content as Reading Mastery. It was written for state adoptions and has a slightly different sequence, but the content for teaching reading is almost 
exactly the same." With students grouped according to these three levels, another repeated measures analysis of variance was conducted to determine whether there were differences between levels. The results of this analysis using W scores are presented in Table 8.

Table 8

Level Comparisons - W Scores.

\begin{tabular}{|c|c|c|c|c|c|c|c|c|c|c|}
\hline & Level & $\mathrm{N}$ & $\begin{array}{l}\text { Mean, } \\
\text { Time } 1\end{array}$ & $\begin{array}{l}\text { Mean, } \\
\text { Time } 2\end{array}$ & $\begin{array}{l}\text { Mean, } \\
\text { Time } 3\end{array}$ & $\begin{array}{l}\text { Mean, } \\
\text { Time } 4\end{array}$ & $\begin{array}{l}\text { Mean, } \\
\text { Time } 6\end{array}$ & $\begin{array}{l}\text { Overall } \\
\text { Mean* }\end{array}$ & $\begin{array}{c}\text { Other } \\
\text { Levels } \\
\text { with } \\
\text { which } \\
\text { Difference } \\
\text { was } \\
\text { Observed }\end{array}$ & $\begin{array}{l}\text { Total } \\
\text { Gain }\end{array}$ \\
\hline Reading & 1 & 9 & 451.56 & 465.44 & 467.11 & 464.56 & 470.44 & 463.82 & 2,3 & 18.88 \\
\hline Comprehension & 2 & 3 & 488.00 & 492.00 & 490.67 & 488.33 & 494.67 & 490.73 & 1 & 6.67 \\
\hline Cluster & 3 & 3 & 503.00 & 505.33 & 498.33 & 505.00 & 506.67 & 503.67 & 1 & 3.67 \\
\hline Total Reading & 1 & 9 & 452.33 & 466.33 & 465.78 & 466.00 & 470.67 & 464.22 & 2,3 & 18.34 \\
\hline F-S & 2 & 3 & 487.67 & 490.00 & 495.33 & 493.67 & 496.00 & 492.53 & 1 & 8.33 \\
\hline Cluster & 3 & 3 & 510.33 & 511.33 & 511.00 & 514.67 & 517.33 & 512.93 & 1 & 7.00 \\
\hline Word & 1 & 9 & 436.00 & 445.56 & 446.11 & 448.44 & 454.33 & 446.09 & 3 & 18.33 \\
\hline \multirow[t]{2}{*}{ Identification } & 2 & 3 & 483.33 & 489.67 & 495.33 & 495.00 & 492.67 & 491.20 & - & 9.34 \\
\hline & 3 & 3 & 521.67 & 514.33 & 527.67 & 526.33 & 530.67 & 524.13 & 1 & 9.00 \\
\hline Word & 1 & 9 & 460.11 & 469.78 & 471.11 & 467.11 & 474.67 & 468.56 & 2,3 & 14.56 \\
\hline \multirow[t]{2}{*}{ Comprehension } & 2 & 3 & 488.67 & 493.33 & 498.00 & 490.67 & 498.00 & 493.73 & 1 & 9.33 \\
\hline & 3 & 3 & 507.00 & 508.00 & 506.67 & 509.33 & 510.00 & 508.20 & 1 & 3.00 \\
\hline Passage & 1 & 9 & 443.11 & 461.22 & 462.89 & 462.33 & 465.89 & 459.09 & 2,3 & 22.78 \\
\hline \multirow[t]{2}{*}{ Comprehension } & 2 & 3 & 488.00 & 490.33 & 486.67 & 486.33 & 491.33 & 488.53 & 1 & 3.33 \\
\hline & 3 & 3 & 499.00 & 503.00 & 490.00 & 500.00 & 503.00 & 499.00 & 1 & 4.00 \\
\hline
\end{tabular}

Note. Overall test showed a level effect for every measure $(\mathrm{p}<0.05)$. $\mathrm{H}_{0}: \mathrm{L}_{1}=\mathrm{L}_{2}=\mathrm{L}_{3}$

Based upon the outcome of the repeated measures analysis of variance across levels based on W scores, there is a significant difference among levels. Level 1 was found to be lower than both Levels 2 and 3. Levels 2 and 3 were not found to be different from each other on any of the subtests or clusters. 
A similar pattern was noted in results of the repeated measures analysis of variance conducted using the students' standard scores, summarized in Table 9.

Table 9

Level Comparisons - Standard Scores.

\begin{tabular}{|c|c|c|c|c|c|c|c|c|c|c|}
\hline & Level & $\mathrm{N}$ & $\begin{array}{l}\text { Mean, } \\
\text { Time } 1 \\
\end{array}$ & $\begin{array}{l}\text { Mean, } \\
\text { Time } 2 \\
\end{array}$ & $\begin{array}{l}\text { Mean, } \\
\text { Time } 3 \\
\end{array}$ & $\begin{array}{l}\text { Mean, } \\
\text { Time } 4 \\
\end{array}$ & $\begin{array}{l}\text { Mean, } \\
\text { Time } 6 \\
\end{array}$ & $\begin{array}{l}\text { Overall } \\
\text { Mean* }\end{array}$ & $\begin{array}{l}\text { Other Levels } \\
\text { with which } \\
\text { Difference } \\
\text { was } \\
\text { Observed } \\
\end{array}$ & $\begin{array}{l}\text { Total } \\
\text { Gain } \\
\end{array}$ \\
\hline Reading & 1 & 9 & 40.89 & 49.89 & 48.22 & 44.89 & 47.78 & 46.33 & 2,3 & 6.89 \\
\hline Comprehension & 2 & 3 & 68.67 & 69.33 & 66.33 & 60.00 & 69.33 & 66.73 & 1 & 0.66 \\
\hline Cluster & 3 & 3 & 80.67 & 81.00 & 73.33 & 75.67 & 79.67 & 78.07 & 1 & -1.00 \\
\hline Total Reading & 1 & 9 & 48.67 & 55.67 & 52.11 & 52.22 & 54.78 & 52.69 & 3 & 6.11 \\
\hline F-S & 2 & 3 & 71.67 & 70.00 & 76.00 & 65.00 & 75.33 & 71.60 & - & 3.66 \\
\hline Cluster & 3 & 3 & 86.00 & 86.33 & 87.00 & 86.00 & 90.67 & 87.20 & 1 & 4.67 \\
\hline Word & 1 & 9 & 57.22 & 55.00 & 52.44 & 53.22 & 51.00 & 53.78 & 3 & -6.22 \\
\hline \multirow[t]{2}{*}{ Identification } & 2 & 3 & 71.33 & 70.67 & 75.00 & 67.67 & 71.67 & 71.27 & - & 0.34 \\
\hline & 3 & 3 & 94.00 & 86.33 & 93.67 & 92.00 & 95.67 & 92.33 & 1 & 1.67 \\
\hline Word & 1 & 9 & 44.44 & 52.11 & 50.56 & 46.78 & 52.22 & 49.22 & 2,3 & 7.78 \\
\hline \multirow[t]{2}{*}{ Comprehension } & 2 & 3 & 69.00 & 71.00 & 70.00 & 62.00 & 71.33 & 68.67 & 1 & 2.33 \\
\hline & 3 & 3 & 84.67 & 83.33 & 80.67 & 78.67 & 83.00 & 82.07 & 1 & -1.67 \\
\hline Passage & 1 & 9 & 46.00 & 51.56 & 49.22 & 47.44 & 46.11 & 48.07 & 3 & 0.11 \\
\hline \multirow[t]{2}{*}{ Comprehension } & 2 & 3 & 72.00 & 70.67 & 66.00 & 58.33 & 68.33 & 67.07 & - & -3.67 \\
\hline & 3 & 3 & 80.00 & 81.67 & 68.67 & 71.67 & 78.33 & 76.07 & 1 & -1.67 \\
\hline
\end{tabular}

Note. Overall test showed a level effect for every measure $(p<0.05)$. $\mathrm{H}_{0}: \mathrm{L}_{1}=\mathrm{L}_{2}=\mathrm{L}_{3}$

Again Level 1 was found to be lower than both Levels 2 and 3. Levels 2 and 3 were not found to be different from each other on any of the subtests or clusters.

Tests for interactions between time and level disclosed that there were no significant differences between levels over time. That is to say, students in no level of the program made gains at a different rate from students in any other level of the program. 


\section{Research Question 2}

The second research question addressed in this study asked "How do teachers using a Direct Instruction reading program to teach students with significant cognitive impairments perceive the effectiveness of the methodology?" The combination of structured interviews, member checking, teacher surveys, document analysis, and observation provided for triangulation of data.

Participant interviews were videotaped and transcribed verbatim. Transcripts were forwarded to each teacher, who then reviewed the transcript and signed a verification document attesting to the accuracy of the transcript. The school provided videotapes of Betty, Jennifer, and Catherine teaching Direct Instruction lessons from year two of the study. The researcher additionally observed and videotaped each of these teachers presenting a lesson during May of the fourth year of the study. The videotapes were then scored for treatment fidelity using a Teacher Presentation Rubric that had been validated for this purpose. This is consistent with the recommendations of Bellg et al. (2004), who note that "the gold standard to ensure satisfactory delivery is to evaluate or code intervention sessions (observed in vivo or video- or audiotaped) according to a priori criteria" (p. 446). To measure treatment fidelity, the researcher reviewed and scored three videotaped lessons presented by each teacher. Comparing the teachers' presentation to the appropriate lesson script, the researcher calculated a fidelity rate for each lesson based on the number of teacher behaviors that had been observed and recorded on the rubric. An average fidelity rate was calculated for each teacher. Catherine scored an average treatment fidelity rate of $80.05 \%$. Jennifer's average fidelity rate was calculated to be $84.92 \%$. Betty demonstrated the greatest fidelity to the Direct Instruction program with an average fidelity rate of $93.94 \%$. A second observer trained in Direct Instruction and certified as both a Special 
Education teacher and a Reading Specialist in the Commonwealth of Pennsylvania independently evaluated a random sample of the videotapes so that interrater reliability could be measured and treatment fidelity validated. Based on this review, interrater reliability was calculated to be $97 \%$.

Cross comparative analysis across participants was conducted to analyze data and to identify emerging themes relative to the second research question. This analysis disclosed a total of four major themes: 1) an incomplete understanding about how Direct Instruction operates pedagogically; 2) adaptation of the Direct Instruction scripted protocol to meet the particular instructional and behavioral needs dictated by their students' diverse disabilities; 3) general satisfaction with the Direct Instruction methodology for teaching students with significant cognitive impairments; and 4) an expression of an "ideal" reading program in which Direct Instruction was a major component. This researcher quotes extensively from the teachers' interview transcripts in the analysis that follows because he believes that the participants should speak for themselves as much as possible.

\section{Pedagogical understanding of Direct Instruction.}

Interview responses concerning preservice teacher training in reading instruction demonstrated that these teachers did not learn about Direct Instruction in their reading teaching methods classes at either the undergraduate or graduate level. While the teachers had diverse undergraduate experiences, all four of the teachers had attended the same graduate program in special education at Seton Hill University. Anita, Betty, and Jennifer reported having earned masters degrees at the University, while Catherine reported being currently enrolled in the masters degree program there. Each of the teachers indicated that she had completed two classes in reading instruction. Direct Instruction did not figure in these courses. Anita reported, 
In college I had two reading courses that I remember vividly. One of them was called Introduction to Reading ... we would examine popular literature stories and we were required to do basically an annotated bibliography based on certain fiction and nonfiction books, and learn about the books, and teach different lessons to the class based on those books in an early childhood environment. I also had a reading course which was called Reading I or whatever, and what it was, was we were introduced to different reading series of the time, you know, MacMillan, Scott Foresman, et cetera, and we would look through them ... so we had both. We had it based in a straight literature and we had it based on the reading series, the basal readers, for that time.

Betty stated, "I can only recall two classes in reading. I learned kiddie lit, but not much reading at that point either except for those two classes." She goes on to specify, "I have had no formal instruction in the Direct Instruction reading method."

Catherine's experience mirrored Anita's, during my undergrad I had two classes in reading instruction and it went through basically kindergarten through high school. The teacher was very creative; we had different projects that we had to do and we had to present lessons on different aspects of reading.

Only Jennifer reported having had any exposure to Direct Instruction in her academic preparation. She describes her course work in reading instruction as "your standard classes as far as reading skills and teaching reading." Jennifer specified, most of them touched on various types of teaching reading, so we got a little bit of input about different types of instruction, what you were looking for, how you were teaching things, maybe what struggles there were and maybe how you could make those 
corrections. DI was hit on, but not an extensive amount of time. Most classes kind of went over different types of instruction - DI was one of them, whole language, but it wasn't an entire class on DI or on any one particular type of methodology. And they just taught about [emphasis added] DI; not how to implement it.

Each of the teachers indicated that professional development experiences in Direct Instruction have been lacking. Thinking back to her time at the school and the types of inservice opportunities provided, Anita recalled,

What I do remember is that at the time we had a lot of personal help inservices going on - personal development things - but I think that was more based upon a lot of the behavior that was going on because they wanted to help the teachers who were feeling overwhelmed. But not on reading instruction.

When asked about what kind of professional development she received regarding Direct Instruction, Betty disclosed, “she [publisher's representative] came in and it was an inservice, but it wasn't an instructional inservice. It was basically, 'this is the product and this is how it's used' - it was almost like a sales pitch."

Catherine echoes the dearth of training in Direct Instruction when she says, "in terms of professional development opportunities in reading, I don't think we've had any here. It's mostly all on behaviors." Jennifer's response agrees with the other teachers. She says, "Professional development? Not a tremendous amount. Most of ours ends up being behavioral. We haven't necessarily had any inservices or conferences that we could go to as far as Direct Instruction ..." When asked, "What kinds of training have you received in Direct Instruction methodologies?" the teachers were extremely clear. "I read the manual and I instructed as per the manual. It was pretty cut and dried. You could read it and administer it within one reading 
of the manual," was Anita's response. Betty was even more succinct, "I read the manual and that was it. I read the manuals, I practiced - just like when I was a new teacher - I practiced.” Jennifer indicated,

Really, we haven't [had training]. Learning it kind of on our own is what we did when we first received it, reading the manuals, that kind of thing ... just that and between the staff bouncing ideas off each other trying to see that we had the understanding.

Only Catherine diverged from the others. She noted,

I didn't really receive any training. Just when I student taught here, I got familiar with it because of the teacher [Anita] using the curriculum. She showed me how to follow the directions and read through and ask the questions when they came up, but other than that I haven't had anything else, not even in my reading instruction classes. Those didn't teach anything about Direct Instruction.

When each of the teachers was asked what she remembered about how she learned to read as a child, the unanimous response was that phonics played the major role in her reading instruction.

The preceding interview results have been presented in a certain level of detail because this researcher believes that they inform the participants' response to a key interview question. That query, "What can you tell me about how Direct Instruction operates?" served as the critical question around which the theme of the teachers' understanding of the Direct Instruction pedagogy is centered. Anita's concept focused on the capacity of Direct Instruction to help students feel successful. She explained,

It gives them the opportunity to succeed, and I feel, as a teacher, I want to give the children that I teach every opportunity to succeed ... because you're giving them that repetition, that time to practice. You're basically planting prior knowledge into them; 
you're giving them that prior knowledge to fall back on: "Wait, did I hear her say that?" and "Two weeks ago she said that," because you're constantly on the cycle, this turning cycle of Direct Instruction. You are scripted, but they know what's coming next. They know that after we're done reading the story, we're going to go over the vocabulary words, or we're going to answer the comprehension questions, so they know what's coming next. It's not a surprise. It gives those clues, those verbal clues, to succeed. Jennifer's understanding centers on the repetition that she sees embedded within the program.

My understanding, I guess, is that it presents different steps in reading skills so you repeat - continually within the program repeat - different skills, so that even once they're mastered, you're still touching base on them so that they're not lost. So it starts out with phonics and then it continues to build on words and word comprehension, word sounds, up through reading stories and paragraphs, also always making sure that they're maintaining the comprehension of what's going on in the story as well. But there's always that repeated - especially in the initial stages of reading - constant repetition of the different skills.

Betty notes that

The one thing I find interesting, especially at the very beginning, and this is just my opinion, is the importance of auditory perception and them listening to you. For our student population that becomes problematic because they aren't always attentive ... so listening, at the beginning because they have to respond back and forth ... is what I see when I see Direct Instruction - a fast paced, listening. 
Catherine's understanding of Direct Instruction centered on comprehension questions embedded in the lessons. She said,

It kind of asks very basic questions so that the kids can understand. They're not such lengthy questions that the kids get confused ... when it's being asked in the story, it's pretty much right after the information has been given, so I think that's how it helps the kids because it kind of jogs their memory saying, "Oh this is an important part, I need to remember this." That's how I think it works with learning.

None of the teachers articulated an entirely accurate or complete conceptualization of the Direct Instruction framework in terms of the stimulus-response-reinforcement contingency.

\section{Adaptation of the Direct Instruction script.}

The second theme that emerged from the interview data dealt with the teachers' implementation of Direct Instruction in their classrooms with students having significant cognitive impairments. When asked how closely they adhered to the scripted lessons, each of the teachers indicated that she made adaptations as necessary to accommodate the unique learning needs of her students.

Anita, who worked with the highest functioning students, claimed to have the strictest adherence to the lesson scripts. She reported,

I adhered almost verbatim. I found it hard to stop sometimes, especially if the kid was on a roll reading. You know how they [the program script] tell you to stop. If the child was really doing a good job reading something and it [the script] said to stop it at this point ... I found it hard to stop. Sometimes it was hard to keep track of exactly how many mistakes they made. I thought it [DI] was good, and I tried to adhere as closely as 
possible because I wanted to see if would work ... you want to implement it as it was supposed to be implemented.

Both Jennifer and Catherine indicated that they followed the script fairly closely, but that where necessary to facilitate the students' comprehension of concepts in the lesson, they would "veer off script." Jennifer said,

In reading it's a little better - easier to adhere to the script at different levels. We also do Direct Instruction with math and that's not as easy because of the more difficult problems they have with it. With reading it's easier to follow, but you still have to keep in mind that if they're not getting something, you need to sidetrack from the script and you need to find another way to get them to understand the concept or the comprehension or whatever's being asked at that time. So I try to follow it, and usually can, depending on the group that I'm with and the level that they're at. But you also have to make sure that you know that they're getting the understanding. If they're stuck on something, you need to be flexible enough to make sure that they get that concept before you can move on. Catherine echoed Jennifer's sentiment but indicated that she also will modify the lesson when the students have already mastered a concept that the lesson is reviewing. When asked about how closely she follows the script, Catherine responded,

Pretty close ... the only time I go off is if the kids aren't understanding the concept ... [or] if they already mastered it, so they can review it on their own. That way they keep going and we can use our time for something else more in depth [at that point in the lesson] that they're not so familiar with.

Data collected through videotaped observation supported Jennifer and Catherine's interview statements. This researcher observed them both to add questions and reword questions 
in the script. These modifications served to scaffold students toward the answers specified as correct in the script.

Betty seemed to take the most liberties with the scripted lesson, but only to modify the presentation to accommodate her students' special learning needs. Betty confessed,

I send the bold print words home. They usually go on Thursday for the following Monday and I know that's [emphasis added] not part of the script. I try to follow. The only points that I really do deviate from would be when they [the script] ask you, "Ok, give us the middle sound," because they have a difficult time just listening and giving the middle sound. However, if you put the word in front of them and they have a visual, and I say, "What is the middle sound?" if the word is mud and I say point to the middle sound, they will point to the u or say "uh."

When asked whether the degree to which they adhere to the DI lesson script has changed over time, each teacher except Catherine indicated that she felt free to take liberties with the presentation script. Anita was candid,

As any teacher knows, as you get familiar with anything that you're teaching, you add your own technique, with anything that you teach. Just from my own experience, whatever you teach, and after you've read the story about the kangaroo going to the circus for the third time, you know what's going to happen next and you're not worried about the stops as much and not worried about how many mistakes the child made as much. You're not keeping track of that as rigidly as you did initially, no. Of course not. And then you add your own slant on it. You know, you want them maybe, to predict more or you want them to think about what's going to happen next, or those purposeful 
questions that could bring a little prediction, a little bit more skill from the child into your reading lesson.

Jennifer also expressed a greater comfort level with deviating from the lesson script in later years than she did initially. She said,

I probably tried to stay to it much more in the beginning because of getting comfortable with the program as well as getting comfortable with the students. Now that I know both better - not that I want to get off track of the script - it's easier when you know that there's a problem with the understanding of the students, to go off the script, do a better explanation - or do a different type of explanation so that they get the understanding then go back to where you were at [in the script]. So I guess I'm probably a little more comfortable doing it now ... if it has to happen, then it something that is definitely done, and then you get back on track with the script.

Betty's adaptations to the script center on varying the modality through which the content is presented. She might not use the presentation book, for example, to teach certain parts of the lesson and present the content using cards, strips, or slates. However, she conveys comfort with her adaptations, noting,

I do think that I know what the goal is with Direct Instruction. Seeing the results of the students I've worked with, and seeing them go on and work with other teachers and have those teachers come back and say they are decoding words, I think that my liberties that I've taken using slates or writing words or putting sound cards or pictures or whatever it may be, I do feel more comfortable doing that now than I did in the beginning as long as it works. I find it difficult to adhere to the specifics because you have to [have a] feel for the student. If we're having a difficult time on one section and it's section three, but I 
think that we can work on the workbook instead, we'll omit that and go to the workbook section if that student, I believe, is ready for the workbook, because he or she needs to write at that particular time. So I am comfortable with changing around, more so, more comfortable now than I was at the beginning.

In follow up correspondence, Betty expanded on her initial response, When I first started using DI I found it difficult to follow the script. I tried to follow it without any adjustments/adaptations. It didn't work for me. I was bored and felt that my students weren't getting my best. Once I felt comfortable with adapting the lessons to meet their needs, I was pleased with using the DI method. This change took place in the first year; probably the first quarter. At that point I was sold. I still make changes in the presentations and will continue to do so.

The videotapes of Betty's lessons confirmed her statements. As noted earlier, Betty demonstrated the highest rate of treatment fidelity (93.94\%). Her adaptations did not depart from the script, so much as serve to make the content from the presentation book more accessible to her students based upon their specific disabilities. For example, one of Betty's students had a visual impairment. It was for this student that Betty put the words from the presentation book onto cards in larger print.

Catherine, however, indicated that she has not changed her approach over time, saying, No, I don't think so. I've kind of tried to stick to it as much as possible, so it's probably been the same over the years ... I don't really think I do it differently today than I did when I was first here.

Another finding from the interviews was that each of the teachers disclosed that she uses Direct Instruction as one component of a broader classroom program. 
Anita said,

I did not change what I needed to do in that [DI presentation] book. I would add supplementary things. I love literature. I love reading. I would read, let's say, Holes, by Louis Sachar, and I would read it aloud to them, or they would have the book and they would read it, and they would answer questions that I made up as per that book. Then we watched the movie, so I was trying to get them more [content] than just that reading series $[\mathrm{DI}]$... I wanted it to be fun ... so I took DI, expanded it and made it one component of a language arts program. And when I did that I think I did use techniques from DI for those supplemental activities ... I felt it was important to practice as Direct Instruction gave me the model to do.

Jennifer echoed Anita's response, It's [DI] probably one of the major components because it's your reading skills. But it's only one of the components we use in the classroom. From that we pull our spelling, we pull our vocab[ulary], and then in addition to that, we have to continue to work on life skills, writing type skills, language arts skills that go into the writing. So it's one of the key components because it works on the reading skills and the comprehension skills, but it's not the only component we use.

Betty also indicated that she folds Direct Instruction presentations into a larger classroom language arts program:

The Direct Instruction I'm using right now, we usually rotate in our reading so that they have language arts in different types of presentations. They'll do spelling for 15 to 20 minutes, they'll do Direct Instruction with me for 15 to 20 minutes, and then they'll rotate. It's important for this population to get up and move around, and if they're just 
seated for 45 minutes they lose interest. Just sensory-wise they need to move ... we do word families, so on the wall right now, I see /ing/, /el/ and /il/. Those are the three sets of words that we're working on, and the only thing that they're adding is the initial sound. So /ing/ is the family and they get that straight, /ing/, then we go /k/-/ing/, king, and that's how they start to blend words. We use magnetic letters in the same way, so they have a tray, and if I give them a word they will spell that word, even from the words that were presented in Direct Instruction. So as often as I can, in different ways, this is how we present it. It sort of reinforces.

Even Catherine indicated that Direct Instruction spills over into other areas in her classroom. She said, Well, in the reading then also in the math program, those are directly Direct Instruction, and the science and the social studies, we kind of read like we do in the reading and the math. Then at certain points I stop them and then I go and ask basic questions so that I know that they're getting knowledge from the reading. If not, we go back and re-read. I do use that idea throughout the whole class in all the content areas to try and keep it the same for the kids.

Another finding was the frequency and duration of the Direct Instruction lesson presentation. Although Anita reported teaching the Direct Instruction reading lesson five days per week, she indicated that the duration of the lesson was only 20 minutes. Owing to students being "pulled out" for therapies and transition training, Jennifer indicated that, "they usually get only a 20 minute period probably twice a week in the Direct Instruction program, more or less." Betty said, "What we normally do is a lesson a week, or we try to. That's usually Monday, Tuesday and Wednesday so that it's back to back, and that works well." Catherine reported "We 
use Direct Instruction in reading three days a week for a total of an hour and twenty minutes each day. Each group works for 20 minutes with me in the Direct Instruction Program on those days." Observation data confirmed the information gleaned from the teacher interviews in this regard. Using three videotaped lesson presentations each for Betty, Jennifer, and Catherine, the researcher timed the duration of the teacher presentation and then calculated an average lesson duration for each teacher in order to triangulate their statements about lesson duration. This analysis revealed that Betty's average lesson lasted 21:24 (minutes : seconds), Jennifer's lasted 22:37, and the average duration of Catherine's lessons was 25:32. Each teacher reported rotating groups, where support staff supervises supplemental activities. In each case, the teacher indicated that only she presented the lesson. Staff simply supports.

Review of the interview responses relevant to this theme suggests that these teachers do indeed deviate from the scripted Direct Instruction program, in terms of lesson presentation, use of supplemental activities and relegating Direct Instruction to the role of component in a larger classroom-wide curriculum.

\section{Satisfaction with Direct Instruction.}

Each of the participants expressed a level of satisfaction with the Direct Instruction methodology for teaching her students with significant cognitive impairments. Part of that satisfaction derived from the students' progress in the program. Anita expressed her belief that, It helped in reading because the children that I taught felt more comfortable reading this series. They felt success in reading this series and it gave them the confidence to go and read those other books that I would bring in. Before, they would never think of picking up a chapter book because they didn't feel that they could read. I do believe that this did 
give them the confidence that they felt that they did have those decoding skills and that they were able to actually do it.

Jennifer was more reticent.

Over the years of using it [DI] they have pretty much always shown some progress sometimes there have been some variances - but it's been minimal steps. It's been slow steps, but definitely progressive steps. I don't see leaps and bounds progress, but I definitely see some progress. I definitely don't see any regression utilizing this program. Betty was much more certain of her position on the students' progress in reading using Direct Instruction.

I can give them a reader and they will sit and attempt to decode. They didn't do that before. They see words. They don't see just letters . . . I send home little vignettes that I create with some of the words that they have [along with] with a list of questions. I have a student who is autistic who one week ago for the very first time independently answered her questions - maybe not grammatically correctly - but you can understand exactly that she understood this little short story. If you ask them to draw a picture of the story, they can draw a picture of the story or parts of the story, so it works. I've been really surprised at the progress actually, because I was extremely fearful, especially when you're working with, ok, "this is /cr/, /c/-/r/-, /cr/," alright and "this is /a/, /a/." When you're doing isolated sounds and then all of a sudden they'll pull a little book or little story and read, even when they have to decode, they're looking at the sounds, they're reading, and it's amazing. It's amazing. 
Asked about her students' progress, Catherine noted,

I think that it's improving them ... because it does go through and show phonetics and using that. Then they have the questions through the stories, even though they're shorter stories in the beginning, but they still start to think, “oh, that's important. They're asking me about it," . . . so it's gaining on their comprehension skills as well. It think it's improving them [the students].

A related question was whether the teachers noticed the students transferring the skills they've learned in Direct Instruction with its specific prompts and format to other settings outside of the program. Each of the teachers reported that her students were, in fact, transferring the skills from Direct Instruction to other settings. Anita responded to this question without hesitation, saying,

Yeah, yeah, because when you teach the program as it's scripted, it works. Of course they're going to transfer. If you teach a kid how to decode a word, later on when they come across a word they're going to decode it because you taught them how to do it. Of course. Yes. Yes. So absolutely I saw them transfer.

Jennifer agreed with Anita's point of view, and offered the following example to illustrate.

I do. I do. Even when we have other groups and stuff and they're doing short stories, you can definitely see them sounding the words out using their decoding skills and even stopping periodically to stop and think about different things in the story. So yes, I do see that [transfer]. 
Betty too, saw transfer of skills and provided the following testimony.

They can carry it across. When they go for tutoring the instructor is amazed at what they're able to do. The one student I'm thinking of will do the shopping, will create a list - it may be done phonetically - and go to the grocery store and look at the signs and try to find a particular product.

Catherine's response was congruent with her colleagues.

Yeah, I do see that, like the science and the social studies ... where they have to read something, in that they sound out the words ... they seem to answer more questions correctly ... so they're kind of learning how to go back and look for an answer if they aren't sure. That's another skill.

The preceding sentiments colored the teachers' responses when asked directly whether they liked Direct Instruction. Anita expressed her position in terms of student progress.

If given an alternative method of learning to read that works for a child and they excel with it, then you have to take it. You have to run with it and you have to implement it just as it's given to you. And if it works, it can only be a positive thing ... so yes, it's a great program. If it helps a child, it's a great program ... and if they need that repetition and this is it, this is great. Do I like it? Do I like teaching it? It's not the most creative way to teach ... if given the Direct Instruction model that must be implemented in my classroom then I will implement it to the full extent. Will I supplement it? Yes, because I need more as a teacher. I can't just teach a scripted thing on a daily basis and feel fulfilled in my teaching because I need more ... but if that helps in getting from point A to point B so that they [students] are reading a novel at the end of the month, I love it. It 
doesn't matter whether you like it or not. If it works, you do it because that's what you're supposed to do because you are a teacher.

Jennifer was less descriptive when she said, 'I don't mind it - I definitely don't hate it. I do think it can get a little boring because you're just following along, sure, but if they're reading a story [in a basal program], you're doing the same thing." Betty was very succinct in her response. 'I like it, but I don't strictly adhere to everything the book says to do - I've made it my own, and I think that's the key." Catherine reported that she likes Direct Instruction, saying, "I like it cause it makes the kids' comprehension a lot better and they're learning. So as long as they're learning, I'm happy."

\section{Ideal reading program.}

The final theme that emerged from the interviews that sheds light on the teachers' perceptions of the effectiveness of Direct Instruction relates to their vision of the ideal reading

program. Each teacher was asked to describe what her ideal reading program would look like if she were able to design any kind of program she wanted. Contributing to this theme were that direct question, as well as a question concerning the strengths and weaknesses of Direct Instruction, on the premise that the perceived strengths or weaknesses of Direct Instruction would likely figure into the teachers' ideal program.

When asked about the strengths of Direct Instruction, Anita reported that, "the strengths are it's repetitive, it's scripted, they know what's coming next ... from a planning point of view, it's fabulous for a teacher." Jennifer expressed a similar opinion. She said, "the strengths definitely that it continues with the skills - and the skills are constantly repeated even after mastery. They're still brought into the program for maintenance. And that with each level you get progressively more difficult skills." Catherine noted two strengths: "the strengths are that it 
does ask them directly the question in the easiest format possible for them to understand ... and they [the program] show them [students] pictures and they understand the story a little bit better." Betty stated, "I like it. I like that fact that it's continuous. We review. You can learn something new but you go back so you maintain skills, which is very important with this population."

Where weaknesses of Direct Instruction were concerned, the teachers were split. For Anita, the lack of creativity was problematic, but a necessary evil.

Drawback? There's no creativity. No [emphasis added] creativity. The stories are blah. Why is a boxing kangaroo going to a circus? They're bad. They're bad [emphasis added]. They're phonics-based, so how great can they be? Kenny Kangaroo going to the freakin' circus for a month. For a month! [emphasis added]. I mean, it was rough. Some of it was rough, but it taught the skills that were necessary to read - to read Little House on the Prairie, to read The Outsiders. It taught those things [skills] that [made it possible] I could go back and read Lilies of the Field at the end of that month - and it was good. Jennifer discovered that the students became accustomed to the routine of the presentation format.

Weaknesses? I guess what I've seen as a weakness is that some of my kids get used to the program itself so they start answering questions before you even get the question out, because they are used to the way it's scripted out and what you are going to ask next. Betty reported no weaknesses, stating, "for my students, in the method of presentation that I use, I don't see any weaknesses. I like it."

Catherine indicated that she would have liked additional scripting to support the teacher at those times when the students do not understand a concept. "I feel like sometimes they [DI 
program] should have 'If they don't understand, ask this question.' So that might be the only weakness."

Asked about what her ideal reading program would look like, Anita evidenced the most fully developed notion. She specified that her program "would take the phonetic approach and skill-based approach of DI and embed it in the whole language approach based in authentic literature." It would be taught as a thematic unit. "Every facet of your day would be based around that literature program."

Jennifer specified that her ideal reading program would "encompass everything." She continued, "Direct Instruction focuses on the reading. I think the ideal reading program would have everything. It would have your reading skills ... writing skills ... language arts ... vocabulary." She also specified grammar as a concern.

Betty and Catherine both indicated that they would prefer a program based in Direct Instruction. Betty indicated, “pretty much what we're doing. It [her ideal reading program] would look like DI enhanced. It would be changed here and there, but I like the method of presentation." Catherine shared that her ideal program "would look basically like Direct Instruction," except that the program would provide more guidance for when students do not understand a concept, and provide supplemental hands on activities to support comprehension. Agreeing with Jennifer, Catherine also would want composition and "nouns, pronouns, all that stuff. I would include that because they get confused about it."

Taken as a whole, the participants' responses around the four themes identified in the cross-comparative analysis suggest that they do, in fact, believe Direct Instruction to be an effective methodology to use for teaching reading to students with significant cognitive impairments. 


\section{Research Question 3}

The third research question in this study examined whether a relationship exists between teacher perceptions of Direct Instruction and gains on the Woodcock Reading Mastery Test that students with significant cognitive impairments achieve in a Direct Instruction reading program. Teacher perceptions were quantified using a 20-item Likert scale survey. For each teacher, responses were averaged to determine a Total Perception Score. Table 10 provides teacher survey responses and descriptive statistics.

Based on the wording and repetition of topics in the questions, it was possible to combine questions into subcategories and to calculate average scores across teachers for those subcategories. The researcher did this simply for the purpose of triangulating interview data. The four subcategories were selected by the researcher because he believed them to be salient indicators of teacher beliefs about 1) the effectiveness of Direct Instruction; 2) the degree to which skills generalized to settings outside the reading classroom; 3) the extent to which the teachers like Direct Instruction; and 4) the extent to which they think that decoding, a critical element of Direct Instruction, is important. The researcher summarized the data in this fashion to facilitate the triangulation of their responses about the theme of the ideal reading program. A table providing the summarized subcategory data is found in Appendix G. 
Table 10

Teacher Perception Survey Data.

\begin{tabular}{|c|c|c|c|c|c|c|c|c|}
\hline \multicolumn{9}{|c|}{$\mathrm{T} 1-\mathrm{T} 2$} \\
\hline Item & Question & Betty & Jennifer & Anita & Catherine & M & Mdn & SD \\
\hline 1 & $\begin{array}{l}\text { The best way to teach reading is using } \\
\text { Phonics }\end{array}$ & 5 & 4 & 3 & 4 & 4 & 4 & 0.816 \\
\hline 2 & $\begin{array}{l}\text { Sight word programs are the best way to } \\
\text { teach reading to children with significant } \\
\text { cognitive impairment.* }\end{array}$ & 3 & 4 & 3 & 4 & 3.5 & 3.5 & 0.577 \\
\hline 3 & $\begin{array}{l}\text { Using scripted Direct Instruction lessons } \\
\text { is easier than planning lessons myself. }\end{array}$ & 5 & 3 & 4 & 4 & 4 & 4 & 0.816 \\
\hline 4 & $\begin{array}{l}\text { Sounding out words is more effective } \\
\text { than memorizing sight word lists. }\end{array}$ & 3 & 4 & 4 & 3 & 3.5 & 3.5 & 0.577 \\
\hline 5 & $\begin{array}{l}\text { Delivering Direct Instruction is } \\
\text { monotonous.* }\end{array}$ & 1 & 3 & 2 & 5 & 2.75 & 2.5 & 1.708 \\
\hline 6 & $\begin{array}{l}\text { My students are better readers because of } \\
\text { Direct Instruction. }\end{array}$ & 5 & 3 & 4 & 4 & 4 & 4 & 0.816 \\
\hline 7 & $\begin{array}{l}\text { I have noticed my students using word } \\
\text { attack skills they learned in Direct } \\
\text { Instruction when reading other materials. }\end{array}$ & 5 & 4 & 5 & 4 & 4.5 & 4.5 & 0.577 \\
\hline 8 & $\begin{array}{l}\text { Direct Instruction has been beneficial to } \\
\text { me because all the materials that I need } \\
\text { for planning are in the presentation } \\
\text { books. }\end{array}$ & 5 & 4 & 4 & 5 & 4.5 & 4.5 & 0.577 \\
\hline 9 & $\begin{array}{l}\text { My students are successful with Direct } \\
\text { Instruction. }\end{array}$ & 4 & 4 & 4 & 4 & 4 & 4 & 0.000 \\
\hline 10 & $\begin{array}{l}\text { I would recommend Direct Instruction to } \\
\text { other teachers. }\end{array}$ & 5 & 4 & 4 & 4 & 4.25 & 4 & 0.500 \\
\hline 11 & $\begin{array}{l}\text { Given a choice, I would continue to use } \\
\text { Direct Instruction. }\end{array}$ & 5 & 4 & 4 & 4 & 4.25 & 4 & 0.500 \\
\hline 12 & $\begin{array}{l}\text { I believe that Direct Instruction is } \\
\text { effective. }\end{array}$ & 5 & 4 & 4 & 4 & 4.25 & 4 & 0.500 \\
\hline 13 & $\begin{array}{l}\text { Presenting Direct Instruction lessons is } \\
\text { easy. }\end{array}$ & 5 & 5 & 5 & 4 & 4.75 & 5 & 0.500 \\
\hline 14 & $\begin{array}{l}\text { Direct Instruction fosters stronger } \\
\text { decoding skills than other reading } \\
\text { methods. }\end{array}$ & 5 & 3 & 5 & 4 & 4.25 & 4.5 & 0.957 \\
\hline 15 & Direct Instruction works for my students. & 5 & 4 & 4 & 4 & 4.25 & 4 & 0.500 \\
\hline 16 & $\begin{array}{l}\text { I have seen the skills my students learn } \\
\text { in Direct Instruction already generalizing } \\
\text { to other settings. }\end{array}$ & 5 & 4 & 4 & 4 & 4.25 & 4 & 0.500 \\
\hline 17 & $\begin{array}{l}\text { I prefer Direct Instruction to other } \\
\text { reading programs. }\end{array}$ & 5 & 4 & 3 & 4 & 4 & 4 & 0.816 \\
\hline 18 & $\begin{array}{l}\text { When my students encounter text, they } \\
\text { now attempt to decode it. }\end{array}$ & 5 & 5 & 4 & 4 & 4.5 & 4.5 & 0.577 \\
\hline 19 & $\begin{array}{l}\text { The scripted lessons in Direct Instruction } \\
\text { free me up for attending to student } \\
\text { performance. }\end{array}$ & 4 & 4 & 3 & 4 & 3.75 & 4 & 0.500 \\
\hline \multirow[t]{2}{*}{20} & $\begin{array}{l}\text { My students pick up other story books } \\
\text { and attempt to read them using skills } \\
\text { learned in Direct Instruction. }\end{array}$ & 3 & 4 & 4 & 4 & 3.75 & 4 & 0.500 \\
\hline & Total Perception Score & 4.4 & 3.9 & 3.85 & 4.05 & 4.05 & 3.975 & 0.124 \\
\hline
\end{tabular}

Note: Survey responses were based on a scale from 1 to 5 , where $1=$ Strongly Disagree and $5=$ Strongly Agree.

Responses to items 2 and 5 were inverted where necessary in the computation of the Total Perception Score. 
These Total Perception scores were then included with students' Total Reading-FS Cluster W scores from the Woodcock Reading Mastery Test in a regression analysis to determine whether a relationship existed. Because there was a change in teachers in one of the classrooms after year 1 of Direct Instruction program implementation, the regression analysis was conducted twice: once using student gains from the first year, measured as $t_{2}-t_{1}$, and once using student gains from years two through four calculated as $t_{6}-t_{3}$. The results of the regression model for year 1 $\left(\mathrm{t}_{2}-\mathrm{t}_{1}\right)$ are summarized in Table 11.

Table 11

Teacher perception and student gains, Total Reading-FS Cluster, Year 1.

\begin{tabular}{|l|r|r|r|r|}
\hline & \multicolumn{4}{|c|}{ Model Summary } \\
Model & $\mathrm{R}$ & $\mathrm{R}$ Square & $\begin{array}{c}\text { Adjusted R } \\
\text { Square }\end{array}$ & $\begin{array}{c}\text { Std. Error of } \\
\text { the Estimate }\end{array}$ \\
\hline 1 & $.568^{\mathrm{a}}$ & .322 & .293 & 8.51515 \\
\hline
\end{tabular}

a. Predictors: (Constant), Teacher perception

\begin{tabular}{|c|c|c|c|c|c|c|}
\hline \multicolumn{7}{|c|}{ Coefficients $^{\mathrm{a}}$} \\
\hline \multirow{2}{*}{\multicolumn{2}{|c|}{ Model }} & \multicolumn{2}{|c|}{$\begin{array}{c}\text { Unstandardized } \\
\text { Coefficients }\end{array}$} & $\begin{array}{l}\text { Standardized } \\
\text { Coefficients }\end{array}$ & \multirow[b]{2}{*}{$\mathrm{t}$} & \multirow[b]{2}{*}{ Sig. } \\
\hline & & $\mathrm{B}$ & Std. Error & Beta & & \\
\hline 1 & (Constant) & -86.885 & 28.513 & & -3.047 & .006 \\
\hline & Teacher perception & 23.428 & 7.087 & .568 & 3.306 & .003 \\
\hline
\end{tabular}

a. Dependent Variable: Total Reading-FS Cluster W Score gain $t_{2}-t_{1}$

The regression analysis in Figure 1 shows a significant positive relationship $(\mathrm{t}=3.306, \mathrm{p}=$ 0.003) between teacher perception and the change in the Total Reading - F.S. Cluster W score between time 1 and time 2. Therefore as teacher perception scores increase, so do the students' Total Reading - F.S. Cluster scores. Teacher perception accounts for $32.2 \%$ of the variability in reading gain scores. On average, a 1-point increase in teacher perception score results in a 23.428-point change in the reading $\mathrm{W}$ score gain. 
Figure 1

Regression relationship between teacher perception and WRMT scores $t_{2}-t_{1}$.

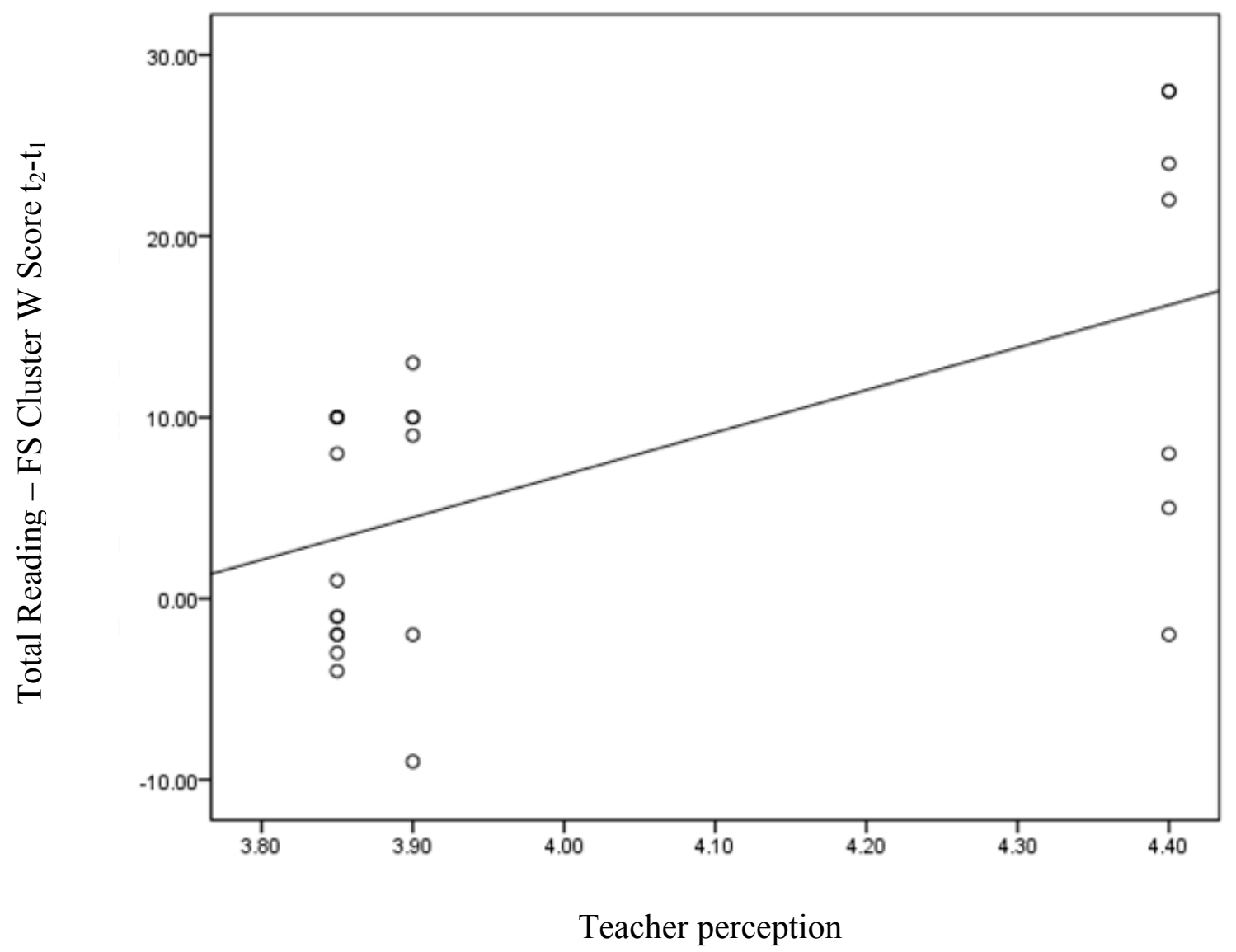

The regression analysis conducted for the period including years two, three, and four of program implementation are summarized in Table 12. 
Table 12

Teacher perception and student gains, Total Reading - FS Cluster, Years 2 - 4.

\begin{tabular}{|l|c|r|c|c|}
\hline Model & $\mathrm{R}$ & $\mathrm{R}$ Square & $\begin{array}{c}\text { Adjusted R } \\
\text { Square }\end{array}$ & $\begin{array}{c}\text { Std. Error of the } \\
\text { Estimate }\end{array}$ \\
\hline 1 & $.255^{\mathrm{a}}$ & .065 & -.007 & .21132 \\
\hline
\end{tabular}

a. Predictors: (Constant), W Score Total Reading - FS Cluster $\mathrm{t}_{6^{-}}$ $t_{3}$

\begin{tabular}{|c|c|c|c|c|c|c|}
\hline \multicolumn{7}{|c|}{ Coefficients $^{\mathrm{a}}$} \\
\hline \multirow{2}{*}{\multicolumn{2}{|c|}{ Model }} & \multicolumn{2}{|c|}{$\begin{array}{c}\text { Unstandardized } \\
\text { Coefficients }\end{array}$} & \multirow{2}{*}{\begin{tabular}{|c} 
Standardized \\
Coefficients
\end{tabular}} & \multirow[b]{2}{*}{$\mathrm{t}$} & \multirow[b]{2}{*}{ Sig. } \\
\hline & & $\mathrm{B}$ & Std. Error & & & \\
\hline 1 & (Constant) & 4.130 & .063 & & 65.268 & .000 \\
\hline & $\begin{array}{l}\text { W_Total_Reading_FS_ } \\
\text { Cluster_diff36 }\end{array}$ & .007 & .007 & .255 & .952 & .359 \\
\hline
\end{tabular}

a. Total Reading - FS Cluster W Score gain $\mathrm{t}_{6}-\mathrm{t}_{3}$

These findings do not suggest a relationship between teacher perceptions and student gains during the second through fourth years of the program implementation. Figure 2 depicts the results of this linear regression analysis graphically. 
Figure 2

Regression relationship between teacher perception and WRMT scores $t_{6}-t_{3}$.

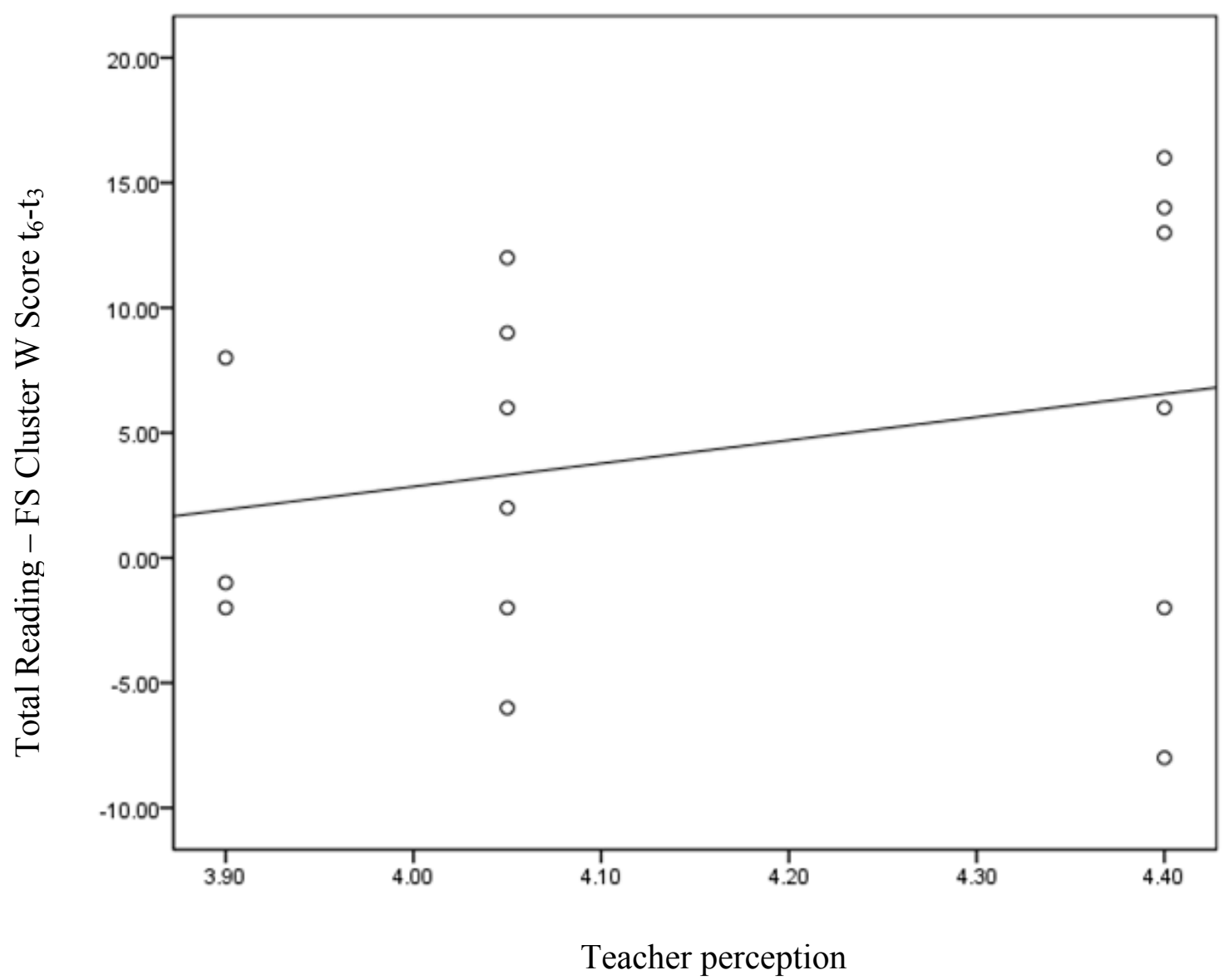

The findings for this third research question are mixed. The results of the regression analysis indicated a significant positive relationship between teacher perceptions and student reading gains in the first year but not in subsequent years of the Direct Instruction implementation. 


\section{Chapter 5}

\section{Discussion}

The stated purpose of the current study was to examine whether students with significant cognitive impairments demonstrate measurable gains in decoding skills and comprehension skills when placed in a Direct Instruction reading program, and to explore the attitudes and perceptions of teachers regarding the effectiveness of their use of Direct Instruction reading programs.

This study is important for a number of reasons. First, it adds to the current knowledge base on the efficacy of Direct Instruction for students with significant cognitive impairments. This is a group for which effective instructional practices are especially necessary, and one for which this intervention has been minimally studied in the past. Second, the current study adds to the research base on the effectiveness of Direct Instruction by describing outcomes of the methodology when it is utilized under typical classroom conditions, with all the disruptions and contingencies that present themselves in a life skills support classroom.

Another reason that this study is important is that it examined the perceptions about Direct Instruction that have been formed by teachers who have adopted Direct Instruction as their primary reading instruction method for students with significant cognitive impairments. While many studies have been conducted that show the efficacy of Direct Instruction, few of them have explored teacher perceptions of the programs. Additionally, the current study explored the relationship between teacher perceptions and the gains achieved by students with significant cognitive impairments who have been taught using Direct Instruction. This is a question that has not been considered in the research corpus on Direct Instruction.

The following discussion of research findings is organized around the three research questions addressed in the study. For each question, significant findings are reviewed in relation to the previous literature on Direct Instruction, data collected through teacher interviews, 
observation, and document analysis as these inform the interpretation of the findings of the current study. Factors that limit the generalizability of the study's findings are identified and recommendations for professional praxis based upon the findings of the current study are offered. Finally, questions for further study are posed.

\section{Student Gains under Direct Instruction}

The results of the current study suggest that students with significant cognitive impairments do make measurable gains in reading when taught using a Direct Instruction reading program. Assessed by a repeated measures ANOVA having a 0.05 significance level, the students demonstrated statistically significant gains on W scores in seven out of ten reported subtest and cluster score categories on the Woodcock Reading Mastery Test - Revised. Among these were the Word Attack Skills subtest, the Basic Skills Cluster, and the Total Reading - F.S. Cluster. Additionally, the students made gains on the Word Attack skills subtest as measured by Standard Scores. Of the score reports generated by the Woodcock Reading Mastery Test Revised, these three areas are perhaps the best indicators of student reading ability as it relates to Direct Instruction. The test's manual indicates that the Word Attack Subtest "measures the subject's ability to apply phonic and structural analysis skills in order to pronounce words with which he or she may be unfamiliar" (p. 6). As such, it provides a measure of the students' ability to decode words, which is a major element of the SRA Direct Instruction reading programs. The manual describes the Basic Skills cluster as providing "a broad measure of basic reading skills." The Basic Skills Cluster score is determined by adding the Word Identification and Word Attack subtest W scores and dividing by 2. (p. 8). The Total Reading - Full Scale (F.S.) cluster can be interpreted as "a broad measure of global reading ability" (p. 9). The student's Word Attack W score contributes to his Total Reading - Full Scale Cluster W score at 
the rate of $25 \%$, along with the $\mathrm{W}$ scores from the Word Identification, Word Comprehension, and Passage Comprehension subtest scores.

Based on the publisher descriptions, Word Attack, Basic Skills Cluster, and Total Reading - Full Scale Cluster seem to be the best indicators of student progress on the core reading skills addressed by Direct Instruction programming but also for comparison to the reading variables measured by other studies of Direct Instruction.

Given the fact that the students showed measurable gains in Word Attack Skills, the Basic Skills Cluster and the Total Reading - F.S. Cluster, a fair degree of confidence may be put in the finding that the students made real gains in reading. It is interesting to note that the same pattern of significant findings was not repeated in the students' standard scores. Only on the Word Attack subtest was a significant gain noted when the standard score data were analyzed. There are three explanations for this.

Measured across time, the students' standard scores actually went down (e.g. Letter Identification, -20.71; Word Identification -3.33; Passage Comprehension, -1.00; and Readiness Cluster, -10.75). This is not a surprising finding. A part of the norming procedure for transforming $\mathrm{W}$ scores into standard scores involves an adjustment for chronological age. Consequently, one would expect that, relative to the rest of the norm group, the standard scores of individuals with significant cognitive impairments would decrease over time. That is to say, that the gap between their measured scores and those of the norming sample would increase. This is one reason why significance was found in the $\mathrm{W}$ scores for other subtests that were not found in the corresponding standard scores. The phenomenon of standard scores decreasing over time for individuals with disabilities has been reported elsewhere in the literature in the work of Bolen (1998) and Mawhood and Howlin (2000). 
A second explanation has to do with the transformation from $\mathrm{W}$ scores to standard scores. Because there was a restricted range of variability in the $\mathrm{W}$ scores, and the data is re-scaled in the norming process, the standard scores rendered for this data set may have too restricted a range to show statistically significant differences.

The small sample size offers a third explanation for the fact that the significant differences found over time in the students' W scores were not reflected in their standard scores. Consequently, $\mathrm{W}$ scores may provide a better gauge of student performance over time than standard scores for students with significant cognitive impairments.

The results of the current study are consistent with the findings of several other studies. Scarlato and Asahara (2004) found gains on the Woodcock Reading Mastery Test-Revised when youth in court-ordered residential treatment facilities were placed in the SRA Corrective Reading program for 19 weeks. The findings of the current study are also congruent with those of Hempenstall (2008), who, though using different instrumentation to measure the effect of a Corrective Reading implementation in Australia, noted statistically significant gains in word attack, phonemic awareness, and spelling for 134 students with serious reading problems. Though the students were not identified in Hempenstall's study as having significant cognitive impairment, the students did meet Australian standards for diagnosis of reading disability.

The findings from the current study also are consistent with a descriptive study conducted by Kamps, Wills, Greenwood, Thorne, Lazo, Crockett, Ackers and Swaggart (2003). Their study compared three reading programs: Reading Mastery, Success for All, and a literaturebased program as reading curriculum reforms for 383 students in kindergarten through grade two. Of the three programs, the Reading Mastery Direct Instruction program outperformed the other two curricula for all students in the study, but particularly for those at highest risk. 
The findings of the present study are also consistent with the work of Shippen (2008), who conducted a pilot study comparing the Corrective Reading Direct Instruction program and the Laubach Literacy program during their implementation with incarcerated adults. The 14 inmate students participating in their study were reading below the $5^{\text {th }}$ grade level at the start of their study, which prevented them from participating in a General Equivalency Diploma program at the prison. While Shippen found neither program to be more effective than the other, the students in her study demonstrated significant gains in grade level equivalence, posting an average gain of 4.1 grade levels on the Word Attack subtest of the Woodcock Reading Mastery Test - Revised, a 1.3 average grade level gain on the Basic Skills Cluster and a 1.1 average grade level equivalent gain on the WRMT-R Total Reading - Short Scale.

Although statistically significant gains are noteworthy, teachers must be concerned with whether the changes in their students' performance under Direct Instruction are socially valid. The current study demonstrated socially valid gains in the students' reading performance under Direct Instruction. Teachers' responses, both in interview and on the survey, repeatedly disclosed that their students were generalizing the reading skills that they learned in the Direct Instruction programs.

\section{Implementation issues.}

Through the interview process several themes emerged that touched on the implementation of the Direct Instruction reading programs. These themes related teacher training, teacher understanding of how Direct Instruction operates pedagogically, and the presentation of Direct Instruction lessons. 


\section{Teacher training.}

A common theme through the interviews dealt with teacher training. Each of the teachers indicated that she had taken no college reading courses that had taught Direct Instruction. Only one teacher, Jennifer, indicated that Direct Instruction had been mentioned in one of her graduate courses, but she noted that it had been described in general terms that provided no information about how to execute Direct Instruction.

The three teachers who had been present when Direct Instruction was adopted, Anita, Betty and Jennifer, disclosed that they were simply given the materials. Each indicated that she had merely studied the teacher's manual that accompanied the programs that she was teaching. Catherine, who had completed her student teaching placement under Anita's supervision, reported that her cooperating teacher had shown her how to present the lessons. The teachers also indicated that they had received no in-service training on reading instruction over the course of the 4 years since Direct Instruction was implemented at the school. Training is an integral part of the proper implementation of Direct Instruction. Hummel, Wiley, Huitt, Roesch and Richardson (2002) describe the implementation of Corrective Reading in the Valdosta Middle School, Valdosta, Georgia. In the implementation process there, teachers received training from SRA personnel prior to the implementation of Direct Instruction. Additionally, during the school year, a faculty member from Valdosta State University supported the teachers as a DI coach. Grossen (2004) reporting on the implementation of Direct Instruction at a secondary school with high-risk students noted "teachers must receive program-specific training that includes in-class coaching" (p. 175).

Despite the fact that the teachers involved in the current study had not received the kinds of training recommended in the literature, their students still made measurable gains on the 
Woodcock Reading Mastery Test. The findings of the current study in relation to teacher training and student gains as measured on the WRMT-R contradict those of Grossen and earlier studies which hold that formalized training is essential for teachers. However, it may be that the system of scripted prompts in DI is specific enough and the manuals descriptive enough that special education teachers can implement the program successfully without specific formal training or professional development opportunities in Direct Instruction.

\section{Incomplete understanding of Direct Instruction.}

Another theme that surfaced during the teacher interviews was the fact that the teachers involved in the study did not have a complete, accurate concept of how Direct Instruction operates as an instructional methodology. Direct Instruction is a Behavioralist approach to instruction (Maggs 1973). It provides a carefully designed, field-tested script of prompts and reinforcers that are meant to be delivered at a fast pace to small groups of students so that each student's opportunities for reinforcement are maximized. Watkins and Slocum (2004) identify the main components of Direct Instruction as program design that identifies concepts, rules, strategies and "big ideas" to be taught using general case programming, organization of instruction with attention to scheduling, student grouping and progress monitoring, and studentteacher interaction that requires each student to be actively engaged in the lesson and taught to mastery of the concepts or skills. The teachers in this study described their understanding of Direct Instruction without reference to any of the components that Watkins and Slocum enumerate. Anita felt that DI works by “basically planting prior knowledge into them." Jennifer talked in terms of the program's sequence of skills, noting that there is "constant repetition of the different skills.” Betty emphasized the importance of pacing to keep the students' attention because from her point of view DI involves "auditory perception and them listening to you." 
Catherine believes that Direct Instruction works by asking "very basic questions so that the kids can understand ... right after the information has been given" [in the story].

Each of the teachers articulated in some fashion one or more principles that undergird Direct Instruction. However, none of the teachers responded in a way that suggested that she completely understood how the method actually works to support mastery of skills and concepts.

\section{Lesson presentation.}

Two issues arose in relation to the teachers' presentation of the Direct Instruction lessons in their classrooms. First, none of the teachers presented lessons of the duration for which the programs were designed. Corrective Reading is designed to be presented five days per week for a total of 45 minutes, and depending on the students' needs, as much as 90 minutes (Jerry Silbert, National Institute for Direct Instruction, personal communication, June 7, 2010). Betty and Jennifer, who teach the Corrective Reading Program, reported teaching a maximum of 20 minutes per day two to three days per week. Reading Mastery and Reading Mastery Plus are designed to be implemented five days per week for 45 minutes per day of teacher presentation, with another 20 minutes of independent student work (Jerry Silbert, National Institute for Direct Instruction, personal communication, June 7, 2010). Other research studies have implemented Direct Instruction interventions for longer durations and at greater frequencies. Malmgren and Leone (2000) implemented Corrective Reading five days per week for a total of 90 minutes per day. Scarlato and Asahara (2004) implemented Corrective Reading for 45 minutes per day, four days per week in their study of a Corrective Reading implementation in a residential treatment facility. Lingo, Slaton, and Jolivette (2006) studied the effects of Corrective Reading with middle school students having reading deficits and challenging behaviors. In their study, they also implemented Corrective Reading for 45 minutes per day. 
A second area of concern that arose during the teacher interviews in terms of the implementation of the Direct Instruction programs was deviation from the lesson script. Each of the teachers disclosed that she adapts the script in some way. For Anita, who claimed to adhere most closely to the script, divergence took the form of the addition of outside literature, but Anita maintained that she when she did bring in outside literature, she "did use the techniques from DI for those supplemental activities," noting elsewhere in her interview that she "felt it was important to practice [other content] as Direct Instruction gave me the model to do.”.

For Jennifer and Catherine, divergence consisted of going "off script" when necessary to facilitate student comprehension in instances where the scripted explanation of a concept was not producing the desired result. Even though DI is scripted to produce the maximum level of student comprehension in the minimum amount of time by very carefully juxtaposing examples and non-examples of concepts, students with significant cognitive impairments do not always comprehend the concepts as Direct Instruction scripts present them. The extent to which Jennifer and Catherine were observed to deviate from the scripts was minimal and was limited to instances where a concept required elaboration.

Betty admitted to adapting the lessons to present the content that better met her students' sensory needs. For Betty, this consisted entirely of presenting in visual form, prompts that the script called to be presented in a verbal form. Additionally, Betty admitted to rearranging the order of lesson segments to accommodate her students' behavioral issues on any given day. No other deviations from the script were noted.

Another area where observation showed divergence from the lesson scripts for all three teachers was in the program component of signaling. All three teachers appear to have abandoned the scripted signaling format in favor of a signal of their own design. Unison 
responding to prompts was not observed. The teachers adapted the lessons to permit individual responses because the nature of their students' disabilities made unison responding cumbersome. The lessons were still fast-paced, but this practice reduced the number of opportunities for each student to respond, to be reinforced, and to be monitored during a lesson.

A very interesting finding in relation to these implementation issues is that the students still showed measurable gains in their reading ability as measured on the Woodcock Reading Mastery Test - Revised despite the fact that the teachers reported having received no real training in the conceptual framework and the implementation of Direct Instruction, did not implement the instruction for the recommended frequency or duration of lessons, and adapted the lesson scripts to suit their own needs and the cognitive and the perceived behavioral needs of their students.

This conclusion must be interpreted with caution, however. Each of the teachers indicated that Direct Instruction comprised one part of an overall classroom-wide program of studies. There were other language-based activities that could have contributed to the students' gains on the WRMT-R. Anita brought in outside literature. Jennifer and Catherine, concerned about the fact that the DI programs do not teach other language arts skills, introduced composition and grammar studies into their classroom routines, as well as other short stories, and vocabulary and spelling studies, though words selected for instruction often came from DI lessons and stories. Depending on the level of the SRA Direct Instruction, composition, vocabulary study, and spelling may be included, but not all levels have those features. Therefore the teachers felt the need to supplement the DI. In follow-up discussion (personal communication, June 12, 2010), Betty indicated that she introduced "functional words," which 
she taught using DI decoding skills, and the Dolch sight word list, which is not typically taught using decoding strategies.

To the extent that these supplemental activities were implemented using teaching behaviors that were not based in the Direct Instruction model, these activities may have impacted students' scores on the Woodcock Reading Mastery Test - Revised. Such impact, if any, would be noted in the Word Identification, Word Comprehension, and Passage Comprehension subtests and their relative contributions to the Basic Skills, Comprehension and Total Reading - F.S. clusters. Teachers reported that decoding skills were exclusively taught using the Direct Instruction programs. With regard to the first research question addressed by the current study regarding whether students with significant cognitive impairments show measurable gains on the Woodcock Reading Mastery Test - Revised when taught using Direct Instruction in reading, this study concludes in the affirmative with respect to Word Attack skills.

\section{Teacher Perceptions of the Effectiveness of Direct Instruction}

The second research question explored by the current study was "how do teachers using a Direct Instruction reading program to teach students with significant cognitive impairments perceive the effectiveness of the methodology?" To respond to this question, teachers were surveyed, interviewed, and observed, and document analysis was conducted. Through this process, a total of four major themes emerged. Two of the themes, an incomplete understanding of the pedagogical underpinnings of Direct Instruction and the adaptation of the scripted protocol to suit their individual needs, have already been discussed in connection with the gains that the students achieved on the WRMT-R after having been taught using Direct Instruction. The final two themes will be explored here. 


\section{The interviews.}

The teachers in this study described a general satisfaction with Direct Instruction after having used the methodology to instruct their students with significant cognitive impairments.

\section{General satisfaction with Direct Instruction.}

Interview data supported the notion that the teachers regarded the Direct Instruction method as being effective for their students with significant cognitive impairments. Their responses to several questions indicated satisfaction. First, when they were asked whether they liked DI their responses were positive for the most part. Anita framed her response in terms of student progress, noting that "if it works, it can only be a positive thing ... so yes, it's a great program.” Catherine echoed Anita, saying that as long as her students were learning, she was happy. Jennifer was non-committal, saying, "I don't mind it - I definitely don't hate it." She went on to talk about the program becoming boring. Betty reported that she initially found it difficult but that after she began to feel comfortable modifying the modalities used in the lesson presentation to accommodate her students' sensory input needs, that "at that point, I was sold." She notes elsewhere in the interview, "I like it, but I don't strictly adhere to everything the book says to do. I've made it my own, and I think that's key."

A second interview question that was used to collect data on the teachers' perceptions of the effectiveness of Direct Instruction was whether they believed their students were making progress in reading under the program. All 4 teacher participants gave comments in the affirmative.

Anita believed the program gave her students the confidence they needed to pick up other literature. Jennifer attested to steady progress, but in minimal increments, noting, "it's been slow steps, but definitely progressive steps." Betty described her students' progress as "amazing," but 
then, Betty had the lowest functioning students in the study. Catherine felt that her students were making progress in comprehension. Review of their students' quarterly IEP reports, which revealed overall progress over time on the goals related to reading skills, confirmed that the teachers are in agreement in their perception that their students are making progress in reading using Direct Instruction. Thus what teachers said in their interviews in this regard is consistent with what they reported to parents. Additionally, teachers' survey responses provided a second means of triangulating the perceptions expressed in the teacher interviews.

A third area which may have contributed to the teachers' overall sense of satisfaction with Direct Instruction was the fact that their students reportedly were generalizing the skills that they were learning in their Direct Instruction reading program. Each of the teachers communicated that her students were using the skills they learned in Direct Instruction in other settings, subjects, or with other instructors. This was triangulated through the survey data. and is consistent with teacher reports from other studies. Besselieu. Kozloff and Rice (2001) reported on teachers' perceptions of Direct Instruction teaching in the Direct Instruction News. They quoted teachers in their study as making such statements as, "I've also noticed my children using the skills they learned when reading other materials," and "It's not only helped the children in reading, but their writing in their journals has been great!!"

\section{The teachers' ideal reading program.}

The fourth theme identified from the interview data that provided evidence of the teachers' perceptions of Direct Instruction was that each teacher, given the freedom to design any kind of reading program she chose, would include a Direct Instruction component. Teacher responses to two interview questions contributed to this theme. When asked about the strengths and weaknesses of Direct Instruction, the teachers offered varied responses. While Anita. 
Jennifer and Betty agreed that repetition of skills even after mastery was an important strength, Catherine felt that the way comprehension questions were structured within the lessons was important. In terms of weaknesses, while Betty felt that there were no significant weaknesses inherent in the program. Jennifer felt that the students become too comfortable with it, Catherine wanted more scripting for when the students do not understand a concept presented in the text, and Anita felt that the program had boring stories and stifled teacher creativity. Ryder and colleagues found this in their study also. They report, "teachers interviewed in this study often were critical of the quality of the stories presented in the DI program" (p. 190). Anita is not alone in her opinion. Each teacher, in her own way, identified areas of concern about Direct Instruction. From their point of view, Direct Instruction is not perfect. They each reported using DI as a component of their overall classroom program. This is consistent with the findings of Ryder and colleagues who noted that in the interviews conducted for their study, "the majority of teachers purported that DI was a good corrective tool and was useful for building phonemic awareness skills and increasing fluency; however, they noted its limitations as a sole reading program" (p. 187).

The second question that contributed to this theme in the interviews directly asked the teachers to describe what their ideal reading program would look like. It is significant to note that while Anita and Jennifer talked about multi-component language arts programs in which Direct Instruction played an important role in skill building, both Betty and Catherine indicated that with specific modifications (to presentation modalities for Betty and greater scripting for difficulties with student comprehension and more activities for Catherine) their ideal reading program would look like Direct Instruction. Thus all 4 of the teacher participants involved in the current study feel that Direct Instruction has sufficient merit to make it a significant part of the 
ideal reading program. Besselieu and colleagues (2001) also reported similar results among the teachers they surveyed, with comments like, "I would use Dl in the future with my students in addition to other reading programs," and "for many of my students I need to allow more time to supplement the curriculum with phonemic awareness skills and spelling as well as additional work in comprehension."

\section{The surveys.}

The Teacher Perception Survey was developed and administered primarily to quantify the teachers' perceptions for statistical analysis in exploring a relationship between student gains and teacher perceptions. Secondarily, it allowed for triangulation of the teacher interview data. As a rule, the results of the Teacher Perception Survey supported the information garnered through interviews. Survey items collected information on a scale of 1 to 5 about the teachers' perceptions of Direct Instruction along four dimensions: overall preference for DI; perceived effectiveness; importance of phonetics; and perception of the extent to which students generalized their skills. The average of the teachers' responses over the dimension of overall preference for DI was 4.03, demonstrating a relatively strong preference for Direct Instruction. A similar finding regarding the teachers' belief about the effectiveness of Direct Instruction for their students with significant cognitive impairments rendered an average across the dimension of 4.13, again suggesting that these teachers are fairly convinced of Direct Instruction's effectiveness for this population. The highest dimension-wide average was for generalization of skills, in which dimension the teachers averaged 4.25 out of 5 , indicating strong consensus about the students generalizing the skills they learn in DI to other situations. Finally, the lowest dimension-wide average was across the dimension concerning the importance of phonetics as a part of a reading program. Given its emphasis on decoding skills, a high average on this 
dimension would represent support for DI. The teachers averaged a total of 3.81 on this dimension. This is consistent with interview findings in which they expressed that while D1 would be an important component of their ideal reading program, it would be only one component. These findings, along with the average Total Perception Score across the four teachers of 4.05, indicates strong support of Direct Instruction and confirms the responses obtained through the interview process.

\section{Relationship between Student Gains and Teachers' Perceptions}

The third research question investigated in the current study was the existence of a relationship between the teachers' perceptions of the effectiveness of Direct Instruction for teaching their students with significant cognitive impairments and the gains that those students achieved on the Woodcock Reading Mastery Test - Revised after being taught in a Direct Instruction reading program.

The analysis of the data collected in regard to this question was complicated by the fact that Anita left the school at the end of the first year of implementation to accept employment in the Pittsburgh City Schools. Catherine replaced Anita. This made it necessary to run the regression analysis twice, once for the first year and then again for years two through four of implementation. A linear relationship was found between the teachers' Total Perception Scores and their students' gains during the first year of the study. This relationship was found to be significant at the 0.05 level, with a calculated significance of 0.003 . Consequently we conclude that a positive relationship existed between teacher perceptions and student gains during the first year of Direct Instruction reading program implementation. This is consistent with the relationship found by Sterbinsky, Ross and Redfield (2006) in their study of Direct Instruction and other curricula used as part of comprehensive school reform programming. 
In the analysis of teacher perceptions and student gains in the remaining years of the study, when Catherine had replaced Anita, no significant relationship was noted. There are several possible explanations for this phenomenon. First, restricted range of variability in the survey data may have impacted the analysis. The teachers' Total Perception Scores ranged from 3.85 to 4.05 , with a mean across all survey items of 4.05 and a standard deviation of 0.124 . Second, attrition of students, who graduated or moved away, reduced the sample size after the first year of the study. Third, while Sterbinsky and his colleagues noted that teacher perceptions of Direct Instruction curricula as a school reform strategy also declined over the second and subsequent years of their study, Sterbinsky had the advantage of being able to survey the participating teachers at the end of each year, whereas this researcher was only afforded that opportunity at the close of the fourth year of DI implementation. In the current study's followup correspondence after the teacher interviews were conducted, each of the teachers was asked if she believes her opinion has changed over time, or whether she felt that she would have completed the survey ratings the same at the end of her first year of implementing the program as she had at the end of year four, when the Teacher Perception Form was completed. Each teacher indicated that her overall rating would have been the same at the end of the first year of implementation. In Anita's case, since she had been away from Direct Instruction for three years, it could be argued that the passage of time might have altered previously negative opinions to make them more positive in retrospect. However, Anita posted the lowest Total Perception Score of the group. Additionally, her very candid comments in critique of DI during her interview do not suggest that her assessment would have become more positive. A fourth possible explanation would be that the addition of Catherine to the mix altered the results. But Catherine's Total Perception Score was higher than Anita's. While it would seem to be 
imprudent to posit any definitive explanation for this finding based on the data from the current study, it may well be that a closer relationship between teacher perceptions and student achievement exists in the earlier phases of new program implementation owing to the novelty of the programming from the perspectives of both the teachers and the students. It may also be that in the earlier phases of program implementation, teachers adhere more closely to the instructional script. This would be one question that bears further scrutiny in future studies.

\section{Limitations}

The current study made use of extant data. This is both a strength and a limitation of the study. It is a strength inasmuch as using existing data provides an opportunity to see how Direct Instruction works when it has been implemented, not with the precision of the research laboratory, but rather with all of the realities and disruptions of the typical classroom. It is a limitation, however, because the use of extant data precludes the formulation of confident assertions about the meaning and significance of the findings.

Another limitation of this study was the small sample size. The study began with 25 students enrolled in the Direct Instruction reading programs in the classrooms studied. By the end of the fourth year, however, 15 students remained. There was attrition as students graduated or moved away from the school.

The teachers participating in this study had a pre-existing relationship to the researcher, who had been their colleague in the past. This could have impacted the way they responded to interview and survey questions. As such, that relationship could pose a limitation to the findings of this study. However, when asked whether their relationship to him had, in any way, influenced their answers to questions or expressed opinions about DI, the teachers answered unequivocally in the negative. Still, the relationship should be acknowledged as a potential 
limitation to the current study.

Rosenshine (2002) noted several difficulties that limit the extent to which the findings of longitudinal studies can be extended to the population. The current study, owing to its use of extant data, was plagued by several of these, including variation in the way that Direct Instruction was both implemented in the individual classrooms and used as a part of a larger language arts program. Another difficulty was teacher turnover, although Anita remained available and willing to participate in the study. In spite of these limitations, the current study, which was, in many ways, exploratory, since such limited research has been conducted on the research questions posed, offers preliminary findings for further investigation.

\section{Recommendations for Instructional Programming}

Based upon the findings of the current study, a number of recommendations can be made concerning the implementation of Direct Instruction reading programs in classrooms with students having significant cognitive impairments.

\section{Reading time daily.}

The Direct Instruction reading programs were designed to be implemented for a minimum of 45 minutes daily. Given the demands and contingencies on teachers' instructional time, particularly in a life skills support classroom, it may not be reasonable or even possible to expect teachers to provide 45 minutes of instruction with each of their reading groups every day. The teachers in this study were not able to do so. Even so, the students showed measurable gains in reading skills as measured on the Woodcock Reading Mastery Test - Revised. However, review of the literature demonstrated that the majority of studies that have investigated the efficacy of Direct Instruction for reading have provided for instruction for a minimum of 30 minutes per day and at least four days per week. In light of the results of this study and the 
patterns of practice noted in the literature, it may be advisable that students be given daily reading instruction for at least 30 minutes, if possible.

\section{Direct Instruction.}

The results of the current study suggest that Direct Instruction in reading is effective in teaching students with significant cognitive impairments. As such, it would seem reasonable to recommend that schools investigate the implementation of Direct Instruction reading programs with their life skills support students. Too often, these students are relegated to sight word reading instruction programs, which while helpful, do not optimize ultimate functional independence. A student who has been taught in a sight word program has no word attack skills to engage when he encounters a new word in the environment. If the student is capable of blending phonemes, it may be better to offer him instruction that will give him access to the many phonetically regular words in English.

\section{Questions for Future Study}

The findings of the present study suggest several possible questions for future study.

First, the quantitative component, in which student gains under Direct Instruction were investigated, needs to be replicated under conditions of experimental control. While the present study contributes to the small body of literature that investigates the implementation of Direct Instruction with students having significant cognitive impairments, replicating the results under experimental conditions would lend strength to the findings of the present study.

Another question that is worthy of investigation relates to the frequency and duration of Direct Instruction lesson presentation. It would be useful for practitioners to identify whether a relationship exists between the frequency and duration of lessons and student outcomes on standardized measures like the Woodcock Reading Mastery Tests. In the current study, the 
teachers admitted to presenting the lessons far less frequently and for less duration than the program materials specify is necessary. Even so, measurable gains were achieved. Is there a minimum frequency for instruction sessions or a minimum duration for which lessons must be presented in order for the students to show gains? In settings like life skills support classrooms, where instruction is often disrupted by behavioral outbursts or students being "pulled-out" for various therapies, it would be very useful to know the answer to this question.

Given the fact that the students in the current study demonstrated measurable gains in reading skills when their teachers claim to have had no real training in Direct Instruction, another question that might bear future study is the relationship between teacher training in Direct Instruction and student outcomes. How important is training, given the fact that the lessons are scripted? Is there an empirical reason why schools should spend limited funds on teacher training in Direct Instruction?

Very limited research has been conducted on teacher perceptions of specific methodologies. Much of the research that has been done on teacher perceptions has centered on the teachers' perceptions of various characteristics related to student ability. Where questions have been raised about teachers' perceptions of specific methodologies, it has tended to do so for social validation purposes. The findings of the current study suggested that these teachers held high opinions about the efficacy of Direct Instruction, but again, other studies should investigate this question before conclusive assertions about teachers' perceptions of Direct Instruction can be made.

The review of literature at the beginning of the current study identified no studies that specifically investigated the relationship between teacher perceptions and student outcomes under Direct Instruction. The results of the current study are inconclusive on this question, as 
noted previously. Consequently, further research to clarify this issue should be conducted in the future.

\section{Conclusion}

The present study was undertaken to investigate the efficacy of Direct Instruction in teaching students with significant cognitive impairments to read and to ascertain teachers' perceptions of DI after having used the methodology to teach this population. The findings suggest that Direct Instruction may work well with students having significant cognitive impairments and may be well received by their teachers. In many ways, the current study was an exploratory study. It took preliminary steps into areas that have been under-investigated in students with significant cognitive impairments. Nonetheless, the current study can help define research questions for future studies while it informs professional practice today. 


\section{Appendices}




\section{Appendix A: Sample Letter \& Consent Form for Teacher Participants}

\section{W. WestVirginiaUniversity.}

Office of Research Compliance

\section{CONSENT AND INFORMATION FORM}

\section{Consent Form for Teacher Participants}

Principal Investigator: Ludlow, Barbara

Department:

HUMAN RESOURCES \& EDUCATION - Special Education

Tracking Number:

(SPED)

$\mathrm{H}-22413$

\section{Study Title:}

Use of Direct Instruction to Teach Reading to Students with Significant Cognitive Impairment

Co-Investigator(s):

Kanfush, Philip,

Sponsor

\section{Contact Persons}

Philip Kanfush 724/532-5086

For information regarding your rights as a research subject, you may contact the Office of Research Compliance at 304/293-7073.

Introduction

You, have been asked to participate in this research study, which has been explained to you by Philip Kanfush, M.Ed. This study is being conducted by Barbara Ludlow, Ed.D and Philip Kanfush, M.Ed. in the Department of Special Education at West Virginia University This research is being conducted to fulfill the requirements for a doctoral dissertation in Speical Education in the Department of Special Education at West Virginia University, under the supervision of Dr. Barbara Ludlow.

\begin{tabular}{lllll}
\hline Tracking \#: & $\mathrm{H}-22413$ & Page 1 of 4 & & \\
Approved On: & $05 / 06 / 2010$ & & & Date \\
Valid Through: & $05 / 05 / 2011$ & & \\
Last Amended: & N/A & &
\end{tabular}


Tracking \#: $\quad \mathrm{H}-22413$

\section{Purposes of the Study}

The purpose of this study is to learn more about Direct Instruction in Reading with students having significant cognitive impairments. WVU expects to enroll approximately 4 subjects.

\section{Description of Procedures}

This study involves videotaping you presenting a Direct Instruction lesson, an interview, and filling out a survey, and will take approximately 105 minutes altogether for you to complete. You will be asked to fill out a questionnaire regarding your perceptions of Direct Instruction. This will take approximately 15 minutes. You do not have to answer all the questions. You will have the opportunity to see the questionnaire before signing this consent form.

\section{Risks and Discomforts}

There are no known or expected risks from participating in this study, except for the mild frustration associated with answering the questions.

\section{Alternatives}

You do not have to participate in this study.

\section{Benefits}

You may not receive any direct benefit from this study. The knowledge gained from this study may eventually benefit others.

\section{Financial Considerations}

You will not be compensated in any way for participating in this study.

\section{Confidentiality}

Any information about you that is obtained as a result of your participation in this research will be kept as confidential as legally possible. Your research records may be subpoenaed by court order or may be inspected by federal regulatory authorities without your additional consent.

\begin{tabular}{lllll}
\hline Tracking \#: & $\mathrm{H}-22413$ & Page 2 of 4 & & \\
Approved On: & $05 / 06 / 2010$ & & & Date \\
Valid Through: & $05 / 05 / 2011$ & & & \\
Last Amended: & N/A & &
\end{tabular}


Tracking \#: $\quad \mathrm{H}-22413$

Videotapes, notes and transcripts will be kept locked up and will be destroyed as soon as possible after the research is finished.

In any publications that result from this research, neither your name nor any information from which you might be identified will be published without your consent.

Signature of Subject or Authorized Representative Date

Print Name of Subject or Authorized Representative

\section{Voluntary Participation}

Participation in this study is voluntary. You are free to withdraw your consent to participate in this study at any time. Refusal to participate or withdrawal will not affect your employee status and will involve no penalty to you. In the event new information becomes available that may affect your willingness to participate in this study, this information will be given to you so that you can make an informed decision about whether or not to continue your participation. You have been given the opportunity to ask questions about the research, and you have received answers concerning areas you did not understand.

\begin{tabular}{lll}
\hline Tracking \#: & $\mathrm{H}-22413$ & Page 3 of 4 \\
Approved On: & $05 / 06 / 2010$ & \\
Valid Through: & $05 / 05 / 2011$ & \\
Last Amended: & N/A &
\end{tabular}

$\overline{\text { Initials }} \overline{\text { Date }}$


Tracking \#: $\quad \mathrm{H}-22413$

Upon signing this form, you will receive a copy.

I willingly consent to participate in this research.

Signature of Subject or

Printed Name

$\overline{\text { Date }} \overline{\text { Time }}$

Subjects Legal Representative

The participant has had the opportunity to have questions addressed. The participant willingly agrees to be in the study.

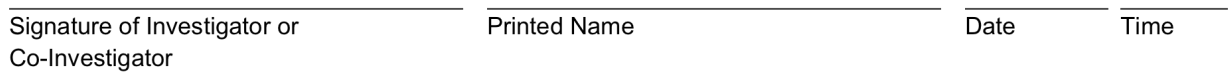

\begin{tabular}{lllll}
\hline Tracking \#: & $\mathrm{H}-22413$ & Page 4 of 4 & & \\
Approved On: & $05 / 06 / 2010$ & & & Date \\
Valid Through: & $05 / 05 / 2011$ & & & \\
Last Amended: & N/A & & &
\end{tabular}




\section{Appendix B: Teacher Interview Script}

Good morning, good afternoon, good evening. Thank you for participating in this research study. The purpose of the study is to explore teacher perceptions of the Direct Instruction reading program. This study is being conducted in partial fulfillment of the requirements for my dissertation at West Virginia University. The topic of the dissertation is Direct Instruction in Reading. I would like to videotape this interview in order to accurately represent what you say. May I have your permission to film this interview? Before we begin I want to make sure you understand the following:

- Your responses will be kept anonymous or confidential; at no time will your name be revealed during reporting.

- Your name will not be attached to either the tape or notes from this interview, or to transcribed data.

- Your participation is entirely voluntary, you can choose to stop the interview at any time, and you do not have to answer every question.

- Your class standing, grades, or job status will not be affected by your refusal to participate or to withdraw from the study.

Thank you again for your willingness to participate in this study.

\section{Teacher Interview Questions:}

1. What is your educational background?

2. Tell me about your teaching experience.

3. Tell me about the kinds of reading that you do personally and professionally.

4. Describe how you learned to read.

5. Describe your college training in reading instruction. Professional development opportunities in reading instruction?

6. If I were to observe a typical reading lesson in your classroom, what would I see?

7. What kinds of training have you received in Direct Instruction methodologies?

8. What can you tell me about how Direct Instruction operates?

9. How do you use Direct Instruction in your classroom? How often/how long are lessons?

10. How closely do you adhere to the lesson script?

11. Would you say that the degree to which you adhere to the DI lesson script has changed over time? In what ways?

12. What role, if any, does other classroom staff, like TSS, aides, etc, have in presenting or supporting DI lessons?

13. How has your experience in teaching reading using Direct Instruction varied from other reading programs you've used?

14. Has your students' progress in reading been what you expected? Can you describe how or how not?

15. Have you experienced any pressure to make Direct Instruction succeed in your classroom? To make it fail?

16. What kinds of communication do you have with parents about your students' reading program?

17. Some teachers have said that they like Direct Instruction reading. Others have shared that they hate Direct Instruction. How do you feel?

18. What do you see as the strengths and weaknesses of Direct Instruction as a reading program for your students?

19. Do you see the kids transferring the skills from DI to other settings?

20. If you could design the ideal reading program, what would it look like?

21. Is there anything I haven't asked about that you think I should know? 


\section{Appendix C: Teachers' Perception of Direct Instruction Survey}

Please read each item carefully. Indicate the degree to which you agree or disagree with the statement by circling the number that corresponds to your answer.

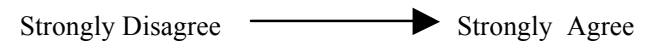

1. The best way to teach reading is using phonics.

2.Sight word programs are the best way to teach reading to children with significant cognitive impairment

3. Using scripted Direct Instruction lessons is easier than planning lessons myself.

4. Sounding out words is more effective than memorizing sight word lists.

5. Delivering Direct Instruction is monotonous.

6. My students are better readers because of Direct Instruction

7. I have noticed my students using word attack skills they learned in Direct Instruction when reading other materials.

8. Direct Instruction has been beneficial to me because all the materials that I need for planning are in the presentation books.

9. My students are successful with Direct Instruction.

10. I would recommend Direct Instruction to other teachers.

11. Given a choice, I would continue to use Direct Instruction to teach reading.

12. I believe that Direct Instruction is effective.

13. Presenting Direct Instruction lessons is easy.

14. Direct Instruction fosters stronger decoding skills than other reading methods.

15. Direct Instruction works for my students.

16. I have seen the skills my students learn in Direct Instruction already generalizing to other settings.

17. I prefer Direct Instruction to other reading programs.

18. When my students encounter text, they now attempt to decode it.

19. The scripted lessons in Direct Instruction free me up for attending to student performance.

20. My students pick up other story books and attempt read them using skills learned in Direct Instruction. 


\section{Appendix D: Direct Instruction Teacher Presentation Rubric}

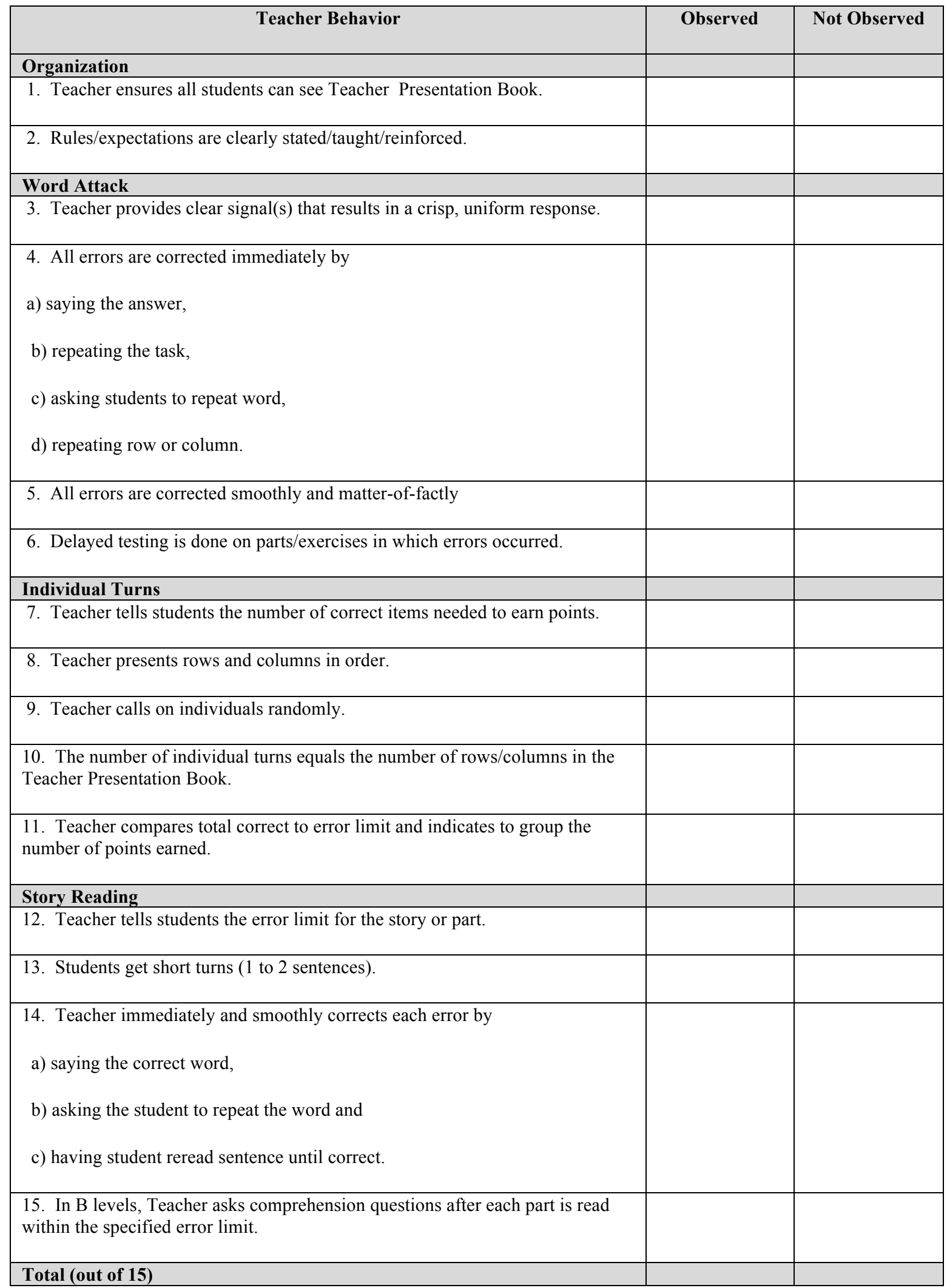




\section{Appendix E: Repeated Measures Analysis of Variance Results - W Scores}

\begin{tabular}{|c|c|c|c|c|}
\hline Subtest/Cluster & Time & $\mathrm{F}$ & DF & p-value \\
\hline Auditory & all & 1.61 & $(4,12)$ & 0.2358 \\
\hline \multirow[t]{4}{*}{ Visual Learning } & $\mathrm{t}_{2}$ & 0.04 & $(1,3)$ & 0.8559 \\
\hline & $\mathrm{t}_{3}$ & 0.08 & $(1,3)$ & 0.7974 \\
\hline & $\mathrm{t}_{4}$ & 1.88 & $(1,3)$ & 0.2641 \\
\hline & $\mathrm{t}_{6}$ & 4.81 & $(1,3)$ & 0.1159 \\
\hline Letter & all & 2.28 & $(4,24)$ & 0.0907 \\
\hline \multirow{4}{*}{ Identification } & $\mathrm{t}_{2}$ & 0.86 & $(1,6)$ & 0.3893 \\
\hline & $\mathrm{t}_{3}$ & 4.10 & $(1,6)$ & 0.0893 \\
\hline & $\mathrm{t}_{4}$ & 4.46 & $(1,6)$ & 0.0793 \\
\hline & $t_{6}$ & 8.08 & $(1,6)$ & 0.0295 \\
\hline Word & all & 9.47 & $(4,56)$ & $<0.0001$ \\
\hline \multirow[t]{4}{*}{ Identification } & $\mathrm{t}_{2}$ & 3.55 & $(1,14)$ & 0.0804 \\
\hline & $\mathrm{t}_{3}$ & 11.76 & $(1,14)$ & 0.0041 \\
\hline & $\mathrm{t}_{4}$ & 12.30 & $(1,14)$ & 0.0035 \\
\hline & $t_{6}$ & 12.92 & $(1,14)$ & 0.0029 \\
\hline \multirow[t]{5}{*}{ Word Attack } & all & 5.57 & $(4,24)$ & 0.0026 \\
\hline & $\mathrm{t}_{2}$ & 11.38 & $(1,6)$ & 0.0150 \\
\hline & $\mathrm{t}_{3}$ & 4.83 & $(1,6)$ & 0.0703 \\
\hline & $\mathrm{t}_{4}$ & 7.13 & $(1,6)$ & 0.0370 \\
\hline & $t_{6}$ & 13.54 & $(1,6)$ & 0.0103 \\
\hline Word & all & 2.93 & $(4,56)$ & 0.0285 \\
\hline \multirow[t]{4}{*}{ Comprehension } & $\mathrm{t}_{2}$ & 6.64 & $(1,14)$ & 0.0220 \\
\hline & $t_{3}$ & 7.29 & $(1,14)$ & 0.0173 \\
\hline & $\mathrm{t}_{4}$ & 4.19 & $(1,14)$ & 0.0599 \\
\hline & $t_{6}$ & 5.79 & $(1,14)$ & 0.0305 \\
\hline Passage & all & 4.45 & $(4,56)$ & 0.0034 \\
\hline \multirow[t]{4}{*}{ Comprehension } & $\mathrm{t}_{2}$ & 6.53 & $(1,14)$ & 0.0229 \\
\hline & $\mathrm{t}_{3}$ & 3.42 & $(1,14)$ & 0.0857 \\
\hline & $\mathrm{t}_{4}$ & 4.36 & $(1,14)$ & 0.0556 \\
\hline & $t_{6}$ & 5.93 & $(1,14)$ & 0.0288 \\
\hline Readiness & all & 2.23 & $(4,12)$ & 0.1263 \\
\hline \multirow[t]{4}{*}{ Cluster } & $\mathrm{t}_{2}$ & 0 & $(1,3)$ & 0.9796 \\
\hline & $\mathrm{t}_{3}$ & 3.93 & $(1,3)$ & 0.1417 \\
\hline & $\mathrm{t}_{4}$ & 11.58 & $(1,3)$ & 0.0424 \\
\hline & $\mathrm{t}_{6}$ & 8.01 & $(1,3)$ & 0.0662 \\
\hline
\end{tabular}


Appendix E: Repeated Measures Analysis of Variance Results - W Scores (con't)

\begin{tabular}{lcccc}
\hline Subtest/Cluster & Time & $\mathrm{F}$ & $\mathrm{DF}$ & $\mathrm{p}$-value \\
\hline & & & & \\
Basic Skills & $\mathrm{all}$ & 8.75 & $(4,24)$ & 0.0002 \\
Cluster & $\mathrm{t}_{2}$ & 11.08 & $(1,6)$ & 0.0158 \\
& $\mathrm{t}_{3}$ & 7.41 & $(1,6)$ & 0.0345 \\
& $\mathrm{t}_{4}$ & 8.77 & $(1,6)$ & 0.0252 \\
& $\mathrm{t}_{6}$ & 14.54 & $(1,6)$ & 0.0088 \\
& & & & \\
Comprehension & $\mathrm{all}$ & 4.88 & $(4,56)$ & 0.0019 \\
Cluster & $\mathrm{t}_{2}$ & 7.76 & $(1,14)$ & 0.0146 \\
& $\mathrm{t}_{3}$ & 6.06 & $(1,14)$ & 0.0274 \\
& $\mathrm{t}_{4}$ & 5.02 & $(1,14)$ & 0.0418 \\
& $\mathrm{t}_{6}$ & 6.83 & $(1,14)$ & 0.0204 \\
Total & & & & \\
Reading FS & all & 8.21 & $(4,56)$ & $<0.0001$ \\
Cluster & $\mathrm{t}_{2}$ & 8.87 & $(1,14)$ & 0.0100 \\
& $\mathrm{t}_{3}$ & 9.93 & $(1,14)$ & 0.0071 \\
& $\mathrm{t}_{4}$ & 9.68 & $(1,14)$ & 0.0077 \\
& $\mathrm{t}_{6}$ & 12.49 & $(1,14)$ & 0.0033 \\
\hline
\end{tabular}




\section{Appendix F: Repeated Measures Analysis of Variance Results - Standard Scores}

\begin{tabular}{|c|c|c|c|c|}
\hline Subtest/Cluster & Time & $\mathrm{F}$ & DF & p-value \\
\hline Auditory & all & 1.24 & $(4,12)$ & 0.3463 \\
\hline \multirow[t]{4}{*}{ Visual Learning } & $\mathrm{t}_{2}$ & 0.00 & $(1,3)$ & 0.9771 \\
\hline & $\mathrm{t}_{3}$ & 1.12 & $(1,3)$ & 0.3680 \\
\hline & $\mathrm{t}_{4}$ & 1.85 & $(1,3)$ & 0.2673 \\
\hline & $\mathrm{t}_{6}$ & 2.98 & $(1,3)$ & 0.1828 \\
\hline Letter & all & 5.19 & $(4,24)$ & 0.0037 \\
\hline \multirow{4}{*}{ Identification } & $\mathrm{t}_{2}$ & 5.62 & $(1,6)$ & 0.0554 \\
\hline & $\mathrm{t}_{3}$ & 5.08 & $(1,6)$ & 0.0651 \\
\hline & $\mathrm{t}_{4}$ & 18.20 & $(1,6)$ & 0.0053 \\
\hline & $\mathrm{t}_{6}$ & 9.75 & $(1,6)$ & 0.0205 \\
\hline Word & all & 1.00 & $(4,56)$ & 0.4137 \\
\hline \multirow[t]{4}{*}{ Identification } & $\mathrm{t}_{2}$ & 9.09 & $(1,14)$ & 0.0093 \\
\hline & $\mathrm{t}_{3}$ & 0.92 & $(1,14)$ & 0.3541 \\
\hline & $\mathrm{t}_{4}$ & 6.16 & $(1,14)$ & 0.0264 \\
\hline & $t_{6}$ & 4.58 & $(1,14)$ & 0.0504 \\
\hline \multirow[t]{5}{*}{ Word Attack } & all & 3.50 & $(4,24)$ & 0.0218 \\
\hline & $\mathrm{t}_{2}$ & 8.65 & $(1,6)$ & 0.0259 \\
\hline & $\mathrm{t}_{3}$ & 1.98 & $(1,6)$ & 0.2085 \\
\hline & $\mathrm{t}_{4}$ & 5.66 & $(1,6)$ & 0.0548 \\
\hline & $t_{6}$ & 17.99 & $(1,6)$ & 0.0054 \\
\hline Word & all & 1.40 & $(4,56)$ & 0.2473 \\
\hline \multirow[t]{4}{*}{ Comprehension } & $\mathrm{t}_{2}$ & 3.65 & $(1,14)$ & 0.0768 \\
\hline & $\mathrm{t}_{3}$ & 0.79 & $(1,14)$ & 0.3883 \\
\hline & $\mathrm{t}_{4}$ & 0.15 & $(1,14)$ & 0.7059 \\
\hline & $\mathrm{t}_{6}$ & 1.22 & $(1,14)$ & 0.2877 \\
\hline Passage & all & 1.96 & $(4,56)$ & 0.1136 \\
\hline \multirow[t]{4}{*}{ Comprehension } & $\mathrm{t}_{2}$ & 2.30 & $(1,14)$ & 0.1520 \\
\hline & $\mathrm{t}_{3}$ & 0.26 & $(1,14)$ & 0.6190 \\
\hline & $\mathrm{t}_{4}$ & 0.90 & $(1,14)$ & 0.3576 \\
\hline & $t_{6}$ & 0.13 & $(1,14)$ & 0.7266 \\
\hline Readiness & all & 0.72 & $(4,12)$ & 0.5946 \\
\hline \multirow[t]{4}{*}{ Cluster } & $\mathrm{t}_{2}$ & 0.48 & $(1,3)$ & 0.5392 \\
\hline & $\mathrm{t}_{3}$ & 0.31 & $(1,3)$ & 0.6142 \\
\hline & $\mathrm{t}_{4}$ & 0.33 & $(1,3)$ & 0.6062 \\
\hline & $\mathrm{t}_{6}$ & 2.93 & $(1,3)$ & 0.1853 \\
\hline
\end{tabular}


Appendix F: Repeated Measures Analysis of Variance Results - S Scores (con't)

\begin{tabular}{lcccc}
\hline Subtest/Cluster & Time & $\mathrm{F}$ & $\mathrm{DF}$ & $\mathrm{p}$-value \\
\hline & & & & \\
Basic Skills & $\mathrm{all}$ & 1.83 & $(4,24)$ & 0.1559 \\
Cluster & $\mathrm{t}_{2}$ & 2.47 & $(1,6)$ & 0.1673 \\
& $\mathrm{t}_{3}$ & 2.25 & $(1,6)$ & 0.1840 \\
& $\mathrm{t}_{4}$ & 3.80 & $(1,6)$ & 0.0993 \\
& $\mathrm{t}_{6}$ & 6.22 & $(1,6)$ & 0.0469 \\
& & & & \\
Comprehension & $\mathrm{all}$ & 1.75 & $(4,56)$ & 0.1526 \\
Cluster & $\mathrm{t}_{2}$ & 4.26 & $(1,14)$ & 0.0582 \\
& $\mathrm{t}_{3}$ & 0.60 & $(1,14)$ & 0.4500 \\
& $\mathrm{t}_{4}$ & 0.01 & $(1,14)$ & 0.9227 \\
& $\mathrm{t}_{6}$ & 1.13 & $(1,14)$ & 0.3056 \\
Total & & & & \\
Reading FS & all & 1.26 & $(4,56)$ & 0.2947 \\
Cluster & $\mathrm{t}_{2}$ & 3.64 & $(1,14)$ & 0.0772 \\
& $\mathrm{t}_{3}$ & 1.00 & $(1,14)$ & 0.3352 \\
& $\mathrm{t}_{4}$ & 0.06 & $(1,14)$ & 0.8176 \\
& $\mathrm{t}_{6}$ & 8.21 & $(1,14)$ & 0.0125 \\
\hline
\end{tabular}




\section{Appendix G: Teacher Perception Survey Questions by Subcategory}

\begin{tabular}{|c|c|c|c|c|c|c|c|}
\hline Item & Question & Betty & Jennifer & Anita & Catherine & M & M \\
\hline \multicolumn{8}{|c|}{ Subcategory 1: DI as Effective } \\
\hline & $\begin{array}{l}\text { My students are better readers because of Direct } \\
\text { Instruction. }\end{array}$ & 5.00 & 3.00 & 4.00 & 4.00 & 4.00 & \\
\hline 9 & My students are successful with Direct Instruction & 4.00 & 4.00 & 4.00 & 4.00 & 4.00 & \\
\hline 12 & I believe that Direct Instruction is effective & 5.00 & 4.00 & 4.00 & 4.00 & 4.25 & \\
\hline 15 & Direct Instruction works for my students. & 5.00 & 4.00 & 4.00 & 4.00 & 4.25 & \\
\hline Subcate & egory Mean & & & & & & 4.13 \\
\hline \multicolumn{8}{|c|}{ Subcategory 2: Skill Generalization } \\
\hline & $\begin{array}{l}\text { I have noticed my students using word attack skills } \\
\text { they learned in Direct Instruction when reading } \\
\text { other materials. }\end{array}$ & 5.00 & 4.00 & 5.00 & 4.00 & 4.50 & \\
\hline 16 & $\begin{array}{l}\text { I have seen the skills my students learn in Direct } \\
\text { Instruction already generalizing to other settings. }\end{array}$ & 5.00 & 4.00 & 4.00 & 4.00 & 4.25 & \\
\hline 18 & $\begin{array}{l}\text { When my students encounter text, they now } \\
\text { attempt to decode it. }\end{array}$ & 5.00 & 5.00 & 4.00 & 4.00 & 4.50 & \\
\hline 20 & $\begin{array}{l}\text { My students pick up other story books and attempt } \\
\text { to read them using skills learned in Direct } \\
\text { Instruction. }\end{array}$ & 3.00 & 4.00 & 4.00 & 4.00 & 3.75 & \\
\hline Subcate & egory Mean & & & & & & 4.25 \\
\hline \multicolumn{8}{|c|}{ Subcategory 3: I Like DI } \\
\hline & $\begin{array}{l}\text { Using scripted Direct Instruction lessons is easier } \\
\text { than planning lessons myself. }\end{array}$ & 5.00 & 3.00 & 4.00 & 4.00 & 4.00 & \\
\hline 5 & Delivering Direct Instruction is monotonous & 1.00 & 3.00 & 2.00 & 5.00 & 2.75 & \\
\hline 8 & $\begin{array}{l}\text { Direct Instruction has been beneficial to me } \\
\text { because all the materials that I need for planning } \\
\text { are in the presentation books. }\end{array}$ & 5.00 & 4.00 & 4.00 & 5.00 & 4.50 & \\
\hline 10 & $\begin{array}{l}\text { I would recommend Direct Instruction to other } \\
\text { teachers }\end{array}$ & 5.00 & 4.00 & 4.00 & 4.00 & 4.25 & \\
\hline 11 & $\begin{array}{l}\text { Given a choice, I would continue to use Direct } \\
\text { Instruction }\end{array}$ & 5.00 & 4.00 & 4.00 & 4.00 & 4.25 & \\
\hline 13 & Presenting Direct Instruction lessons is easy. & 5.00 & 5.00 & 5.00 & 4.00 & 4.75 & \\
\hline 17 & $\begin{array}{l}\text { I prefer Direct Instruction to other reading } \\
\text { programs. }\end{array}$ & 5.00 & 4.00 & 3.00 & 4.00 & 4.00 & \\
\hline 19 & $\begin{array}{l}\text { The scripted lessons in Direct Instruction free me } \\
\text { up for attending to student performance. }\end{array}$ & 4.00 & 4.00 & 3.00 & 4.00 & 3.75 & \\
\hline \multicolumn{2}{|c|}{ Subcategory Mean } & & & & & & 4.03 \\
\hline & Subcategory 4: Ideal Reading Program & & & & & & \\
\hline 1 & The best way to teach reading is using Phonics & 5.00 & 4.00 & 3.00 & 4.00 & 4.00 & \\
\hline 2 & $\begin{array}{l}\text { Sight word programs are the best way to teach } \\
\text { reading to children with significant cognitive } \\
\text { impairment. }\end{array}$ & 3.00 & 4.00 & 3.00 & 4.00 & 3.50 & \\
\hline 4 & $\begin{array}{l}\text { Sounding out words is more effective than } \\
\text { memorizing sight word lists. }\end{array}$ & 3.00 & 4.00 & 4.00 & 3.00 & 3.50 & \\
\hline 14 & $\begin{array}{l}\text { Direct Instruction fosters stronger decoding skills } \\
\text { than other reading methods. }\end{array}$ & 5.00 & 3.00 & 5.00 & 4.00 & 4.25 & \\
\hline \multicolumn{7}{|c|}{ Subcategory Mean } & 3.81 \\
\hline
\end{tabular}




\section{Appendix H: IRB Approval Notice}

Page 1 of 1

\section{Kanfush, Philip}

From: wvuecomp@wvu.edu

Sent: Thursday, May 06, 2010 11:38 AM

To: bludlow@mail.wvu.edu; Kanfush, Philip

Subject: BRAAN2: New IRB Protocol Approved

The following new IRB Protocol has been approved.

Tracking \#: H-22413

PI: Ludlow, Barbara

Title: Use of Direct Instruction to Teach Reading to Students with Significant Cognitive Impairment

Approval Date: 05/06/2010

Expiration Date: 05/05/2011

The BRAAN2 website can be accessed by clicking the following link: BRAAN2 Login 


\section{References}

Adams, G. L., \& Englemann, S. (1996). Research on Direct Instruction: 25 years beyond Distar. Seattle, WA: Educational Achievement Systems.

American Federation of Teachers, W. (1999). Building on the best, learning from what works: Five promising programs for remedial reading intervention.

Becker, W., \& Gersten, R. (1982). A Follow-up of Follow Through: The later effects of the Direct Instruction model on children in fifth and sixth grades. American Educational Research Journal, 19(1), 75-92.

Bell, N., Lassiter, K., Matthews, T., \& Hutchinson, M. (2001). Comparison of the Peabody Picture Vocabulary Test-Third Edition and Wechsler Adult Intelligence Scale Third Edition with university students. Journal of Clinical Psychology, 57(3), 417-422.

Bellg, A., Resnick, B., Minicucci, D., Ogedegbe, G., Ernst, D., Borrelli, B. ... Czajkowski, S. (2004). Enhancing treatment fidelity in health behavior change studies: best practices and recommendations from the NIH Behavior Change Consortium. Health Psychology, 23(5), 443-451.

Benner, G., Trout, A., Nordness, P., Nelson, J., Epstein, M., Knobel, M., et al. (2002, June 1). The effects of the Language for Learning Program on the receptive language skills of kindergarten children. Journal of Direct Instruction, 2(2), 67-74.

Bessellieu, F. (2001). Teachers' perceptions of Direct Instruction teaching. Direct Instruction News, 1(1), 14-18.

Bolen, L. (1998). WISC-III score changes for EMH students. Psychology in the Schools, 35(4), 327-332. 
Booth, A., Hewitt, D., Jenkins, W. \& Maggs, A. (1979). Making retarded children literate: A five year study. The Australian Journal of Mental Retardation, 5(7), 257-260.

Bracey, S., Maggs, A., \& Morath, P. (1975). The effects of a direct phonic approach in teaching reading with six moderately retarded children: Acquisition and mastery learning stages. International Journal of Disability, Development and Education, 22(2), 83-90.

Browder, D., \& Cooper-Duffy, K. (2003). Evidence-based practices for students with severe disabilities and the requirement for accountability in "No Child Left Behind." Journal of Special Education, 37(3), 157-163.

Browder, D., Wakeman, S., Spooner, F., Ahlgrim-Delzell, L., \& Algozzine, B. (2006). Research on reading instruction for individuals with significant cognitive disabilities. Exceptional Children, 72(4), 392-408.

Browder, D., \& Xin, Y. (1998). A meta-analysis and review of sight word research and its implications for teaching functional reading to individuals with moderate and severe disabilities. Journal of Special Education, 32(3), 130-53.

Carvajal, H., Nowak, S., Fraas, A., \& McConnell, M. (2000). Saving time: Using the Peabody Picture Vocabulary Test-III as a screening test of intelligence with undergraduates. College Student Journal, 34(2), 281.

Collins, S., \& Salzberg, C. (2005). Scientifically based research and students with severe disabilities: Where do educators find evidence-based practices? Rural Special Education Quarterly, 24(1), 60-63.

Craig, R., \& Olson, R. (1991, May). Relationships between Wechsler Scales and Peabody Picture Vocabulary Test-Revised scores among disability participants. Journal of Clinical Psychology, 47(3), 420-429. 
Cronin, M., Patton, J., \& Wood, S. (2005). Life Skills Instruction: A practical guide for integrating real-life content into the curriculum at the elementary and secondary levels for students with special needs or who are placed at risk. Austin, TX: PRO-ED.

Curtin, M., \& Fossey, E. (2007). Appraising the trustworthiness of qualitative studies: Guidelines for occupational therapists. Australian Occupational Therapy Journal 54(2), 88-94.

Dakin, A. (1999, May 1). The effectiveness of a skill based explicit phonics reading program K-2 as measured by student performance and teacher evaluation.

Demant, P., \& Yates, G. (2003). Primary teachers' attitudes toward the direct instruction construct. Educational Psychology, 23(5), 483.

Doyle, W., Hancock, G., and Kifer, E. (1971). Teachers' perceptions: Do they make a difference? Paper presented at annual meeting, AERA.

Elementary and Secondary Education Act (No Child Left Behind), Pub. L. No. 107-110 (2001).

Flores, M., Shippen, M., Alberto, P., \& Crowe, L. (2004). Teaching letter-sound correspondence to students with moderate intellectual disabilities. Journal of Direct Instruction, 4(2), 173-188.

Frankhauser, M., Tso, M., \& Martella, R. (2001). A comparison of curriculum-specified reading checkout timings and daily 1-minute timings on student performance in Reading Mastery. Journal of Direct Instruction, 1(2), 85-96.

Frederick, L., Keel, M., \& Neel, J. (2002). Making the most of instructional time: Teaching reading at an accelerated rate to students at risk. Journal of Direct Instruction 2(1), 57-63. 
Gay, L., \& Airasian, P. (1996). Educational research: Competencies for analysis and application. Upper Saddle River, NJ: Merrill.

Gelberg, D. (2008). Scripted curriculum: Scourge or salvation? Educational Leadership, 65(6), 80-82.

Gersten, R. (1985). Direct Instruction with special education students: A review of evaluation research. Journal of Special Education 19(1), 41-58.

Gersten, R., \& Keating, T. (1987). Long-term benefits from Direct Instruction. Educational Leadership, 44(6), 28-31.

Gersten, R., \& Maggs, A. (1982). Teaching the general case to moderately retarded children: Evaluation of a five year project. Analysis \& Intervention in Developmental Disabilities, 2(4), 329-343.

Glang, A., Singer, G., Cooley, E., \& Tish, N. (1992). Tailoring Direct Instruction techniques for use with elementary students with brain injury. The Journal of Head Trauma Rehabilitation 7(4), 93-108.

Gravetter, F. \& Wallnau, L. (2007). Statistics for the behavioral sciences $\left(7^{\text {th }}\right.$ ed.). Belmont, CA: Thomson Wadsworth.

Greenberg, D., Fredrick, L., Hughes, T., \& Bunting, C. (2002). Implementation issues in a reading program for low reading adults. Journal of Adolescent and Adult Literacy, 45(7), 626-632.

Grossen, B. (2004). Success of a Direct Instruction model at a secondary level school with high-risk students. Reading and Writing Quarterly, 20(2), 161-178.

Hempenstall, K. (2008). Corrective Reading: an evidence-based remedial reading intervention. Australasian Journal of Special Education, 32(1), 23-54. 
Hummel, J., Wiley, L., Huitt, W., Roesch, M., \& Richardson, J. (2002, November). Implementing Correcting Reading: coaching issues. Paper presented at the annual meeting of the Georgia Educational Research Association, Savannah, GA.

Individuals with Disabilities Education Improvement Act, 20 U.S.C. $1462 \S 662$ (2004).

Kamps, K., Wills, H., Greenwood, C., Thorne, S., Laxo, J., Crockett, J., Akers, J., \& Swaggart, B. (2003). Curriculum influences on growth in early reading fluency for students with academic and behavioral risks: A descriptive study. Journal of Emotional and Behavioral Disorders, 11(4), 211-224.

Kohl, F., McLaughlin, M., \& Nagle, K. (2006). Alternate achievement standards and assessments: A descriptive investigation of 16 states. Exceptional Children, 73(1), 107-123.

Kraemer, J., Kramer, S., Koch, H., Madigan, K., \& Steely, D. (2001). Using Direct Instruction programs to teach comprehension and language skills to deaf and hard-of-hearing students: A 6-year study. Direct Instruction News, 23-31.

Knight, S. (1992). Relation between elementary students' perceptions of teacher behaviors and reading strategy. Journal of Educational Research 85(6), 326-338.

Kuder, S. J. (1990/2001). Effectiveness of the DISTAR reading program for children with learning disabilities. Journal of Learning Disabilities 23(1), 69-71.

Lingo, A., Slaton, D., \& Jolivette, K. (2006). Effects of Corrective Reading on the reading abilities and classroom behaviors of middle school students with reading deficits and challenging behavior. Behavioral Disorders 31(3), 265-283.

Lockery, M. \& Maggs, A. (1982). Direct Instruction research in Australia: A ten-year analysis. Educational Psychology, 2(3), 263-288. 
Maggs, A. (1973). Precision teaching: A behavioural model for cognitive development. The Australian Journal of Mental Retardation (2), 180-184.

Maggs, A. (1983). Direct Instruction research in Australia: Hard to teach and regular learners. International Journal of Rehabilitation Research, 6(4), 477-479.

Maggs, A. \& Morath, P. (1976). Effects of direct verbal instruction on intellectual development of institutionalized moderately retarded children: A 2-year study. The Journal of Special Education, 10(4), 357-364.

Marchand-Martella, N., Kinder, D., \& Kubina, R. (n.d.) Special education and Direct Instruction: An effective combination [Brochure]. DeSoto, TX: McGraw-Hill.

Malmgren, K., \& Leone, P. (2000). Effects of a short-term auxiliary reading program on the reading skills of incarcerated youth. Education and Treatment of Children 23(3), 239-247.

Marchand-Martella, N., Martella, R., \& Przychodzin-Havis, A. (n.d.) The research base and validation of SRA's Corrective Reading Program [Brochure]. Retrieved October 23, 2006 from http://SRAonline.com.

Mawhood, L. \& Howlin, P. (2000). Autism and developmental receptive language disorder - a comparative follow-up in early adult life. I: cognitive and language outcomes. Journal of Child Psychology \& Psychiatry, 41(5), 547-559

McBrien, B. (2008). Evidence-based care: enhancing the rigour of a qualitative study. British Journal of Nursing 17(20), 1286-1289.

Moderate Disabilities, 34 C.F.R., Sec. 300[b][6] (2004). 
National Institute of Child Health and Human Development. (2000). Report of the National Reading Panel. Teaching Children to Read: An Evidence-Based Assessment of the Scientific Research Literature on Reading and its Implications for Reading Instruction: Reports of the subgroups. NIH Publication No. 00-4754. Washington, DC: US Government Printing Office.

Nietupski, J., Hamre-Nietupski, S., Curtin, S., \& Shrikanth, K. (1997). A review of curricular research in severe disabilities from 1976 to 1995 in six selected journals. Journal of Special Education, 31(1), 36-55.

O'Connor, R., Jenkins, J., Cole, K., \& Mills, P. (1993). Two approaches to reading instruction with children with disabilities: Does program design make a difference? Exceptional Children, 59(4), 312-323.

Ogletree, E. (1997/2001). Evaluating the reading needs of inner-city kindergarten pupils. Journal of Educational Research 71(2), 67-70.

Patton, M. (2002). Qualitative research \& evaluation methods $\left(3^{\text {rd }}\right.$ ed.). Thousand Oaks, CA: Sage Publications

Pearson Assessments (n.d.). Qualification Levels. Retreived from http://www.pearsonassessments.com/forms/levels.htm)

Rosenshine, B. (2002). Helping students from low-income homes read at grade level. Journal of Education for Students Placed at Risk, 7(2), 273-283.

Ryder, R., Burton, J., \& Silberg, A. (2006) Longitudinal study of Direct Instruction effects from first through third grades. The Journal of Educational Research, 99(3), 179-191

SAS Institute Inc., SAS OnlineDoc ${ }^{\mathrm{TM}} 9.2$ [Computer software]. Cary, NC: SAS Institute Inc. 
Scarlato, M., \& Asahara, E. (2004). Effects of Corrective Reading in a residential treatment facility for adjudicated youth. Journal of Direct Instruction 4(2), 211-217.

Sexton, C. (2001). Effectiveness of the DISTAR Reading I Program in developing first graders’ language skills. Journal of Educational Research 82(5), 289-293.

Shippen, M. (2008). A pilot study of the efficacy of two adult basic literacy programs for incarcerated males. The Journal of Correctional Education, 59(4), 339-347.

Snitz, B., Bieliauskas, L., Crossland, A., Basso, M., \& Roper, B. (2000). PPVT-R as an estimate of premorbid intelligence in older adults. Clinical Neuropsychologist 14(2), 181186.

Stein, M., Carnine, D., \& Dixon, R. (1998). Direct Instruction: Integrating curriculum design and effective teaching practice. Intervention in School and Clinic, 33(4), 227-233.

Sterbinski, A., Ross, S., \& Redfield, D. (2006). Effects of comprehensive school reform on student achievement and school change: A longitudinal multi-site study. School Effectiveness and School Improvement 17(3), 367-397.

Swanson, H. (2001). Searching for the best model for instructing students with learning disabilities. Focus on Exceptional Children 34(2), 1-15.

Tarver, S. (1999). Focusing on Direct Instruction. Current Practice Alerts (2), 1-4. United States Department of Education, Office of Special Education Programs (2006). Children with disabilities receiving special education under part $B$ of the Individuals with Disabilities Education Act. Retrieved from https://www.ideadata.org/tables29th/ar_1-7.xls. 
Waldron-Soler, K., Martella, R., Marchand-Martella, N., Tso, M, Warner, D., \& Miller, D. (2002). Effects of a 15-week Language for Learning implementation with children in an integrated preschool. Journal of Direct Instruction 2(2), 75-86.

Watkins, C., \& Slocum, T. (2003). The components of Direct Instruction. Journal of Direct Instruction (3), 75-110.

What Works Clearinghouse. (2007). Intervention: Corrective Reading. Retrieved from http://ies.ed.gov/ncee/wwc/reports/beginning_reading/cr/)

Wiesner, M., \& Beer, J. (1991). Correlations among WISC-R IQs and several measures of receptive and expressive language for children referred for Special Education. Psychological Reports 69(31), 1009-1010.

Wolery, M., Bailey, D., \& Sugai, G. (1988). Effective teaching: Principles of applied behavior analysis with exceptional students. Boston: Allyn and Bacon, Inc.

Woodcock, R. (1998). Woodcock Reading Mastery Test-Revised/Normative Update: Examiner's Manual. Circle Pines, MN: American Guidance Service, Inc. 